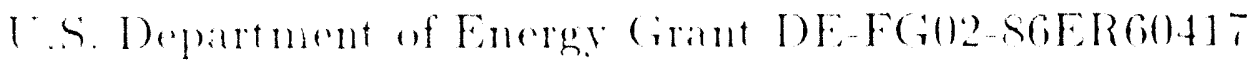

I)( )E Report H D()E/ER/6(1) H17-1)(16

\title{
FAST NEUTRON DOSIMETRY
}
For the period (1) - July- 199!
(1) - Sin)- 19!2

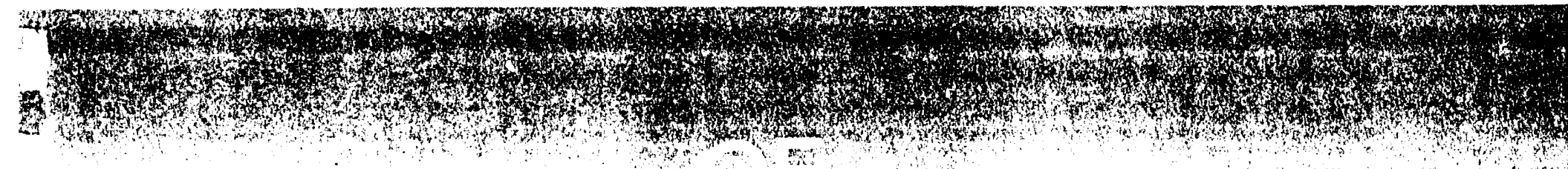

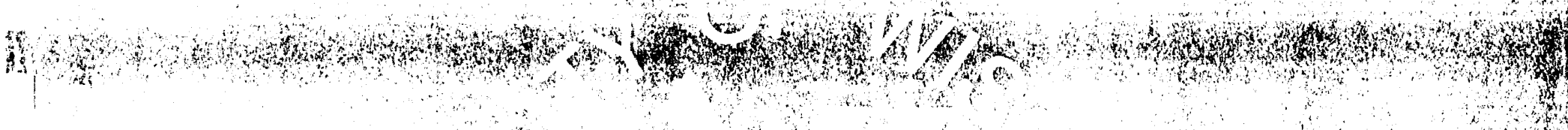

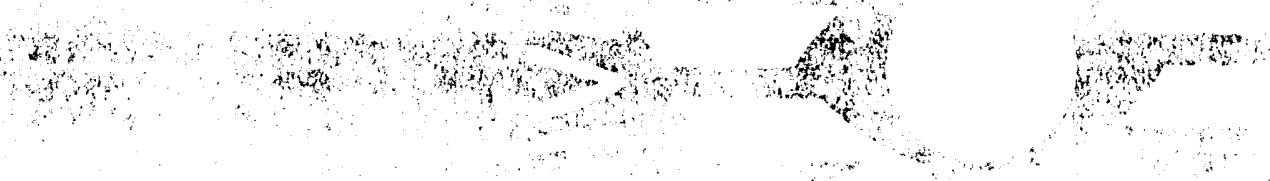

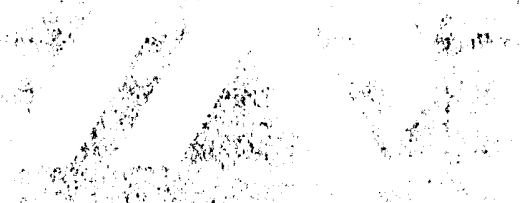


Progress Report for

U.S. Department of Energy Grant DE-FG02-86ER60417

DOE Report \# DOE/ER/60417-006

FAST NEUTRON DOSIMETRY

For the period

DOE/ER/60417--006

DE93 003659

$$
\text { 01-July-1991 - 01-Sep-1992 }
$$

Principal Investigator:

Co-Principal Investigator:

Consultant:

Consultant:
Paul M. DeLuca, Jr., Ph.D.

Professor of Medical Physics

D. W. Pearson, Ph.D.

Associate Scientist.

Department of Medical Physics

F. H. Attix, M.S.

Professor Emeritus

Department of Medical Physics

H. H. Barschall, Ph.D.

Professor Emeritus

Departments of Medical Physics,

Physics, and Nuclear Engineering

\section{Department of Medical Physics \\ 1530 Medical Sciences Center \\ 1300 University Avenue \\ University of Wisconsin \\ Madison, WI 53706 \\ USA}

\section{DISCLAIMER}

This report was prepared as an account of work sponsored by an agency of the United States Government. Neither the United States Gnvernment nor any agency thereof, nor any of their employees, makes any warranty, express or implied, or assumes any legal liability or responsibility for the accuracy, completeness, or usefulness of any information, apparatus, product, or process disclosed, or represents that its use would not infringe privately owned rights. Reference herein to any specific commercial product, process, or service by trade name, trademark, manufacturer, or otherwise does not necessarily constitute or imply its endorsement, recommendation, or favoring by the United States Government or any agency thereof. The views and opinions of authors expressed herein do not necessarily state or reflect those of the United States Government or any agency thereof. 


\section{Contents}

1 PROGRESS 1991-1992

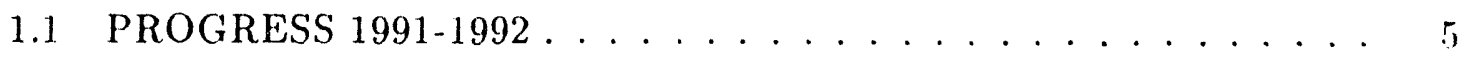

1.1 .1 Summary ........................ 5

1.1.2 Fast Neutron Kerma Factor Determinations . . . . . . . . 5

1.1.3 Ultra-Soft X-ray TLD Measurements . . . . . . . . . . 6

1.1.4 Ultra thin TLD Response to Ultra-Soft X-rays . . . . . . . . 6

1.1.5 Ultra-thin TLD Response to Beta-Rays ......... i

2 Publications/Presentations 1991-1992 8

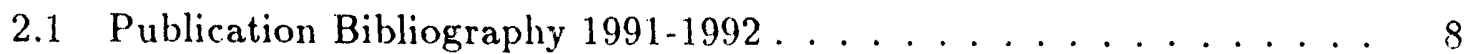

2.2 Invited Presentations 1991-1992 . . . . . . . . . . . . . . 9

3 Fast Neutron Dosimetry 10

3.1 Introduction . . . . . . . . . . . . . . . 10

3.2 Neutron Kerma Factor Measurements . . . . . . . . . . . . . . 11

3.3 White Source Neutrons - 20 to $400 \mathrm{MeV}$ Neutron Energy Measurements 12

3.4 Measurements With Monoenergetic 17, 45, 66 MeV Neutron Energies 15

3.5 Absorbed Dose Measurements in a Water Phantom . . . . . . . . . 19

4 Ultra-soft X-Ray Response of TLD 29

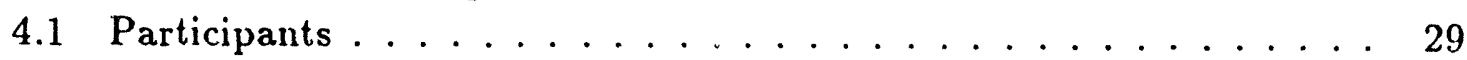

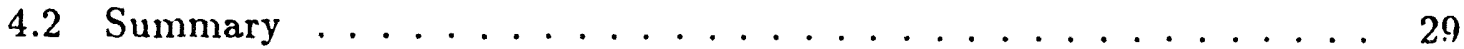

4.3 Introduction . . . . . . . . . . . . . . . . . . 29

4.4 Materials and Methods . . . . . . . . . . . . . . 30

4.5 Results for $\mathrm{LiF}: \mathrm{Mg}, \mathrm{Ti}(\mathrm{TLD}-100) \ldots \ldots \ldots . \ldots . \ldots . \ldots 32$

4.5.1 TL response as a function of dose . . . . . . . . . . 32

4.5 .2 Glow curves in He. . . . . . . . . . . . . . . 36

4.5.3 Glow curve comparison of TLDs annealed in air and in He. . 44

4.5.4 Surface dose calculations. . . . . . . . . . . . . . 45

4.5.5 TL response per unit mean dose and mass; calculation of supralinearity factors . . . . . . . . . . . . 48

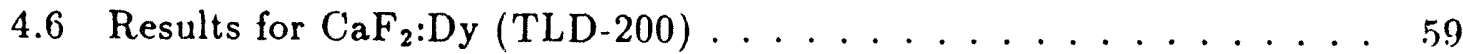

4.6.1 TL response as a function of dose . . . . . . . . . 59

4.6.2 Glow curves in He ... . . . . . . . . . . . . 61

4.6.3 Glow curve comparison of chips annealed in air and in He . 65

4.6.4 Surface dose calculations . . . . . . . . . . . . . 65

4.6.5 TL response per unit mean dose and mass; calculation of supralinearity factors. .............. 67 
5 Ultra-thin TLD Response to Ultra-Soft X-rays 78

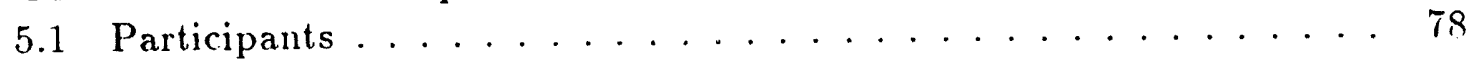

5.2 Introduction . . . . . . . . . . . . . . .

5.3 Methods and Materials . . . . . . . . . . . . . . 79

5.4 Results and Conclusion ................. 80

6 Dosimetry of ${ }^{90} \mathrm{Sr}$ Ophthalmic Applicators 83

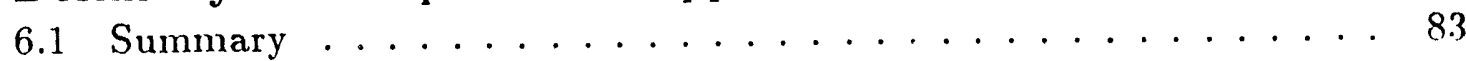

6.2 Introduction . . . . . . . . . . . . . . . 83

6.3 Materials and Methods . . . . . . . . . . . . . . . . 84

6.4 Results and Conclusions . . . . . . . . . . . . . 85

\section{List of Figures}

1 Schematic diagram of the cylindrical proportional counters . . . . 19

2 Schematic diagram of the matched pairs Birmingham proportional counters ..................... . . . 20

$3 \quad \mathrm{Zr}$ and $\mathrm{ZrO}_{2}$ proportional counter ionization yield spectra ..... 21

4 Oxygen and carbon ionization yield spectra ........... 22

5 LANL WNR targets and flight paths . . . . . . . . . . . . 24

6 Tissue equivalent proportional counter spectrum in a water phantom. 25

7 Fission foil ionization chamber time-of-flight spectrum . . . . . . 26

8 Medical Physics Beam Line . . . . . . . . . . . . . . 33

9 Mean free path of photons in TLD-100 . . . . . . . . 34

10 R.OI response of TLD-100 crystals vs energy deposited . . . . . . . 35

11 ROI response of TLD-100 chips $v$ s energy deposited . . . . . . . 36

12 Peak height of TLD-100 crystals vs energy deposited . . . . . . . . 37

13 Peak height of TLD-100 chips vs energy deposited . . . . . . . . 38

14 Glow curves of TLD-100 crystals exposed to several energies . . . . . 40

15 Glow curves of TLD-100 chips exposed to several energies . . . . . 41

16 Glow curve of TLD-100 crystals exposed to ${ }^{137} \mathrm{C}$ s gammas . . . . . . 42

17 Glow curve of TLD-100 chips exposed to ${ }^{137} \mathrm{Cs}$ gammas . . . . . . 43

18 Glow curves of TLD-100 crystals exposed to $1500 \mathrm{eV}$. . . . . . . 44

19 Glow curves of TLD-100 crystals exposed to $900 \mathrm{eV}$. . . . . . . 45

20 Glow curves of TLD-100 crystals exposed to $730 \mathrm{eV}$. . . . . . . 46

21 Glow curves of TLD-100 chips exposed to $1500 \mathrm{eV} \ldots . . \ldots 47$

22 Glow curves of TLD-100 chips exposed to $730 \mathrm{eV} \ldots \ldots . . . . .448$

23 Glow curves of TLD-100 chips exposed to $600 \mathrm{eV} \ldots \ldots . . . . . .49$

24 Dose vs depth in TLD-100. . . . . . . . . . . . 50

25 ROI TL of TLD-100 crystals vs surface dose . . . . . . . . . 51

26 ROI TL of TLD-100 chips vs surface dose ............ 52 
27 Peak height of TLD-100 crystals vis surface dose . . . . . . . . . 5.3

28 Peak height of TLD-100 chips vs surface dose . . . . . . . . . . . 54

29 ROI TL per unit dose and mass "s dose for TLD-100 crystals . . . . 55

30 ROI TL per unit dose and mass $v$ s dose for TLD-100 chips . . . . 56

31 Peak height per unit dose and mass $v s$ close for TLD-100 crystals . . 5

32 Peak height per unit dose and mass vs dose for TLD-100 chips . . . 58

33 Mean free path of photons in TLD-200 . . . . . . . . . . 59

34 ROI TL response of TLD-200 chips vs energy deposited . . . . . . 60

35 Peak height of TLD-200 chips vs energy deposited . . . . . . . . 62

36 Glow curves of TLD-200 chips exposed to several energies . . . . . . 63

37 Glow curve of TLD-200 chips exposed to ${ }^{137} \mathrm{C}$ s gammas . . . . . . 64

38 Glow curves of TLD-200 chips exposed to $1500 \mathrm{eV}$. . . . . . . 66

39 Glow curves of TLD-200 chips exposed to $730 \mathrm{eV} \ldots \ldots . \ldots 67$

40 Glow curves of TLD-200 chips exposed to $600 \mathrm{eV} \ldots \ldots . \ldots 8$

41 Dose vs depth in TLD-200. . . . . . . . . . . . . . 69

42 ROI TL of TLD-200 chips vs surface dose . . . . . . . . . . . T0

43 Peak height of TLD-200 chips vs surface dose . . . . . . . . . . i1

44 ROI TL per unit dose and mass vs dose for TLD-200 chips . . . . . 72

45 Peak height per unit dose and mass $v s$ dose for TLD-200 chips . . . T3

46 Ultra-soft X-ray attenuation . . . . . . . . . . . . . . 79

\section{List of Tables}

1 Absorbed dose measurement values . . . . . . . . . . . . . 25

2 Main elements present in TLDs, their concentration and absorption

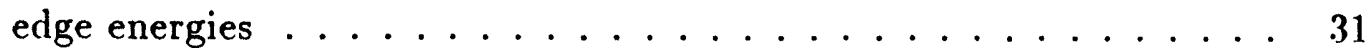

3 Energy fluence measurements . . . . . . . . . . . . . 81

4 Transmission through $\mathrm{LiF}$ and $\mathrm{CaSO}_{4} \ldots \ldots \ldots$.......... 81

5 Average surface dose rate using extrapolation chamber and UT-TLD. 85 


\section{'1 PROGRESS 1991-1992}

\subsection{PROGRESS 1991-1992}

\subsubsection{Summary}

During the past grant period, which includes some efforts from the previous grant. period due to the misalignment in time of the grant periods and progress reports, efforts concentrated on two major areas of dosimetry research: [1] measurement. of fast neutron kerma factors for several elements for monochromatic and white spectrum neutron fields and [2] determination of the response of thermoluminescent. phosphors to various ultra-soft $\mathrm{X}$-ray energies and beta-rays. Each research area is summarized in more detail below.

Of special note during the last grant period was the participation in our research program of Dr. Zhixin Zhou from the Shanghai Institute of Radiation Medicine, People's Republic of China (PRC). Dr. Zhou brought with him special expertise in the fabrication and use of ultra-thin TLD materials. Such materials are not available in the USA. The rather unique properties of these materials were investigated during this grant period.

Two other major collaborative efforts were also conducted this grant periorl. The first involved scientists from the Physikalisch-Technishe Bundesanstalt, Ferleral Republic of Germany, University of Birmingham, United Kingdom, Universität des Saarlandes, Federal Republic of Germany, and Paul Scherrer Institut, Switzerland. A preliminary report of this collaboration was presented at the Eleventh Symposium on Microdosimetry in Gatlinburg, TN. The second collaboration involved scientist.s from the Los Alamos National Laboratory. Specifically, we participated in joint. experiments at LAMPF with scientists from the Health and Safety (HS) Division and from the nuclear data group (P-17). These experiments were concerned with the dose equivalent produced in tissue from bombardment by a broad spectrum of neutrons one might encounter near proton accelerators in the energy region of 200 to $1000 \mathrm{MeV}$. Drs. Robert C. Haight (P-15), Paul W. Lisowski (P-17), John Bliss of Texas A\&M University, Ken Alvar (HS), Richard Brake (HS), and Wells Harvey (HS) collaborated in this experiment.

Finally, we have deferred our proposed measurements at the Loma Linda University proton facility until the next grant period due to severe time and resource constraints.

\subsubsection{Fast Neutron Kerma Factor Determinations}

In 1992 we measured kerma factors in carbon, oxygen, A-150 Plastic, iron, magnesium, nitrogen, zirconium, aluminum, and silicon at either Los Alamos $\mathrm{Na}$ tional Laboratory, the Paul Scherrer Institute (Switzerland), or the Physikalisch- 
Technische Bundesanstalt (Germany). These were low pressure proportional counter measurements in which pulse height and time-of-flight techniques were simmltaneously used to measure neutron kerma. A fission foil ionization chamber, also operated with both $\mathrm{PH}$ and TOF analysis, was used to measure the flux at LANL while a NE213 scintillator was used at PSI.

These new neutron kerma factor values will provide basic data needed for cancer therapy dosimetry, radiation damage studies, and for benchmark testing nuclear model calculations.

Analysis of the data has begun and will continue through the 1993 grant year.

\subsubsection{Ultra-Soft X-ray TLD Measurements}

Ultra-soft photon irradiation $(<3,000 \mathrm{eV})$ of cells for radiobiology studies pursued under this grant in previous years as well as similar beam irradiation employed for $x$-ray lithography pointed out the need for a practical, economical, and nonintrusive dosimeter that could be used concurrently during the exposure in such experiments. This would allow precise determination of the exposure and would permit accounting for any changes in the photon beam power during the exposure. Thermoluminescent dosimeters were proposed due to their small size and proved usefulness to monitor successfully shallow penetrating beta rays and photons of higher $(>15 \mathrm{keV})$ and lower $(<100 \mathrm{eV}$, UV light) energy than those generated by electron synchrotrons. However, despite an extensive bibliographical search, only one study was identified which reported the response and application of TLD-100 ribbons to monitoring of $1,500 \mathrm{eV}$ photon doses. Consequently, a research protocol was designed and submited as part of this grant to study the response of these phosphors, particularly lithium fluoride (TLD-100), to monoenergetic photon beams with energies between 100 and $3,000 \mathrm{eV}$, the electromagnetic energy spectrum largely produced by our $1-\mathrm{GeV}$ electron synchrotron, Aladdin. Most of the proposed irradiations have been completed and the collected data are being analyzed. Preliminary results are presented in the following sections for the three TL phosphors used.

\subsubsection{Ultra-thin TLD Response to Ultra-Soft X-rays}

During the last grant period, Dr. Zhixin Zhou from the Shanghai Institute of Radiation Medicine presented two ultra-thin thermoluminescent materials to this research group. These materials are manufactured in the PRC and are not currently available in the USA. While Dr. Zhou was here, we included TLDs made from these materials in some of the TLD irradiations at the synchrotron to examine their response to ultra-soft $x$-rays. The results are presented in one of the following sections. 
4

\subsubsection{Ultra-thin TLD Response to Beta-Rays}

Measurements of average surface dose rate on ${ }^{90} \mathrm{Sr}$ ophthalmic applicators were performed using the new CaSo4:Tm ultra-thin thermoluminescent dosimeter brought by Dr. Zhou. The use of this particular TLD allows precise and quick measurements compared to the usual methods employed currently. TLD results were compared with the extrapolation ion chamber technique and are presented in this clocument. 


\section{Publications/Presentations 1991-1992}

\subsection{Publication Bibliography 1991-1992}

1. Carrillo, R.E., and DeLuca, Jr., P.M., 1991, "Thermoluminescent. Dosimetry of 0.1-30 keV Electrons with Lithium Fluoride", Proc. of the IV Congreso Nacional sobre Dosimetria Termoluminiscente, Mexico DF, 12-13 Sept 1991.

2. Carrillo, R.E., Pearson, D.W., DeLuca, Jr. P.M., and Mackay, J.F., 1992, "Thermoluminescent response of lithium fluoride (TLD-100) to monoenergetic photon beams of $600,730,900$, and $1,500 \mathrm{eV}$, submitted to Rad. Prot. Dos.

3. Carrillo, R.E., Pearson, D.W., DeLuca, Jr. P.M., and Mackay, J.F., 1992, "The thermoluminescent response of calcium fluoride (TLD-200) to monoenergetic photon beams of $600,730,900$, and 1,500 eV", Proc. of the V Congreso Nacional sobre Dosimetria Termoluminiscente, Mexico DF, 3-5 Sept 1992.

4. Hartmann C.L. and DeLuca, Jr., P.M., 1991, "Measurement of the ${ }^{19} \mathrm{~F}(\mathrm{n}, 2 \mathrm{n}){ }^{18} \mathrm{~F}$ Cross Section from 18 to $27 \mathrm{MeV}$," Nucl. Sci. and Eng., 109, 319-323.

5. Hartmann, C.L., DeLuca, Jr., P.M., and Pearson, D.W., "Measurement of $\mathrm{C}, \mathrm{Mg}$, and $\mathrm{Fe}$ kerma factors and the ${ }^{19} \mathrm{~F}(\mathrm{n}, 2 \mathrm{n}){ }^{18} \mathrm{~F}$ cross section for 18 to 27 $\mathrm{MeV}$ neutrons," Nuclear Data for Science and Technology Ed: S.M. Qaim, Springer-Verlag, Berlin, 1992, 589-591.

6. Siebers J.V., DeLuca, Jr., P.M., Fearson D.W., and Coutrakon G., 1992, "Shielding Measurements for 230-MeV Protons," Nucl. Sci. and Eng., (in press).

7. White R.M., DeLuca, Jr., P.M., Dietze G., Haight. R.C., Kawashima K., Menzel H.G., Olsson N., and Wambersie A., 1992, "Status of Nuclear Data for Use in Neutron Therapy," Rad. Prot. Dos., (in press).

8. DeLuca, Jr., P.M., 1992, "Dosimetric Instruments and Methods," In: ICRU Report on Proton Beam Dosimetry for Therapy, ICRU Committee on Proton Therapy, Chapter 5, International Commission on Radiation Units and Measurements, Inc., Bethesda, MD (to be published).

9. Schrewe, U.J., de Aro, A.C.A., Brede, H.J., Dangendorf, V., DeLuca, Jr., P.M., Gerdung, S., Lim, T., Newhauser, W., Nolte, R., Schmelzbach, P., Schumacher, H., Scott, M.C.", Ionization yield spectra in Nitrogen and oxygen for neutron energies of $17 \mathrm{MeV}, 45 \mathrm{MeV}$ and $66 \mathrm{MeV}$, Proc. of the Eleventh Symposium on Microdosimetry, Gatlinburg (1992), in press. 
IISDQE Ptogress DE-FG02-86ER6041

10. Newhauser, W., Absorbed dose measurements in a water phantom irrarliated with LANL WNR neutrons - Report to the Los Alamos Weapons Neutron Research Facility, 1992

\subsection{Invited Presentations 1991-1992}

1. R.E. Carrillo, and P.M. DeLuca, Jr., "Thermoluminescent Dosimetry of 0.1-30 keV electrons with lithium fluoride", IV Ciongreso Nacional sobre Dosimetria Termoluminiscente, Sept. 12-13, 1991, Mexico City.

2. R.E. Carrillo, D.W. Pearson, P.M. DeLuca, Jr., and J.F. Mackay, "Thermoluminescent response of lithium fluoride (TLD-100) to monoenergetic photon beams of 600, 730, 900, and 1,500 eV", 10th International Conference on Solid State Dosimetry, July 13-17, 1992, Washington, DC!

3. R.E. Carrillo, D.W. Pearson, P.M. DeLuca, Jr., and J.F. Mackay, "The thermoluminescent response of calcium fluoride (TLD-200) to monoenergetic photon beams of $600,730,900$, and 1,500 eV", V Congreso Nacional sobre Dosimetria Termoluminiscente, Sept. 3-5, 1992, Mexico Clity.

4. P.M. DeLuca, Jr., "Fast Neutron Kerma Factors-Recent Determinations Below $100 \mathrm{MeV",} \mathrm{American} \mathrm{Nuclear} \mathrm{Society} \mathrm{Topical} \mathrm{Meeting,} \mathrm{A} \mathrm{pril} \mathrm{26-30,} \mathrm{1992,}$ Pasco, WA.

5. P.M. DeLuca, Jr., "Dosimetric Instruments and Methods," PTCOG XVI Meeting, March 30-31, 1992, Vancouver, British Columbia, Clanada.

6. M.N. Gould, J.F. Mackay, D.W. Pearson, W. Kennan, S. Muller, P. Shulman, T.R. Mackie, C. Hill, and P.M. DeLuca, Jr., "The Use of SynchrotronProduced Ultrasoft X-rays to Model Radiobiological Processes," Proc. of the 4th Int. Conf. on Biophysics and Synchrotron Radiation, August 30-Sept. 5, 1992, Tsukuba, Japan.

7. P.M. DeLuca, Jr., "Proton Radiation Therapy: A New Modality," Cleveland Area Medical Physics Society, Cleveland, OH, November 4, 1992. 


\section{Fast Neutron Dosimetry}

\subsection{Introduction}

Three distinct measurements comprise our fast neutron dosimetry research during 1992; kerma factors at 50 and $70 \mathrm{MeV}$ neutron energies at the Paul Scherrer Institute, kerma factors at 20 to $400 \mathrm{MeV}$ neutron energies at the Los Alamos Meson Physics Facility (LAMPF), and track-etch dosimeter response investigations also at LAMPF.

Kerma is an acronym for kinetic energy released to matter. This transfer of neutron energy to charged particles is the first of two steps for producing radiation effects in matter. The second step, the deposition of the charged particles' energy in a mass element, is termed absorbed dose. A kerma factor is the kerma per unit neutron fluence. The kerma factor measurements described here provide basic nuclear data needed for fast neutron radiotherapy, radiobiology, space exploration, and radiation damage studies. Neutron kerma factors for A-150 Plastic, carbon, oxygen, magnesium, and silicon from $20 \mathrm{MeV}$ to $400 \mathrm{MeV}$ neutron energies were measured at the LAMPF - Weapon Neutrons Research white source (WNR). The neutron kerma and neutron energy were measured simultaneously with small gasfilled ionization chambers with signal processing electronics for pulse height analysis (PHA) and neutron time-of-flight (TOF) analysis. The differential neutron fluenre was measured with a separate ionization chamber with thin uranium coated walls and PHA and TOF signal processing electronics.

Kerma factors for carbon, oxygen, nitrogen, zirconium, and aluminum were also measured using similar microdosimetric techniques at the Physikalisch Technische Bundesanstalt and the Paul Scherrer Institute. Psuedo monoenergetic neutrons of 50 and $70 \mathrm{MeV}$ energy were used, however, and the neutron fluence was measured with a recoil telescope.

Absorbed dose, defined as the expectation value of the energy imparted to matter per unit mass, is often used to model the response of systems to radiation. In radiation protection, absorbed dose must often be measured under conditions which make active dosimeters impractical. Currently, there is interest in using tracketch detectors as personnel neutron dosimeters for space missions and in accelerator environments. To investigate the response of track-etch dosimeters to fast neutrons, we irradiated track etch foils at several depths in a water phantom, again using the spallation neutron source at LAMPF WNR. Proportional counter microdosimetric spectra, which give the absorbed dose as well as qualitative information about the radiation, were also collected at similar positions in the phantom. In addition, a fission foil counter using time-of-flight techniques gave neutron energy spectra and fluences. Qualitative differences in the ionization spectra are observed at different. depths. 
Analysis of data from all three experiments is currently under way at the University of Wisconsin - Madison.

\subsection{Neutron Kerma Factor Measurements}

Kerma factors are used two ways. If the neutron fluence and energy spectrum are known, the kerma is simply the product of the appropriately averaged kerma factor and the fluence. A more common application is the desire to know the absorberl dose in one material (e.g. tissue) from a measurement of dose in a different material (e.g. dosimeter). The absorbed dose to the tissue is the product of the dosimeter absorbed dose and the kerma ratio $k_{t} / k_{m}$. The $k_{t} / k_{m}$ is needed since we lack material which is both tissue-like in composition (for fast neutrons interactions) and suitable for building dosimeters.

Kerma factor and ratio measurements discussed here provide basic nuclear data needed for fast neutron radiotherapy $[17,19]$, radiobiology, space exploration, and radiation damage studies.

Neutron radiotherapy has proven superior to photon treatment for locally extended inoperable salivary gland and paranasal sinus tumors, slow growing well differentiated soft tissue sarcomas, bone- and chondrosarcomas, locally extended prostatic adenocarcinoma $(n+\gamma)$, in the palliative treatment of melanomas, and for some tumors of the head and neck [19]. Neutrons are not indicated for brain tumors, however [18]. The scope of clinical applicability is significant - about 10 percent of radiotherapy patients could benefit from treatment with neutrons [18].

The therapeutic superiority of fast neutrons over photons for some tumors is due in part to the effectiveness with which neutrons kill hypoxic and anoxic cells. These cells, which are prevalent in tumors due to poor vasculature, show less variation in radiosensitivity over the course of the cell life cycle when irradiated with neutrons[7]. Reduced repair of sublethal cell damage from neutrons results in clinically advantageous relative biological effectiveness (RBE) and is attributed to the high LET secondary spectra associated with fast neutrons [7].

In radiotherapy, the quantity of interest is generally biological effect. Why then, would one be interested in kerma or absorbed dose? Absorbed dose is a good physical parameter for modelling biological response to radiation. Also, both quantities are more readily measured than cell damage or kill in a clinical setting. Kerma has two additional advantages. First, it is independent of the complex energy transport of secondary charged particles, which is not the case for absorbed dose. Second, kerma represents the transfer of energy to charged particles at a point in space. This permits the convenient description of a neutron field in terms of kerma or kerma rate in a small mass of the material of interest (e.g. tissue) in free space or inside another material (e.g. water phantom). Such field characterizations are essential to accurate treatment planning and delivery. 
Clinically, the tissue absorbed dose can be measured or calculated. Using cross sections for all relevant energies, angles, reaction channels, and elements, an arlequate three dimensional elemental description of a treatment site, and a well characterized neutron beam one can calculat $\epsilon$ the absorbed dose with a computer simulation. In lieu of such knowledge and computational resource, we measure the dose in a tissue-like phantom with a tissue-like dosimeter. However, our tissuelike dosimeter material (A-150 plastic) has an excess of carbon and a deficiency of oxygen compared to real tissue $[13,14]$. For neutrons, we must therefore multiply the absorbed dose in tissue-like material by the ratio of kermas $k_{t} / k_{m}$ to get the absorbed dose in tissue. There are several ways to calculate $k_{t} / k_{m}$, each requiring somewhat different input data. Some or all of the kerma factors or kerma ratios for hydrogen, oxygen, carbon, nitrogen, and A-150 are needed, as well as the relative or absolute neutron fluence as a function of energy. The kerma factor or herma ratio measurements require much less effort than complete cross section measurements yet are of immediate relevance to clinical dosinetry.

Recently there has been a trend toward higher energy neutron beams, up to $70 \mathrm{MeV}$, which deliver greater dose at depth and produce higher LET due to the increased $(n, \alpha)$ reaction probabilities in carbon, oxygen, and nitrogen. However, dosimetry suffers from a lack of accurate fast neutron kerma factors and ratios, gas-to-wall absorbed dose conversion factors $\left(r_{m, g}\right)_{n}$, and gas ionization potential $\left(W_{n}\right)$ values. The total uncertainty in tissue absorbed dose should be reduced to \pm 3.5 percent $(1 \sigma)[11]$. While this is now possible below $14 \mathrm{MeV}$ [10], the proposed carbon, oxygen, and A-150 kerma measurements will allow a much more accurate tissue absorbed dose determination at higher energies than is now possible.

Kerma factor measurements for iron are needed to test calculated cross sections employed in the design of neutron beam collimators. The magnesium, aluminum, and silicon measurements are useful for predicting radiation damage to space vehicles.

\subsection{White Source Neutrons - 20 to $400 \mathrm{MeV}$ Neutron En- ergy Measurements}

\section{Neutron Source and Flight Path}

The Los Alamos National Laboratory Weapons Neutron Research Facility, part of the Los Alamos Meson Physics Facility (LAMPF), provides a white source of neutrons in the energy range of about $100 \mathrm{keV}$ to over $750 \mathrm{MeV}$ neutron energy. A pulsed beam of $800 \mathrm{MeV}$ protons from LAMPF, nominally about. $500 \mathrm{nA}$, incident. on a water cooled tungsten target produces spallation neutrons. The measurements were made at a distance of $15 \mathrm{~m}$ from the target and at an angle of 30 degrees from the proton beam line. Figure 5 shows the WNR spallation target and flight paths.

A bunched and chopped proton beam bombards the WNR tungsten target pro- 
ducing spallation neutrons. The beam time structure consists of micropulses and macropulses. A macropulse is comprised of 300 micropulses, each separated by $1.8 \mu \mathrm{s}$. There are 40 macropulses per second, or 12000 micro pulses per second. The neutron beam spot diameter is approximately $8 \mathrm{~cm}$. The beamlines are not evacuated. Lisowski et al. describes the LANL neutron sources in detail [9].

\section{Proportional Counters}

Gas proportional counters were chosen for this investigation because of their ahility to provide valuable qualitative information about the secondary particle spectra and because of their high sensitivity. Since photon induced events may deposit as little as $30 \mathrm{eV}$ (roughly the energy required to generate an ion pair in gas), the collection and amplification of charge is crucial in obtaining adequate sensitivity and resolution. Because of the high mobility of ions in a gas and because of the high signal-to-noise ratio of gas amplification, proportional counters provide adequate sensitivity and resolution.

We used commercial ${ }^{1}$ spherical Rossi type proportional counters [15]. The walls typically consist of a spherical shell, $0.127 \mathrm{~cm}$ thick, with a inside diameter of 1.27 $\mathrm{cm}$. The shell is held at ground potential, while the axial wire anode and coaxial helix were held at positive potentials with respect to the shell. The counters were filled with $\mathrm{ArCO}_{2}$ or tissue equivalent propane gas to 60 Torr. Since the counter walls are relatively thin compared to the maximum charged particle ranges, they do not provide the gas cavities with full equilibrium spectra of secondary charged particles). Therefore, external "build-up" caps (each made of the corresponding detector wall material) were introduced to provide charged particle equilibrium for neutrons up to $70 \mathrm{MeV}$.

The proportional counters were calibrated using the internal alpha calibration technique. With this technique, a collimated beam of alpha particles crosses the cavity diameter, depositing a known amount of energy in the gas. With a knowledge of the mass collision stopping power of the alpha particles and the cavity diameter, the proportional counter pulse height was directly calibrated to absorbed close or, equivalently, event size $\mathrm{Y}[12]$.

The proportional counter charge pulses were converted to voltage pulses with preamplifiers, then amplified by two linear amplifiers of gains differing by a factor of 15. Each event was digitized by at least one of two adcs, by both adcs if the event was in an overlap region common to both adcs. While the useful dynamic range of an amplifier/adc is about two decades, the event size spectra span five decades. Events range in size from about $0.15 \mathrm{MeV} \mathrm{cm} \mathrm{cm}^{-1}$ for a single ionization event. to

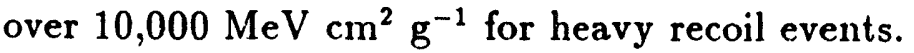

\footnotetext{
${ }^{1}$ Model LET 1/2, Far West Technology, Inc., Goleta.
} 
Fission Foil Ionization Detectors

The neutron energy spectrum and total fluence were measured relative to the fast. fission cross section of ${ }^{235} \mathrm{U}$ using fission foil ionization detectors with time-of-flight. techniques [9]. The fission foil counter was positioned $37 \mathrm{~m}$ from the source.

Using PHA and TOF to discriminate neutron energy and background ( $U$ alpha. decay), the TOF spectrum is revealed. The fission pulses are so much greater than the background pulses in size, we can assume unit efficiency in detecting fissions. With the differential fission cross section, the absolute differential neutron fluence can be calculated from

$$
\Phi_{E}=\frac{f_{E}}{\eta_{E}}=\frac{f_{E}}{\rho t A_{M_{A} f_{E}}^{N_{\sigma_{E}}}},
$$

where $f_{E}=$ fissions induced by neutrons of energy $\mathrm{E}$,

$\eta_{E}=$ differential efinciency of the fission foil counter,

$\rho=$ mass density of fissionable material,

$t=$ thickness of fissionable material,

$A=$ area of fission foil in the beam,

$N_{A}=$ Avogadro's number,

$M=$ atomic mass of the fissionable material, and

${ }_{f} \sigma_{E}=$ differential fission cross section.

The performance of a fission foil counter depends on the mass of fissile or fissionable foil material in the beam. The mass, mass thickness, and uniformity of the fisisonable material have been previously determined by the WNR group. If too little $U$ is used, the efficiency of the counter will too low and the accuracy of the measurement is limited by counting statistics. On the other hand, if the $U$ thickness is too great, some fission fragments will be absorbed in the foil and the uncertainty in the efficiency increases. Our foil is about $200 \mu \mathrm{g} \mathrm{cm}^{-2}$ of ${ }^{235} \mathrm{U}$, was electrodeposited onto a $10 \mathrm{mg} \mathrm{cm} \mathrm{cm}^{-2}$ stainless steel plate.

\section{Data Acquisition System}

We simultaneously collected and displayed two parameter data (time-of-flight and pulse height) from a proportional counter and a fission foil counter. An Apple Quadra microcomputer, running commercial data acquistition software, was interfaced to a CAMAC crate, containing the ADCs and scalars, with a buffered dual ported memory unit. Events are recorded and stored in the buffer's memory until the buffer is about half full. The interface then interrupts the computer, which then reads and clears the data present in the buffer. The buffer reduces the number of software operations for storing the data, thereby decreasing dead time counting losses.

Each spectrum, a two parameter historgram, is projected to the pulse-height and TOF plane. Due to the large dynamic range of the pulse-heights, two linear 
amplifiers with overlapping gains were used for each proportional counter. 'The amplifiers' gains were adjusted so that an intermediate (overlap) range of pulse-heights are common to both amplifiers. A Y. $\Delta Y$ vs. $\log \mathrm{Y}$ display mode enables the inmediate visual verification that the high and low gain amplifiers are consistently calibrated. High and low gain event spectra should appear superposed in the region of overlapping gain.

\section{Collaborators}

Drs. Robert Haight and P. Lisowski of P-15 and P-17 Divisions of Los Alamos National Laboratory have again participated in this experiment.

\subsection{Measurements With Monoenergetic 17, 45, $66 \mathrm{MeV}$ Neutron Energies}

Our ability to measure absorbed close in a particular material is dependent on constructing a dosimeter of that material. While oxygen, and to a much lesser extent, nitrogen kerma factors are important in cancer therapy, we cannot construct dosimeters of the pure elements. Instead, we use a pajr of detectors in which one detector has, for example, walls of an oxygen compound while the other detectors wall is of that coumpound material but without the oxygen. The oxygen kerma is then deduced by subtraction, taking into account the weight fractions in the wall materials.

Using conventional and subtraction techniques, we have measured kerma factors for oxygen and carbon at the Physikalisch-Technische Bundesanstalt in Braunschwieg, Germany, at $17 \mathrm{MeV}$. We also measured the kerma factors at 45 and 66 $\mathrm{MeV}$ with pseudo monoenergetic neutrons at the Paul Scherrer Institute in Villigen, Switzerland. Preliminary results of the PSI data show that the ionization event. size distributions in carbon and in oxygen are remarkably similar. This suggests that the mass-fraction weighted-average kerma factor ratio, needed to convert from dosimeter to tissue absorbed dose, will be a small correction (see general discussion of kerma factors elsewhere in this document). The nitrogen event size distribution, also determined by subtraction, indicates that the nitrogen $(n, p)$ cross section is higher than that of carbon at neutron energies up to $66 \mathrm{MeV}$.

In order to subtract the portion of kerma which results from contaminaling low energy neutrons, the proportional counter events were acquired with time-of-flight. neutron energy discrimination. This allows the kerma contribution from neutrons below some "low neutron energy threshold" to be directly subtracted. Ideally, this threshold would be just below the nominal neutron energy. Unfortunately, owing to the poor time resolution of the proportional counter and the short flight path, this "low neutron energy theshold" is well below the nominal neutron energy. As a result, the remaining kerma is really the sum of contributions from nominal and 
intermediate energy neutrons. The intermediate energy region extends from the "low neutron energy threshold" to just below the nominal neutron energy peak. The intermediate energy neutrons' contribution to kerma is calculated from previously known or assumed kerma factors combined with the neutron fluence in intermediate energy region, which was measured with NE213 scintillator. In this region the scintillator provides excellent neutron energy discrimination and its efficiency can be calculated accurately. After subtracting the kerma contributions from low and intermediate energy neutrons from the total kerma, that remaining is from the nominal energy neutrons.

Analysis of the proportional counter data is underway at the University of Wisconsin, the PTB, and the University of Saarlandes, Cermany. Fluenre data are being analyzed at the Physikalish-Technische Bundesanstalt in Braunschweig, (iermany.

\section{Matched Pair Proportional Counter Technique}

Two matched pairs were used for oxygen kerma factor determinations and an additional pair gave the nitrogen kerma factor data. $\mathrm{A} \mathrm{Zr}$ and $\mathrm{ZrO}_{2}$ pair and an $\mathrm{Al}$ and $\mathrm{Al}_{2} \mathrm{O}_{3}$ pair were both used at 45 and $66 \mathrm{MeV}$.

\section{$\mathrm{Zr}, \mathrm{ZrO}_{2}$ Detectors from the University of Wisconsin}

A matched pair of cylindrical proportional counters were constructed to determine the oxygen neutron kerma by subtraction [6]. Otherwise identical in design, one counter's cavity wall was made of zirconium metal while the other counter's was made of zirconium oxide ceramic.

Figure 1 shows the basic features of the detectors. Field tubes, surrounding both ends of the anode, prevent gas multiplication near the ends of the chamber where the electric field is not axially uniform. The field tubes each extend $7.0 \mathrm{~mm}$ into the cylinders. The $\mathrm{Zr}$ and $\mathrm{ZrO}_{2}$ cylinders are $52.3 \pm 0.01 \mathrm{~mm} l o n g, 15.9 \pm 0.1 \mathrm{~mm}$ inside diameter, and $3.18 \pm 0.04 \mathrm{~mm}$ thick. To provide equilibrium spectra of charged particles, additional $\mathrm{Zr}$ or $\mathrm{ZrO}_{2}$ were placed outside the detectors during some irradiations. A $110 \mathrm{~mm}$ square $\mathrm{Zr}$ plate, $12 \mathrm{~mm}$ thick, was placed perpendicular to the beam between the detector and the target. This additional thickness of $\mathrm{Zr}$ provides charged particle equilibrium up to $75 \mathrm{MeV}$. A hollow thin walled aluminum right circular cylinder, filled with $\mathrm{ZrO}_{2}$ ceramic powder, was placed over the $\mathrm{ZrO}_{2}$ detector during some irradiations. The $\mathrm{ZrO}_{2}$ thickness was $10.6 \pm 0.1 \mathrm{~mm}$, providing charged particle equilibrium up to $70 \mathrm{MeV}$.

Both counters were filled with a mixture of 95 percent $\mathrm{Ar}$ and 5 percent. $\mathrm{CO}_{2}$ gas to 68 Torr. The proportional counter absorbed dose calibration was similar to that used in previous investigations $[3,4,5]$.

In order to deduce absorbed dose, the active volume of the counter, which is less than the geometric volume because of the field tubes, must be known. Actually, 
the ratio of the detector diameter to active volume $d / f$ is required and was previously determined by Hartmann et al. by simultaneously irradiating spherical and cylindrical A-150 plastic-walled proportional counters with $1.85 \mathrm{MeV}$ neutrons[8]. The cylindrical plastic, $\mathrm{Zr}$, and $\mathrm{ZrO}_{2}$ counters were of very similar dimension. $d / V$ for the $\mathrm{Zr}$ and $\mathrm{ZrO}_{2}$ detectors is $2.65 \cdot 10^{-3} \pm 0.04 \mathrm{~mm}^{-2}$.

\section{Al and $\mathrm{Al}_{2} \mathrm{O}_{3}$ Detectors from the University of Birmingham}

Aluminum, $\mathrm{Al}_{2} \mathrm{O}_{3}$, and $\mathrm{AlN}$ counters built by the Birmingham group after the design criteria of Benjamin et al. are shown in Figure 2[1]. Cavity dimensions are similar to commercially available units ${ }^{2}$, described earlier in this document. All three counters were filled to 68 Torr with tissue equivalent propane gas.

\section{Cyclotron Neutron Source}

The PSI two stage proton accelerator consists of a injector cyclotron, which supplied protons at either 50 or $72 \mathrm{MeV}$, and a ring cyclotron, which further accelerates the protons to $590 \mathrm{MeV}$. We used the injector cyclotron to produce 45 or $66 \mathrm{MeV}$ neutrons. A kicker was used to create a pulsed beam of protons on target, thus producing suitable neutron pulses for time-of-flight measurements with low pressure proportional counters.

A two mm thick berilium target produced quasimonoenergetic neutrons via the ${ }^{9} \mathrm{Be}(\mathrm{p}, \mathrm{n})^{9} \mathrm{~B}$ reaction. The proportional counter dose and recoil telescope fluence measurements were made on a 0 degree flight path at about $8 \mathrm{~m}$ from the target.

\section{Preliminary Results}

Preliminary analysis of ionization spectra, without neutron energy discrimination, indicates good agreement in the oxygen spectra by subtraction as determined from both the Wisconsin and Birmingham matched pair detectors.

Figure 3 shows the ionization yield spectra at $45 \mathrm{MeV}$ from oxygen, using the Wisconsin detectors with the subtraction technique, in $\mathrm{ArCO}_{2}$ propane gas. ionization yield from carbon, also in TE gas.

Figure 4 shows the lineal energy weighted ionization yield spectra from oxygen and from carbon in $\mathrm{ArCO}_{2}$ (lower curves) and in TE propane (upper curves). Here the oxygen spectrum is from the subtracion technique using the matched pair detectors. The carbon spectra are again from commercial counters, otherwise iclentical one was filled with TE gas and the other with $\mathrm{ArCO}_{2}$. Spectra in Figure 4 are from $45 \mathrm{MeV}$ neutrons. The results at $66 \mathrm{MeV}$ (not shown) are similar.

It is apparent that the shape of the ionization spectra of oxygen and carbon are very similar. This suggests that the $(n, p)$ and $(n, x \alpha)$ cross sections are similarly proportioned in both elements. Further, if the final analysis shows that the kerma

\footnotetext{
${ }^{2}$ Model LET 1/2, Far West Technology, Inc., Goleta.
} 


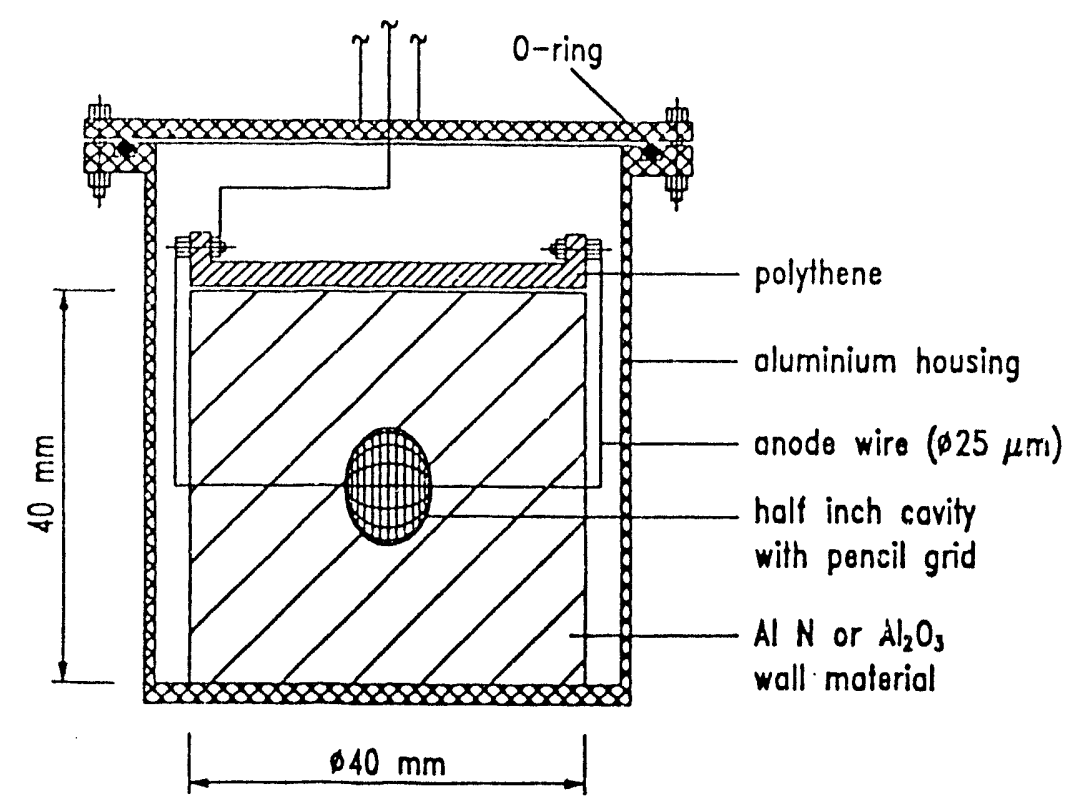

Figure 2: Diagram of the $\mathrm{Al}, \mathrm{Al}_{2} \mathrm{O}_{3}$, and $\mathrm{AlN}$ matched spherical proportional counters from the University of Birmingham, U.K.

for personnel dosimeters. The measurements indicate that C!R-39 Plastic provides a correlation between absorbed dose and dose equivalant for fast neutrons (above $20 \mathrm{MeV})$.

The study consisted of three types of measurements: absorbed dose measurements using microdosimetric techniques, neutron fluence measurements using fission foil and scintillation counters, and track registration in CR-39 Plastic foils. The proportional counters, fission foil counter, and the WNR neutron source are described elsewhere in this document.

Preliminary work indicates that the A-150 Plastic absorbed dose is delivered mainly by protons, with the alpha and heavy recoil particle contributions increasing very slightly with increasing water depth. Those measurements demonstrated the suitability of the detectors to the WNR neutron flux. The absorbed close per nelltron fluence increases modestly with increasing depth in the water phantom. This 


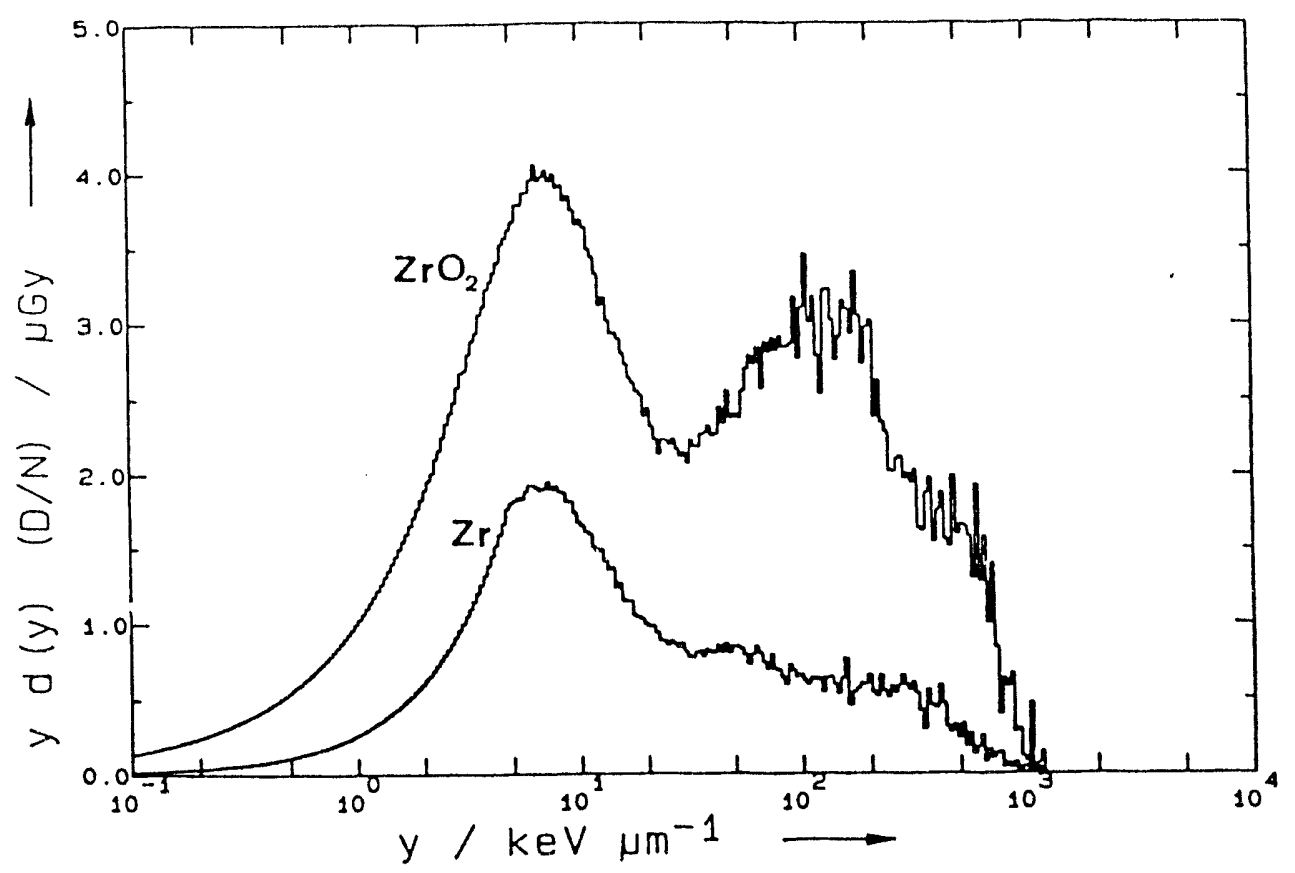

Figure 3: Lineal energy weighted ionization yield spectra in $\mathrm{ArCl}_{2}$ gas from $\mathrm{Zr}$ and $\mathrm{ZrO}_{2}$ bombarbed with $45 \mathrm{MeV}$ neutrons.

may be attributed to the increase in secondary charged particle fluence (build-np) with increasing water depth. While the depth of the phantom is about equal to the range of $200 \mathrm{MeV}$ protons, the proton fluence extends to over $700 \mathrm{MeV}$. Therefore, charged particle equilibrium did not occur for any of these measurements. Since there is significant removal of the primary beam by the water phantom, the kerma rates also decreases in proportion resulting (at some large depth greater than the phantom dimensions) in transient charged particle equilibrium. Therefore, a maximum absorbed dose rate probably occurs at a depth between 5.7 and $16.7 \mathrm{~cm}$, though this is difficult to establish with only three measurements.

The normalized absorbed dose values, in order of increasing dipth, are 4.23, 4.27 , and $3.45 \mu \mathrm{Gy}$ per fission foil count. Absorbed dose and neutron fluence values are summarized in Table 1 . Since absolute neutron fluences were not needed in these preliminary tests, relative fluences were obtained by integrating the number of counts in the time-of-flight spectra up to the fission edge. 


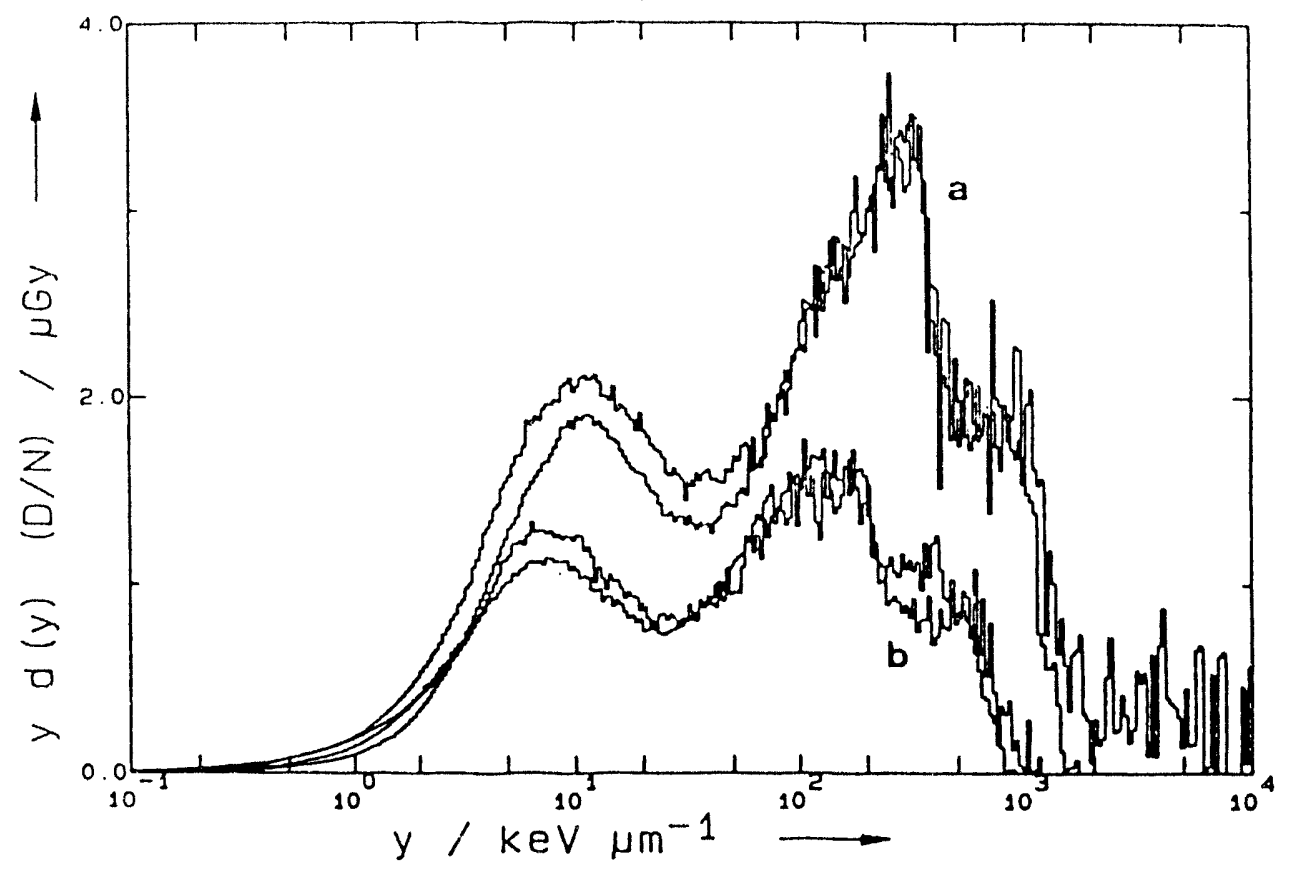

Figure 4: Oxygen and carbon ionization yield spectra at $45 \mathrm{MeV}$ neutron energy from (a) $\mathrm{Al}, \mathrm{Al}_{2} \mathrm{O}_{3}$ detectors and (b) $\mathrm{Zr}, \mathrm{ZrO}_{2}$ detectors. The oxygen kerma is deduced by subtracting appropriately weighted spectra from matched pair detectors.

Absorbed dose to A-150 plastic decreases by about a factor of 1.2 when the depth of water build-up is increased from 6 to $27 \mathrm{~cm}$. It is possible that transient charge particle equilibrium is established within the phantom. The nicrodosimetric spectra show that the contributions of alphas, and heavy recoils are very similar at 6.7 and $16.7 \mathrm{~cm}$ water depths relative to the proton contribution. At $26.7 \mathrm{~cm}$ depth, the alpha and heavy recoil contributions increase substantially.

Microdosimetric event size spectra, presented in the $Y \cdot \Delta Y$ us. $\log Y$ format, show the $(n, p)$ scattering on hydrogen contributes greatly to absorbed dose at all three depths. There is relatively little difference in the shape of the specta at 5.7 and $16.7 \mathrm{~cm}$ depths. At $26.7 \mathrm{~cm}$ depth the relative contributions of alpha particles and heavy recoils increases slightly. Figure 6 shows the event size spectra at $5.7 \mathrm{~cm}$ water depth normalized to relative neutron fluence. Figure 7 shows the associated fission foil time-of-flight spectra. 
The overall uncertainty in the absorbed dose, about 10 percent, is dominated by the extrapolation of the spectra below the electronic discriminator cuttoff. Radio frequency pickup and microphonic noise masked the photon events and a significant fraction of the proton events. To correct for these effects, proportional counter spectra were extrapolated below $40 \mathrm{MeV} \mathrm{cm} \mathrm{g}^{-1}$ for each measurement. This correction, which represents about $10 \%$ of the absorbed dose, is estimated to introduce at most a $5 \%$ uncertainty in the absorbed dose values.

\section{Conclusions}

In 1992 we repeated tissue equivalent absorbed dose measurements made at LANL WNR in 1991, adding the simultaneuous pulse-height and time-of-flight neutron energy discrimination techniques developed by Schrewe $[2,16]$ et al. for low pressure proportional counters. We also were able to improve the experiment through noise reduction efforts and by using a longer $(40 \mathrm{~m})$ flight path. These absorbed close measurements are also part of a collaboration with the HS Division of LANL to test. the response of $\mathrm{C} R$-39 Plastic to fast neutrons for personnel dosimeters.

Computer codes to analyze the two parameter proportional counter data are presently under development at the University of Wisconsin in Marlison. This work is closely related to the carbon and oxygen kerma factor measurements also made at WNR in 1992 and 1992.

\section{Collaborators}

Drs. Robert Haight and P. Lisowski of P-15 and P-17 Divisions of Los Alamos National Laboratory provided valuable assistance with the fission foil counters and the data acquistion for this experiment. J. Bliss of Texas A\&M University, Dr. $K$. Alvar, and R. Brake of LANL Health and Safety (HS) Division were reponsible for the CR-39 work. 


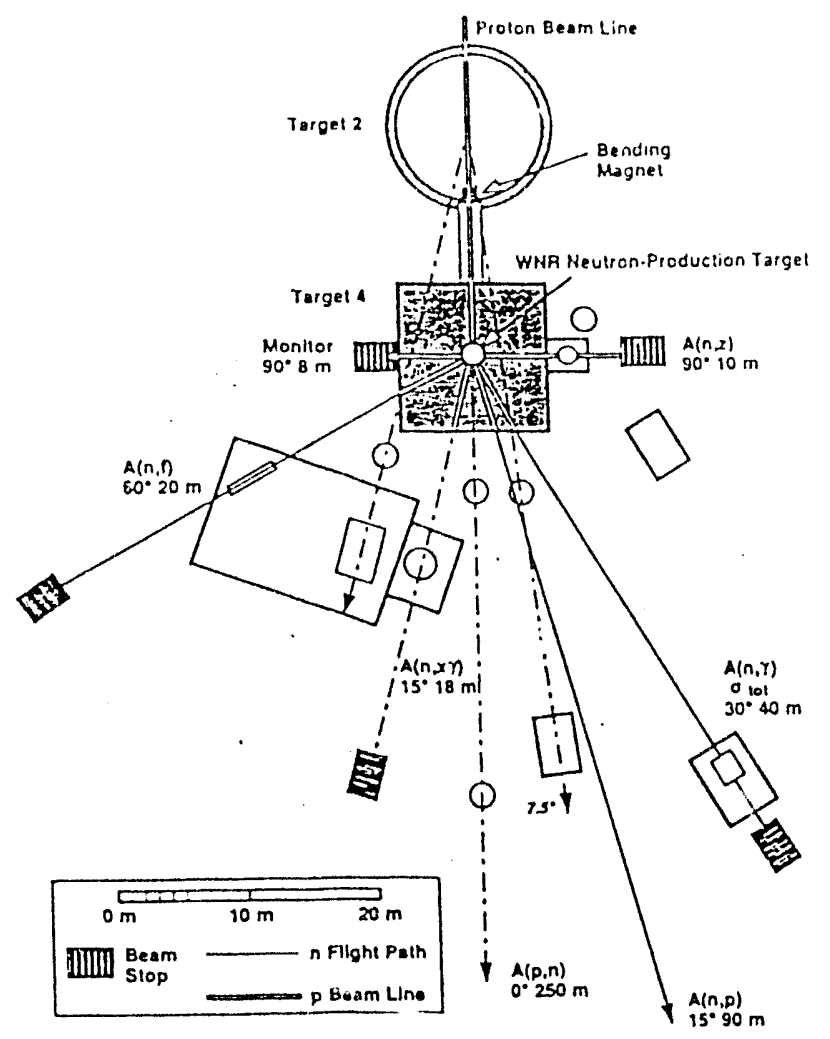

Figure 5: Los Alamos National Laboratory Weapons Neutron Research Facility targets and flight paths. A-150 absorbed dose measurements wer made at $15 \mathrm{~m}$ in 1991 and 1992. All measurements were made on the 30 degree left flight path. 
Table 1: A-150 tissue equivalent plastic absorbed doses measured with a low pressure proportional counter submerged at various positions in a water phantom.

\begin{tabular}{|c|c|c|c|}
\hline $\begin{array}{c}\text { Water } \\
\text { Depth } \\
(\mathrm{cm})\end{array}$ & $\begin{array}{c}\text { Absorbed } \\
\text { Dose } \\
(\mathrm{mCly})\end{array}$ & $\begin{array}{c}\text { Neutron } \\
\text { Fluence } \\
(\text { counts })\end{array}$ & $\begin{array}{c}\text { Normalized } \\
\text { Dose } \\
(\text { Gy/cnt })\end{array}$ \\
\hline 5.7 & $14.6 \pm 0.2 \%$ & 3444 & $4.23 \cdot 10^{-6}$ \\
16.7 & $20.8 \pm 0.2 \%$ & 4872 & $4.27 \cdot 10^{-6}$ \\
26.7 & $2.10 \pm 0.2 \%$ & 6409 & $3.45 \cdot 10^{-6}$ \\
\hline
\end{tabular}

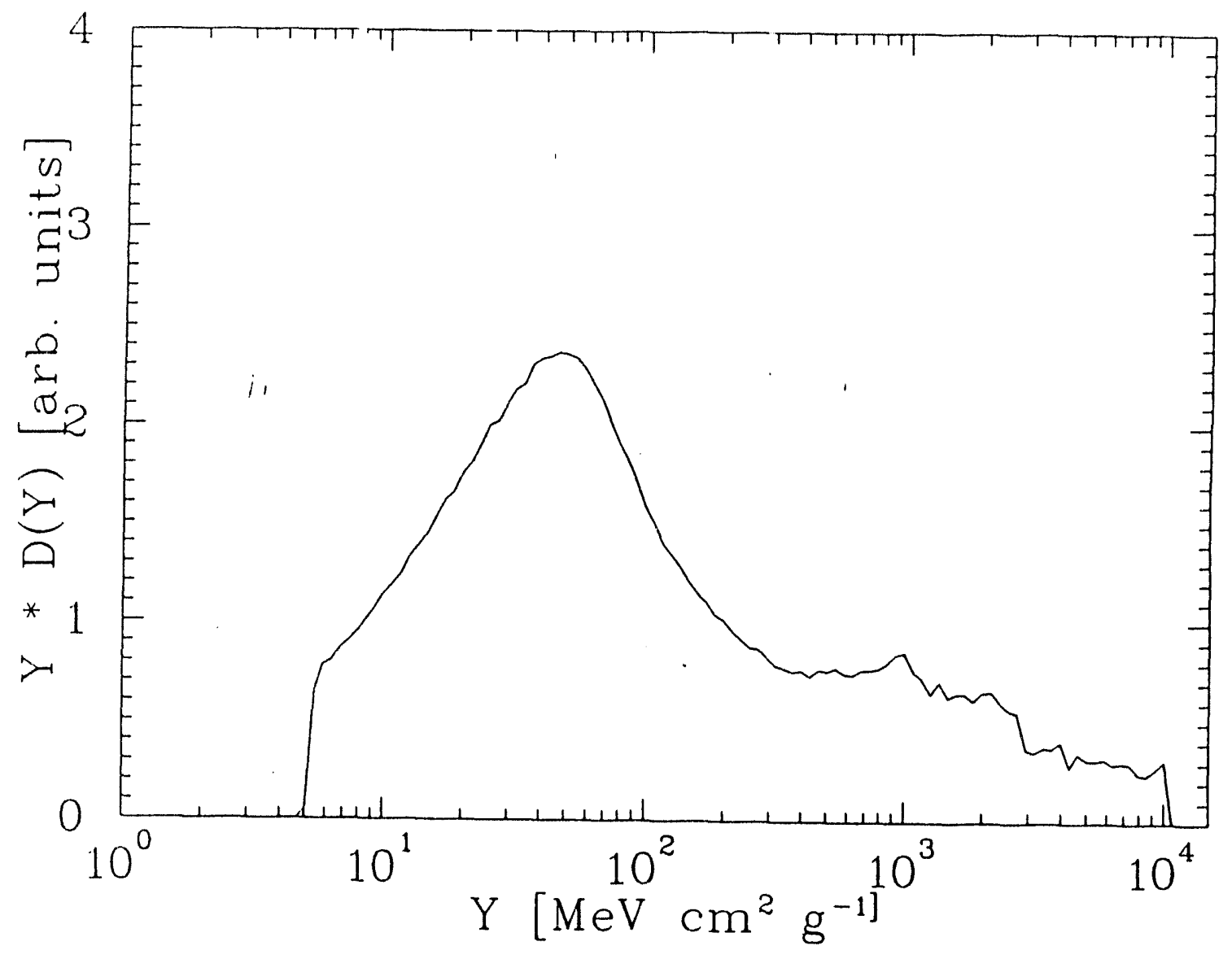

Figure 6: Fluence normalized A-150 Plastic proportional counter event size spectrum with $5.7 \mathrm{~cm}$ of water build-up. 


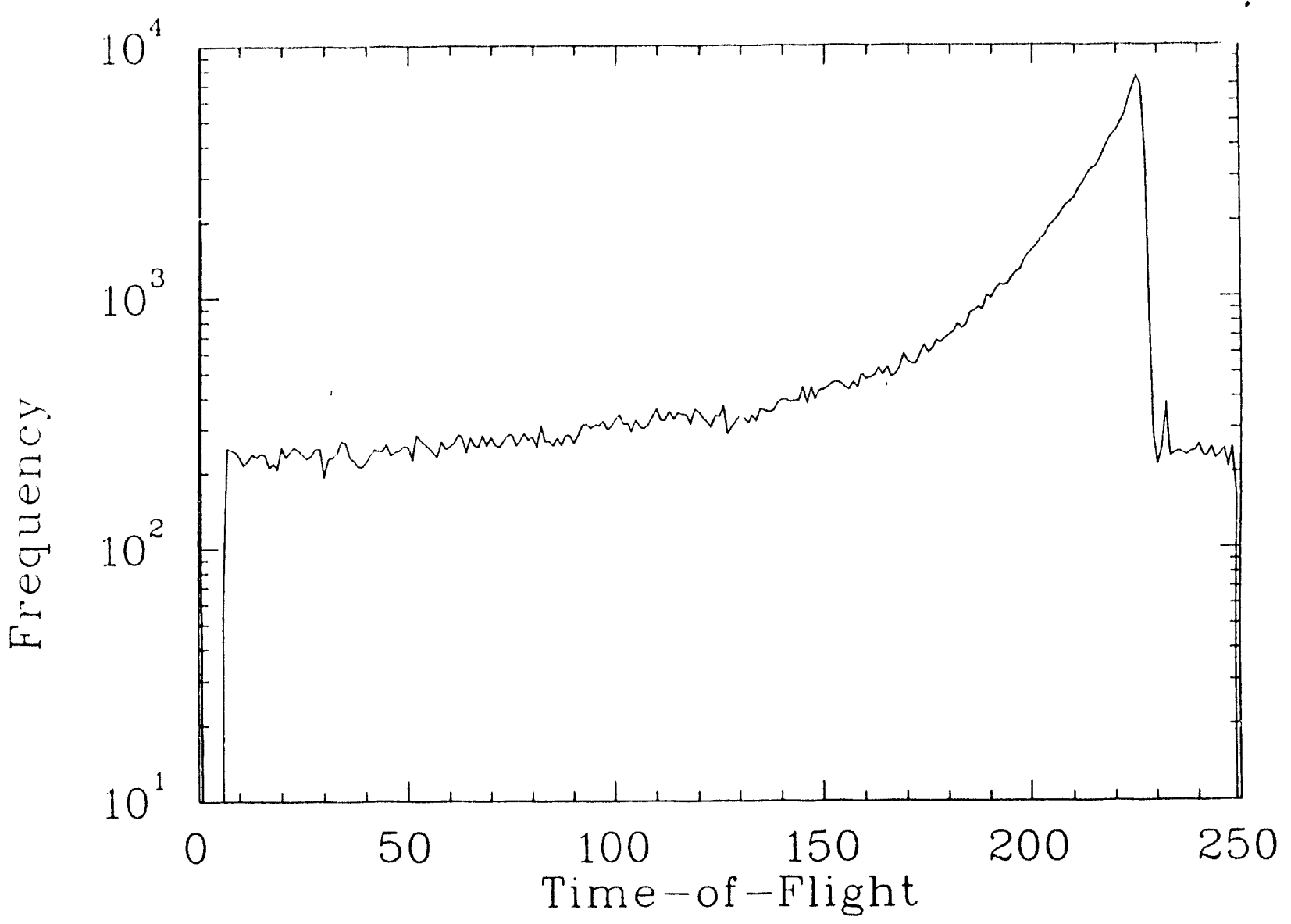

Figure 7: Fission foil ionization chamber time-of-flight spectrum. Note the $\gamma$-flash (photo fission peak) on the far right. 


\section{References}

11] P.W.W. Benjamin, C.D. Kemshall, and J.A. Redfern. Iligh resolution spherical proportional counter. Nucl. Instr. and Mcth., 59:Ti 85, 1968.

(2] P.J. Binns, J.H. Hough, and B.R.S. Simpson. 'Time-resolved microdosimetry in a quasi-monoenergetic neutron beam. Presented at the $T^{\text {th }}$ Symposium on Neutron Dosimetry, Berlin, 1991.

[3] P.M. DeLuca, Jr., H.H. Barschall, M. Burhoe, and R.C!. Haight. Carbon kerma factor for 18- and 20-MeV neutron. Nucl. Sci. Eng., 94:192, 1986.

[4] P.M. DeLuca, Jr., H.H. Barschall, R.C:. Haight, and J.C. McDonald. Kerma factor of carbon for 14.1 MeV neutrons. Radiat. Res., 100:78, 1984.

[5] P.M. DeLuca, Jr., H.H. Barschall, C.L. Hartmann, and D.W. Pearson. C!orrections to kerma factor measurements made by integral techniques. Nucl. Inst. Meth., 40/41:1279, 1989.

[6] P.M. DeLuca, Jr., H.H. Barschall, Y. Sun, and R.C. Haight. Kerma factor of oxygen, aluminum, and silicon for $15-$ and $20-\mathrm{MeV}$ neutrons. Radiat. Prot. Dos., 23:27, 1988.

[7] E. Hall. Radiobiology for the Radiologist, Third Edition. J. B. Lippincott. Company, Philadelphia, 1988.

[8] C.L. Hartmann. Measurements of neutron kerma factors at 18, 2.3, and 2.5 MeV. PhD thesis, University of Wisconsin, Madison, Wisconsin, 1991.

[9] P.W. Lisowski, C.D. Bowman, and S.A. Wender. Los alamos national laboratory spallation neutron sources. University of California, Los Alamos National Laboratory, Physics Division, Los Alamos, NM.

[10] B.J. Mijnheer. Protocols for the determination of absorbed dose in patients irradiated by beams of nuclear particles on radiotherapy proceedures. In Proc. Advisory Group Meeting (Rijswijk 1985) Nuclear and Atomic Data for Radiotherapy and Related Radiobiology, pages 141-154, Vienna, 1987. International Atomic Eenergy Agency.

[11] B.J. Mijnheer, J.J. Batterman, and A. Wambersie. What degree of accuracy is required and can be achieved in photon and neutron therapy. Radiother. Oncol., 8:237-252, 1987.

[12] International Commission on Radiation Units and Measurements. Micro. dosimetry, ICRU Report 36. International Commission on Radiation Units and Measurements, Bethesda, MD, 1983. 
[13] International Commission on Radiation Units and Measurements. Tissue Substitutes in Radiation Dosimetry and Measurc, ICRU Report 44. International Commission on Radiation Units and Measurements, Bethesda., MD, 1989.

[14] International Commission on Radiological Protection. Report of the task group on reference man, ICRP Publication 23. International Commission on Radiological Protection. Pergamon Press, Oxford, 1975.

[15] H.H. Rossi and W. Rosenweig. A device for the measurement of dose as a function of specific ionization. Radiology, 64:404, 1955.

[16] U.J. Schrewe, H.J. Brede, and H. Schuhmacher. The use of microdosimetric detectors combined with time-of-flight techniques. Nucl. Instr. and Meth. in Phys. Res., pages 225-230, 1990.

[17] A. Wambersie and V. Grégoire. Nuclear data relevant for particle radiation therapy today and tomorrow. In Proc. Int. Conf. on Nuclear Data for Science and Technology, Jülich, Germany. in press, 1991.

[18] A. Wambersie, P. Pihet, and H.G. Menizel. The role of microdosimetry in radiotherapy. Radiat. Prot. Dosim., 31(1/4):421, 1990.

[19] A. Wambersie and F. Richard. Present status of fast neutron therapy, survey of the clinical data and of the clinical research programmes. In Nuclear Data. Needed for Neutron Therapy, Coordinated Research Programme (2 $2^{\text {nd }}$ mecting). IAEA (submitted), 1989. 


\section{Ultra-soft X-Ray Response of TLD}

\subsection{Participants}

Ricardo E. Carrillo, Paul M. DeLuca, Jr., David W. Pearson, and James F. Mackay.

\subsection{Summary}

In order to determine the potential of thermoluminescent. (TL) phosphors to be used as dosimeters of ultrasoft $x$-rays, the thermoluminescent response of TL materials, including LiF (TLD-100), to monoenergetic photon beams with energies between 100 and $3,000 \mathrm{eV}$ produced by the Aladdin synchrotron storage ring at the University of Wisconsin-Madison is being obtained. The change of the TL response as a function of total energy deposited is being experimentally obtained and reported. Normalized TL glow curves for exposures below saturation and for the different phosphors are presented. The effect of the annealing atmosphere in the TL sensitivity of the phosphors to the photons of interest is reported. Finally, preliminary calculations of supralinearity factors at several photon energies used are presented.

\subsection{Introduction}

Ultra-soft photon irradiations $(<3,000 \mathrm{eV})$ of cells for radiobiology studies pursued under this grant in previous years pointed out the need of having a practical, economical, and non-intrusive type of dosimeter that could be used at the same time cells are being irradiated to account for small changes in photon beam power $[1,2,3,4,5]$. We used photons generated by the Wisconsin Synchrotron Radiation Center $1 \mathrm{GeV}$ electron storage ring, Aladdin for the TLD irradiations. Thermoluminescent dosimeters were proposed due to their small size and proven usefulness to successfully monitor shallow penetrating beta rays $[6,7,8,9]$, and photons of higher ( $>15 \mathrm{keV}$ ) and lower ( $<100 \mathrm{eV}$, UV light) energy than those generated by Aladdin $[10,11]$. However, despite the extensive bibliographical search undertaken, only one study was found in the literature reporting the response of TLD-100 ribbons to $1,500 \mathrm{eV}$ photon doses [12], within the intermediate photon energy region from a few $\mathrm{eV}$ to a few $\mathrm{keV}$ available from Aladdin. Consequently, a research protocol was designed and submited [13] as part of this grant to study the response of these phosphors, particularly lithium fluoride (TLD-100), to monoenergetic photon beams with energies between 100 and $3,000 \mathrm{eV}$, the electromagnetic energy spectrum largely produced by Aladdin, and up to doses below saturation. Most of the irradiations proposed for the 1992 grant period have been achieved and the collected data are being analyzed. Preliminary results are presented in the following sections for the three TL phosphors used. 


\subsection{Materials and Methods}

Commercial LiF:Mg,Ti TLD-100 crystal and extruded ribbons, and CaF 2 Dy TLD200 extruded ribbons ${ }^{3}$ were used in this study. Extruded chips were $3.18 \times 3.18$ $\times 0.89 \mathrm{~mm}$ in size. Single crystal samples had slightly varying sizes as a result of the cleaving procedure, but were similar in size to the chips. The entire TLD-100 crystal was annealed at $400^{\circ} \mathrm{C}$ in air for $1 \mathrm{hr}$, after which the crystal was removed from the oven and placed on an aluminum block to reach room temperature. Then the crystal was placed in an $80^{\circ} \mathrm{C}$ oven for $24 \mathrm{hr}$. After this, the crystal was cleaved. To prevent the use of dosimeters which may have excessive $\mathrm{OH}$ impurities already diffused due to the initial air anneal, the outer face of the virgin crystal was discarded, and the crystals used in this study prepared from the immer portions of the parent crystal. To remove any TL associated with the cleaving process or due to background radiation absorbed by the dosimeters before their use, all dosimeters were read out right before use. The read-out cycle consisted of a fast pre-heat from room temperature to about $90{ }^{\circ} \mathrm{C}$; this temperature was held for about $4 \mathrm{sec}$ and was followed by a linear heating rate to about $420^{\circ} \mathrm{C}$. ' T'he read out took a total of about $64 \mathrm{sec}$. Helium was flushed thru the reader at a rate of about $350 \mathrm{ml}$ per min. To purge any air left inside the TL, reader drawer, a delay of 1 min was adopted from the moment the drawer of the TL reader was closed to the beginning of the read out. Helium not only inhibited any chemiluminescence and diffusion of impurities into the dosimeters, but also improved thermal contact between the phosphors and the heating planchet. For the extruded ribbons the annealing consisted in a single read out in helium as described above to erase any previous close and reset their TL response before use. To test the adverse effect of air annealing, a set of crystals and extruded ribbons were annealed in air at $400^{\circ} \mathrm{C}$, for 1 and $23 \mathrm{hr}$, respectively, and then read out in helium before and after use. Table 2 lists dopant concentrations of the TLDs employed in this study [14]. Also quoted in that table are their associated $K$ - and L-edge energies [15]; relevant energies within the energy region of interest. of this study have been highlighted.

The TL reader employed was a modified Harshaw reader, Model $2000 \mathrm{~A}$. This reader had no optical filtration in front of the photomultiplier tube (PMT) to be able to read several types of phosphors. Blackbody radiation subtraction from the recorded glow curves was done by reading out the dosimeters twice. Both response curves were recorded in a computer and the subtraction done by matching of the high temperature portion of the curves. The cooled PMT employed by the reader has a $\mathrm{S}-11$ response. Single photon counting was used by using a commercial photon counting amplifier/discriminator ${ }^{4}$ to reduce errors in the TL output caused by PMT gain variations and leakage currents. This output was then fed to a pre-scaler and

\footnotetext{
${ }^{3}$ Harshaw Chemical Company, now Solon Technologies, Solon, Ohio.

${ }^{4}$ Model 1120, SSR Instruments Comp., Santa Monica, California.
} 
Table 2: Chemical tements, including dopants, making up the TLDs used. Dopant concentrations, $\mathrm{K}-$, and L-edge energies are stated. Highlighted values are within the photon energy region covered by this study.

\begin{tabular}{|c|c|c|c|c|}
\hline TLD & Components & Conc. (ppm) & K-edge (keV) & L-edge (keV) \\
\hline LiF TLD-100 & $\mathrm{Li}$ & & 0.055 & \\
& $\mathrm{~F}$ & & $\mathbf{0 . 6 8 5}$ & 0.031 \\
& $\mathrm{Mg}$ & 200 & $\mathbf{1 . 3 0 0}$ & 0.089 \\
& $\mathrm{Si}$ & 40 & $\mathbf{1 . 8 4 0}$ & $\mathbf{0 . 1 4 9}$ \\
& $\mathrm{Al}$ & 20 & $\mathbf{1 . 5 6 0}$ & $\mathbf{0 . 1 1 8}$ \\
& $\mathrm{Ca}$ & 6 & 4.040 & $\mathbf{0 . 4 3 8}$ \\
& $\mathrm{Ti}$ & 12 & 4.970 & $\mathbf{0 . 5 6 4}$ \\
$\mathrm{CaF}_{2}$ TLD-200 & $\mathrm{Dy}$ & 200 & 53.800 & 9.050 \\
\hline
\end{tabular}

to a multichannel analyzer. ${ }^{5}$. The pre-scaler prevented the dead time of the MCA from exceeding $1.0 \%$. The multichannel scaling mode dwell time was 50 msec per channel, and a total of about $51 \mathrm{sec}$ was required to capture the glow curve from room temperature to about $370^{\circ} \mathrm{C}$. A neutral density optical filter made of inconel ${ }^{6}$ was inserted in front of the PMT for those dosimeters exposed to doses exceeding the useful range of the MCA and pre-scaler. Standard deviations quoted in the results were calculated by using the response of four dosimeters per exposure.

The Medical Physics Beamline of the Wisconsin Synchrotron Radiation Cienter was the source of ultrasoft $\mathrm{X}$-rays. This synchrotron storage ring was operating at. an electron energy of $0.8 \mathrm{GeV}$ with typical electron beam currents of less than 150 $\mathrm{mA}$. The synchrotron radiation spectrum consists of photons with energies from less than $10 \mathrm{eV}$ up to $4,000 \mathrm{eV}$. The design of the beamline was described in previous publications $[4,5]$. Two multilayer mirrors are used as the monochrometer to further reduce off-energy photon contamination produced by harmonics of the selected energy. These mirrors work according to the Bragg equation and consist of a periodic structure made of alternating layers of materials with high and low values of reflective index. W:C mirrors were used with a d-spacing of $2.92 \mathrm{~nm}$. C: and $W$ layers had the same thickness of $1.46 \mathrm{~nm}$ each; 55 layers were employed. The monochromatic beam of photons was then sent through a thin and narrow Be or $\mathrm{Mg}$ window to the experimental chamber where the TLD holder or photodiode (for power measurements) were set. A Si:Li detector ${ }^{7}$ was employed to calibrate the

\footnotetext{
${ }^{5} \mathrm{MCA}, 1024$ channels, Model 3100, Canberra Industries, Inc., Meriden, Connecticut.

${ }^{8}$ Oriel Optics Corp., Stamford, Connecticut.

${ }^{7}$ Micro-Z-Series, Model No. D-2366, Noran Instruments, Inc., Middleton, Wisconsin.
} 
mirror angle corresponding to the photon energy of interest. The beamline operated under high vacuum conditions to all $\cdots$ the transport of this low-energy radiation. Several methods were studied and used for photon power measurements $[1,3]$. More recently, the use of a $\mathrm{Si}$ photodiode ${ }^{8}$ has becn adopted. Previous to any irradiation and once the desired photon energy has been set, a power measurement was done with the photodiode. The experimental chamber had a computer controlled scanning mechanism to achieve irradiation of the TLDs at the desired exposures. The decay of the synchrotron beam and large power available made long irradiations undesirable. The aluminum-made TLD holder positioned the TLDs perpendicular to the photon beam. Circular holes with area of $6.13 \mathrm{~mm}^{2}$ were drilled in the cover of the holder on top of each TLD position to allow the photons to reach the dosimeters and delimit the irradiated area. Only the central part of a face of the TLDs were irradiated. The irradiated face of the TLD was the one set toward the PMT at the time of the TLD read out. A schematic view of the beamline is shown in figure 8 .

\subsection{Results for LiF:Mg,Ti (TLD-100)}

\subsubsection{TL response as a function of dose}

Figure 9 shows the mean free path of photons in $\mathrm{LiF}: \mathrm{Mg}, \mathrm{Ti}$ based upon available cross section data of the main constituents of TLD-100 [16]. The dots in the figure indicate the energies of the monoenergetic photon beams used during the TID irradiations. The discontinuity seen in that figure is the result of the K- absorption edge of fluorine, one of the main constituents of TLD-100. That figure also illustrates the fact that the mean free path of photons in the energy region of interest of this study is indeed very small, causing the shallow penetration that these lowenergy photons have in materials, including TLD-100 chips or crystals. The shallow photon penetration, of the order of microns, makes surface effects of the irradiated specimens of critical importance. This situation is similar to the one encountered when attempting to perform TL dosimetry of low-energy beta particles $[6,7,8,9]$.

Figure 10 shows the TL response obtained as a function of energy deposited in the He-annealed crystals for the photon energies used. Figure 11 presents similar results obtained with the He-annealed ribbons. The TL response in both cases is measured by the integrated area (ROI) of the glow curve between $130{ }^{\circ} \mathrm{C}$ and 215 ${ }^{\circ} \mathrm{C}$. The fact that glow curves for $\mathrm{He}$-annealed ribbons exposed to photons with energy of $730 \mathrm{eV}$, and to a lesser extent to $900 \mathrm{eV}$ as discussed in following sections, show an increased TL response between 150 and $170{ }^{\circ} \mathrm{C}$, region where fading could be noticed, could make this interval of integration less desirable than anticipated. However, if the dosimeter undergoes a low-temperature post-irradiation anneal, as is

${ }^{8}$ Model XUV-005, UDT Sensors, Inc., Hawthorne, California. 


\section{EXPERIMENTAL CHAMBER}

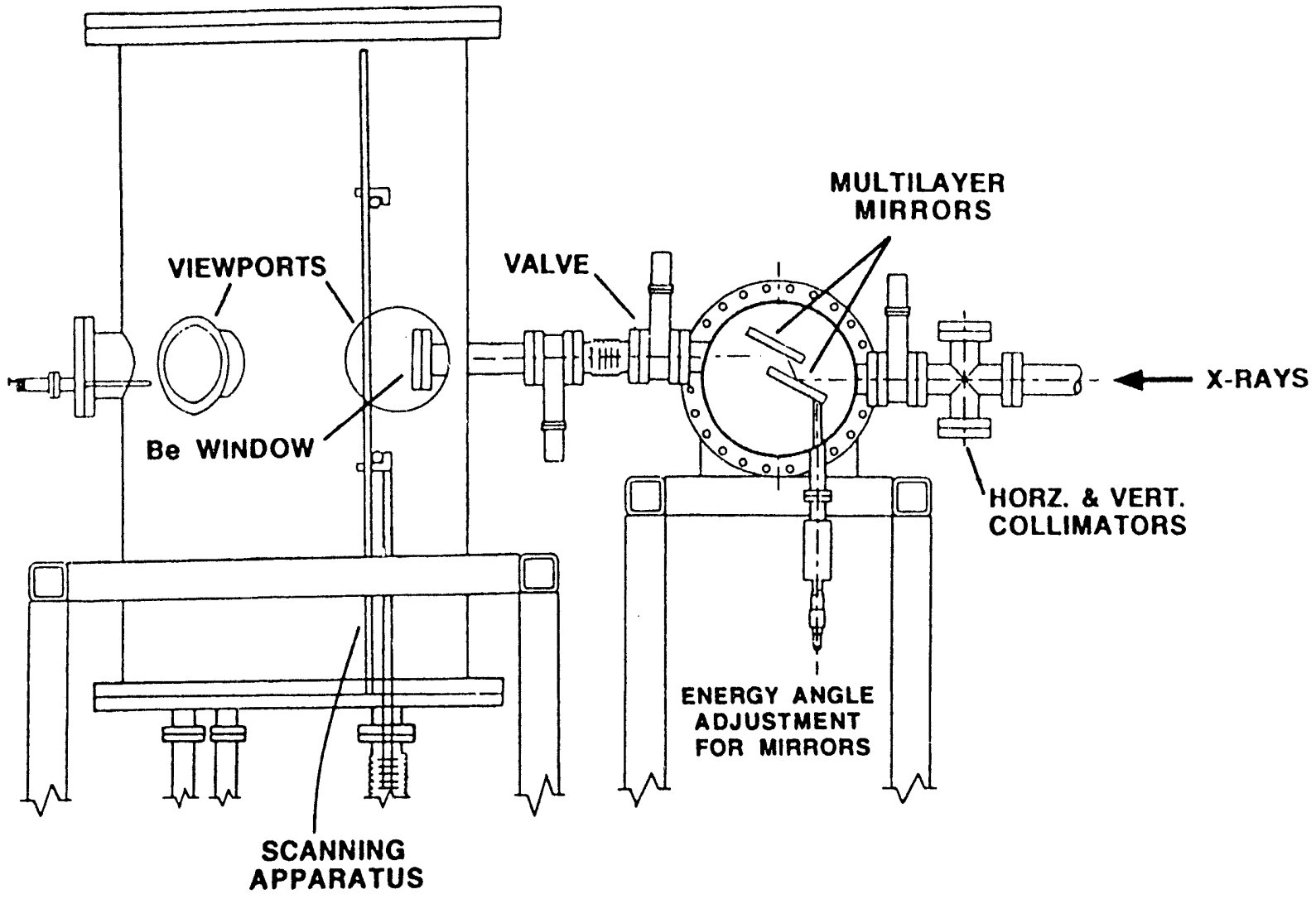

Figure 8: A schematic representation of the Medical Physics Beam Line, Port 051, showing important beam-line elements for the TLD irradiations.

frequently done for some phosphors, or is read out shortly after irradiation, making TL fading a non-important factor, this interval of TL integration becomes adequate because it covers most of the TL output.

As noticed in figures 10 and 11 , the integrated TL response as a function of energy deposited in the TLD seems to follow a linear behaviour for all photon energies used so far. Also, most of the TL responses for the crystals at all energies seem to follow a single line indicating that the dosimeters employed in this study are indeed responding similarly to each other. The same behaviour is mostly seen in the case of the chips. When the batch of chips was purchased, it was requested to have a bulk response (volume) sensitivity with a deviation of $\pm 5 \%$ from the mean response to ${ }^{137} \mathrm{Cs}$ gamma rays. The fact that they were sorted according to their volume TL response is certainly helping to have similar responses at low-energy photons, although the TL response in the latter case is caused mainly by superficial layers of the chips and not by the complete volume of the TLDs as for gamma rays. 


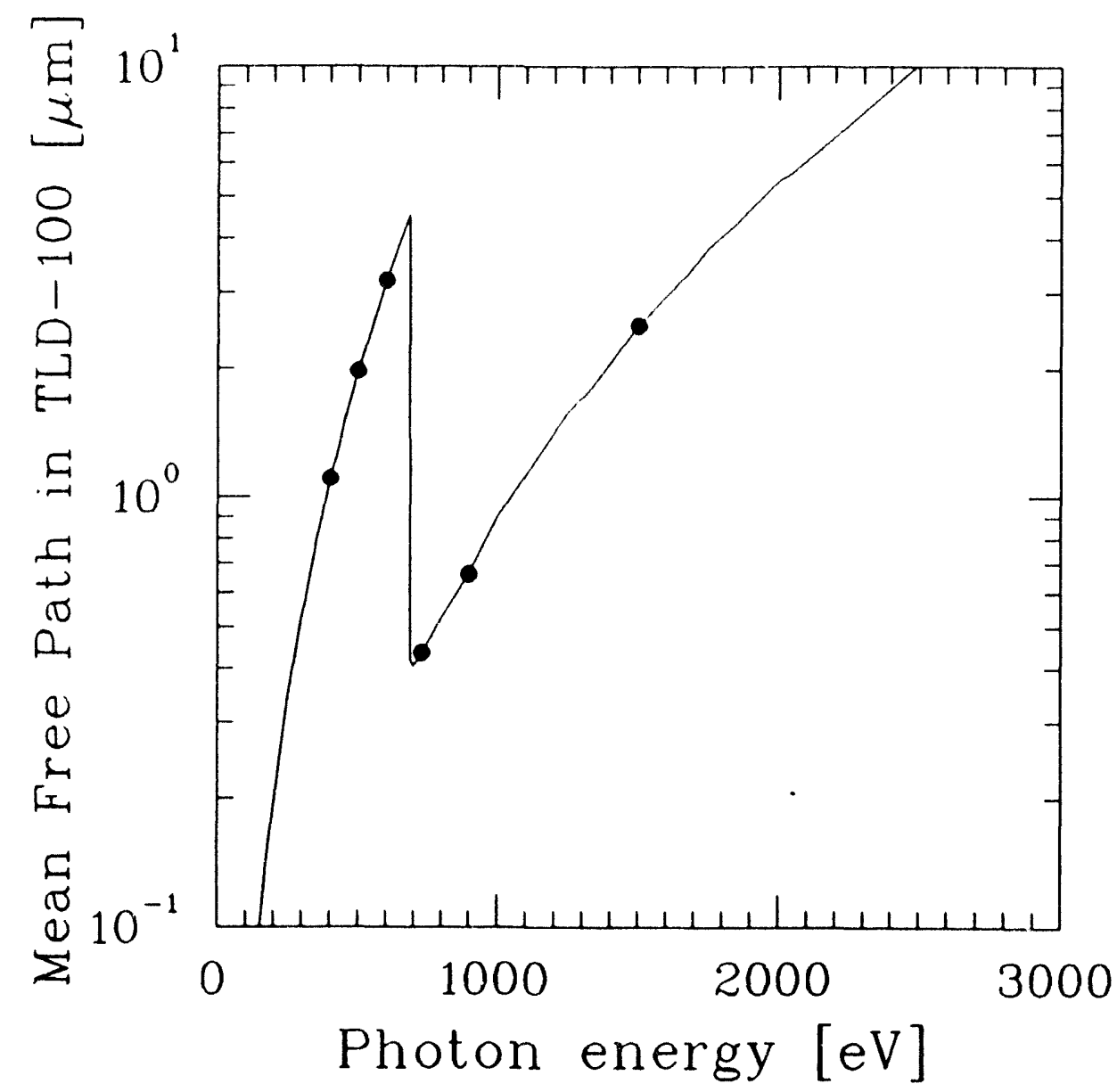

Figure 9: Mean free path in LiF:Mg, Ti (TLD-100) as a function of photon energy. The $\mathrm{K}$ - absorption edge of fluorine at $685 \mathrm{eV}$ is responsible for the discontinuity seen in the figure. Dots illustrate the energies used in this study.

In the case of the crystals, a single parent crystal was purchased so, responses of dosimeters obtained from it are expected to be similar to each other. Some response sensitivity spread is possible, however, which could be caused by slight changes in dopant concentrations throughout the parent crystal. Both types of dosimeters, the parent crystal and the batch of chips, were brand new before this study, so their surfaces have had little opportunity of being subjected to uncontrolled etching agents (repeated pressure and scratching from tweezers, high temperature changes on gaseous atmospheres as in air anneals, oil form hands, et.c.) that could adversely affect their TL response to shallow penetration radiation, as in this case.

For both types of dosimeters the $1,500 \mathrm{eV}$ data points seem to be following a somewhat different response pattern. This is believed to be caused by beam misalignment problems present when irradiations at this energy were performed. To re-check these results, $1500 \mathrm{eV}$ photon exposures are currently being repeated. 


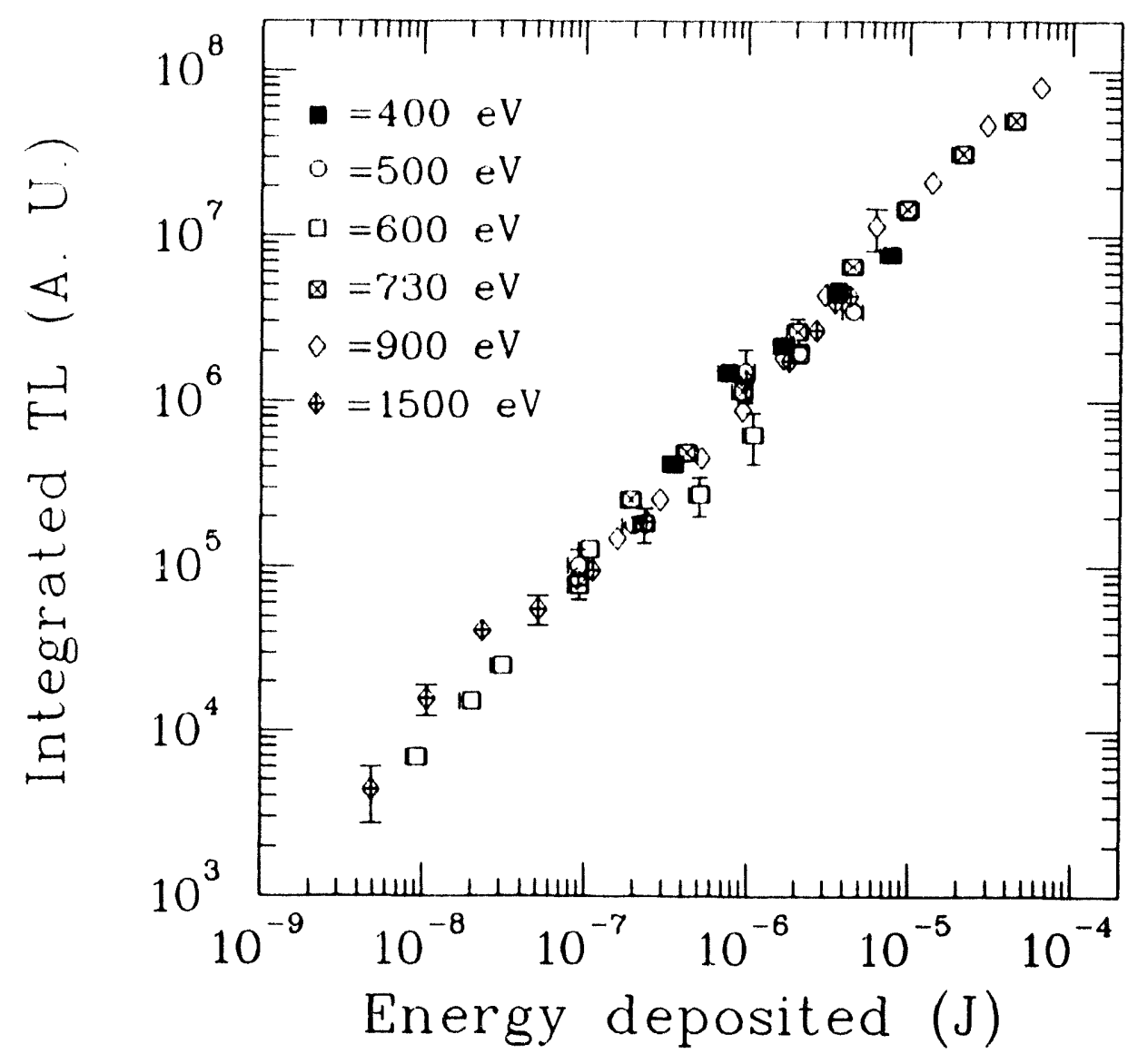

Figure 10: Integrated TL response of TLD-100 crystals vs energy deposited

As confirmed by the glow curves to be presented in the following sections, several peaks are usually seen in the glow curves obtained for both types of TLD100 dosimeters following the low-energy photon irradiations. The most prominent. peak is still the one at about $200{ }^{\circ} \mathrm{C}$, as in the case of gamma irradiations [1T]. This peak, also called the "dosimetric peak", presents very little fading at room temperature and is the one contributing the most to the integrated TL response normally employed in routine TL dosimetry of ionizing radiation, including this study. In some cases where integrating TLD readers are not readily available, peak heights are used instead to perform the dosimetry. Figure 12 shows the TL response of this peak at $200{ }^{\circ} \mathrm{C}$ as a function of energy deposited for the crystals. The peak height is being used to quantify the reported response. On the other hand, figure 1.3 presents the TL response of this peak, as given by its height, as a function of energy deposited in the case of the chips. 


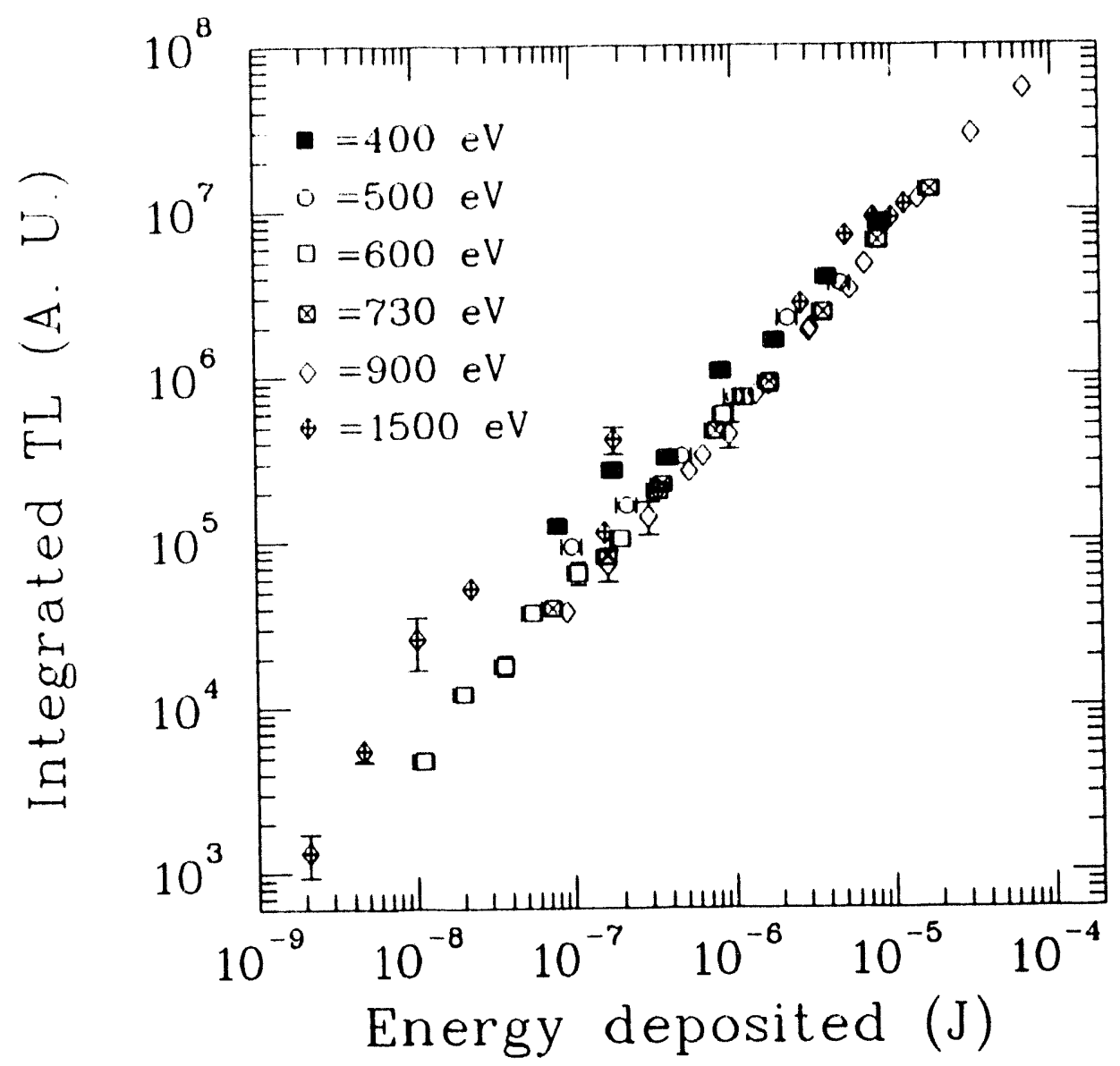

Figure 11: Integrated TL response of TLD-100 chips us energy deposited

\subsubsection{Glow curves in He.}

Figure 14 presents glow curves for TLD-100 crystals exposed to several photon energies. The glow curves have been normalized to have the same height for the main dosimetric peak. Exposures for all cases originally delivered about $260 \mathrm{~nJ}$ to the crystals, value low enough to have the TL response of the crystals within its linear region. From this figure we can see that the shape of the glow curve is about the same for all photon energy.

Figure 15 presents the glow curves obtained for the TLD-100 chips when exposed to several low-energy photon beams. The curves have been normalized to have the same height for the main dosimetric peak at $200{ }^{\circ} \mathrm{C}$. Total energy delivered in each case was also $260 \mathrm{~nJ}$ to prevent any supralinearity effects from changing the shape of the glow curve. From this figure we can see that glow curves for TLD-100 chips change as a function of photon energy, with the least penetrating photons so far studied (730 eV) producing the more changes in the glow curve. (Hlow curves after $730 \mathrm{eV}$ irradiations present a peak at about $155^{\circ} \mathrm{C}$, which is comparable in 


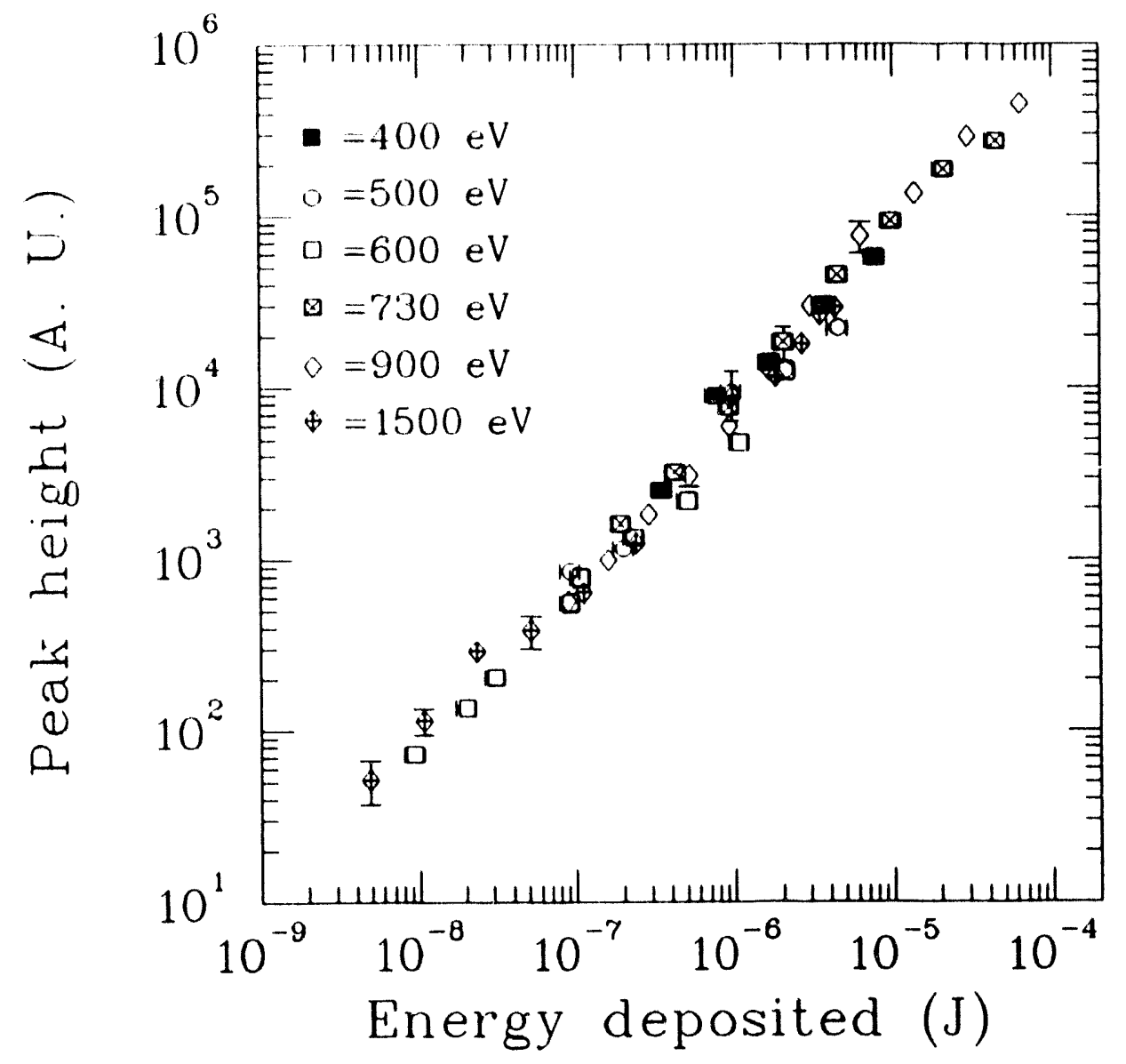

Figure 12: Peak height TL response of the main peak at $200^{\circ} \mathrm{C}$ in TLD-100 crystals as a function of energy deposited.

height to the main dosimetry peak at $200^{\circ} \mathrm{C}$. C Glow curves after $900 \mathrm{eV}$ irradiations present an increase in the TL response between 150 and $170{ }^{\circ} \mathrm{G}$. For $900 \mathrm{eV}$ photons the mean free path in TLD-100 is slightly larger than at $730 \mathrm{eV}$, causing a deeper penetration of the photons in the chips. Since this relatively low-temperature region of the glow curve presents some fading at room temperature, and fading is more pronounced at lower temperatures, it is possible that the peak seen at 165 ${ }^{\circ} \mathrm{C}$ for $900 \mathrm{eV}$ irradiations is the same one seen at $155^{\circ} \mathrm{C}$, for $730 \mathrm{eV}$ exposures. A higher fading at low temperatures can cause a peak to "shift" to slightly higher temperatures.

Glow curves for crystals and chips present a high-temperature peak at about 260 ${ }^{\circ} \mathrm{C}$, which is stable at room temperature and become prominent at higher exposures. More data are being collected regarding this feature of the glow curves.

As a matter of comparison, gamma induced glow curves were collected. Figure 16 shows the glow curve obtained for crystals following a ${ }^{13 i} \mathrm{C}$ s gamma ray 


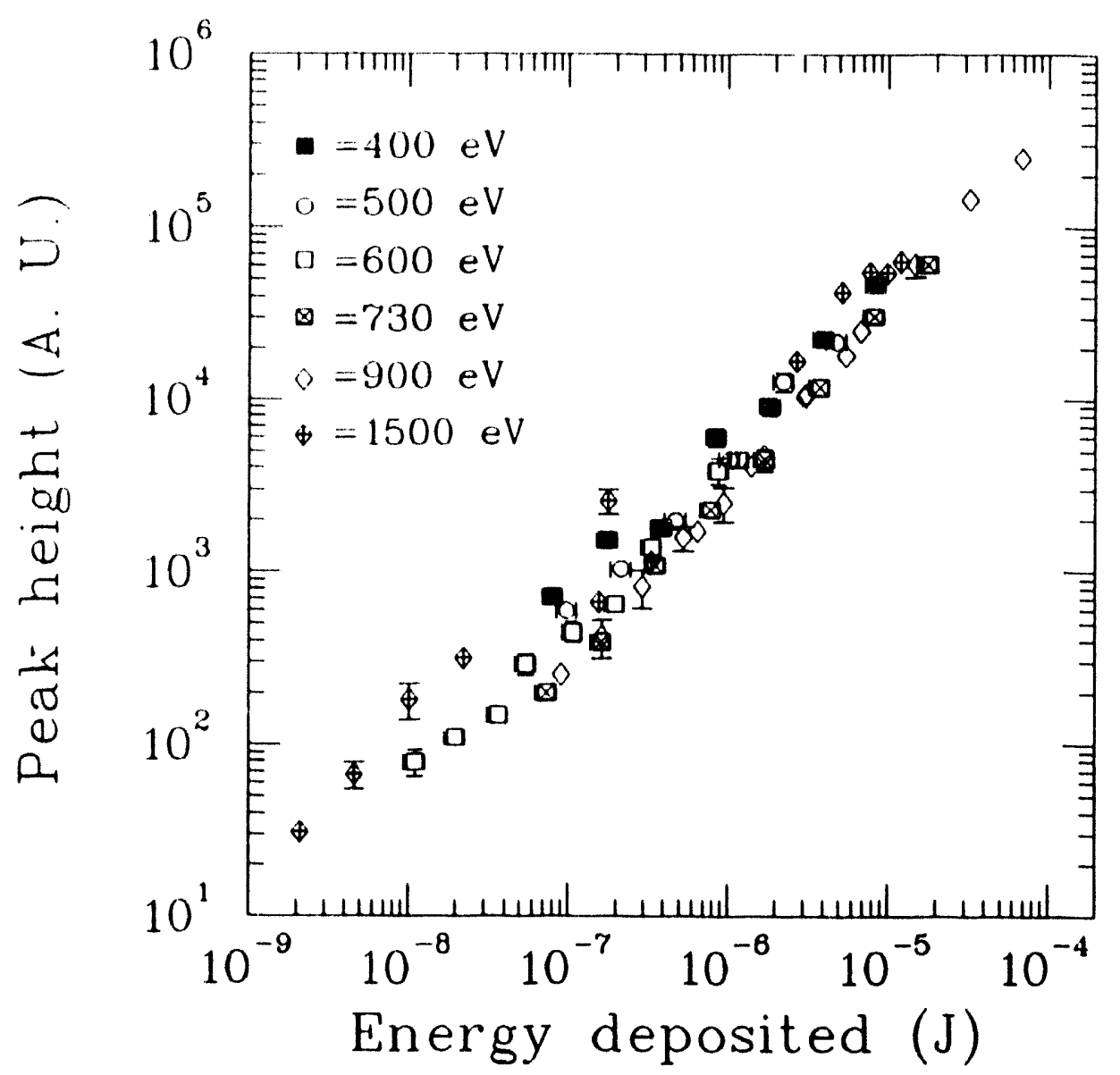

Figure 13: Peak height TL response of the main peak at $200{ }^{\circ} \mathrm{C}$ in TLD-100 chips as a function of energy deposited.

exposure of $258 \mu \mathrm{C} / \mathrm{kg}(1 \mathrm{R})$. Figure 17 presents the glow curve obtained for chips with the same source and exposure level. In general, glow curves for crystals exposed to low-energy photons during this study resemble the glow curves usually obtained following gamma irradiations. On the other hand, glow curves for chips exposed to low-energy photons $(1500,600,500$, and $400 \mathrm{eV})$ still resemble the gamma induced glow curves. However, chips irradiated with 730 and $900 \mathrm{eV}$ photons present a higher TL response than the one for gammas in the $150-170^{\circ} \mathrm{C}$ temperature interval. This is particularly noticeable for the exposures with $730 \mathrm{eV}$ photons. This could be explained by the fact that chips are made from powder lithium fluoride, which presents a large surface to air as compared to crystals. The large surface presented by powder means that humidity, and consequently $\mathrm{OH}^{-}$ions, present in air have a higher probability of migrating into inner layers of the chip during high temperature anneals. Humid air has been proven to be the main reason why glow curves and TL response of shallow penetrating radiation ( $x$-rays and betas) are 
adversely affected, as reported in previous sections and discussed below. 

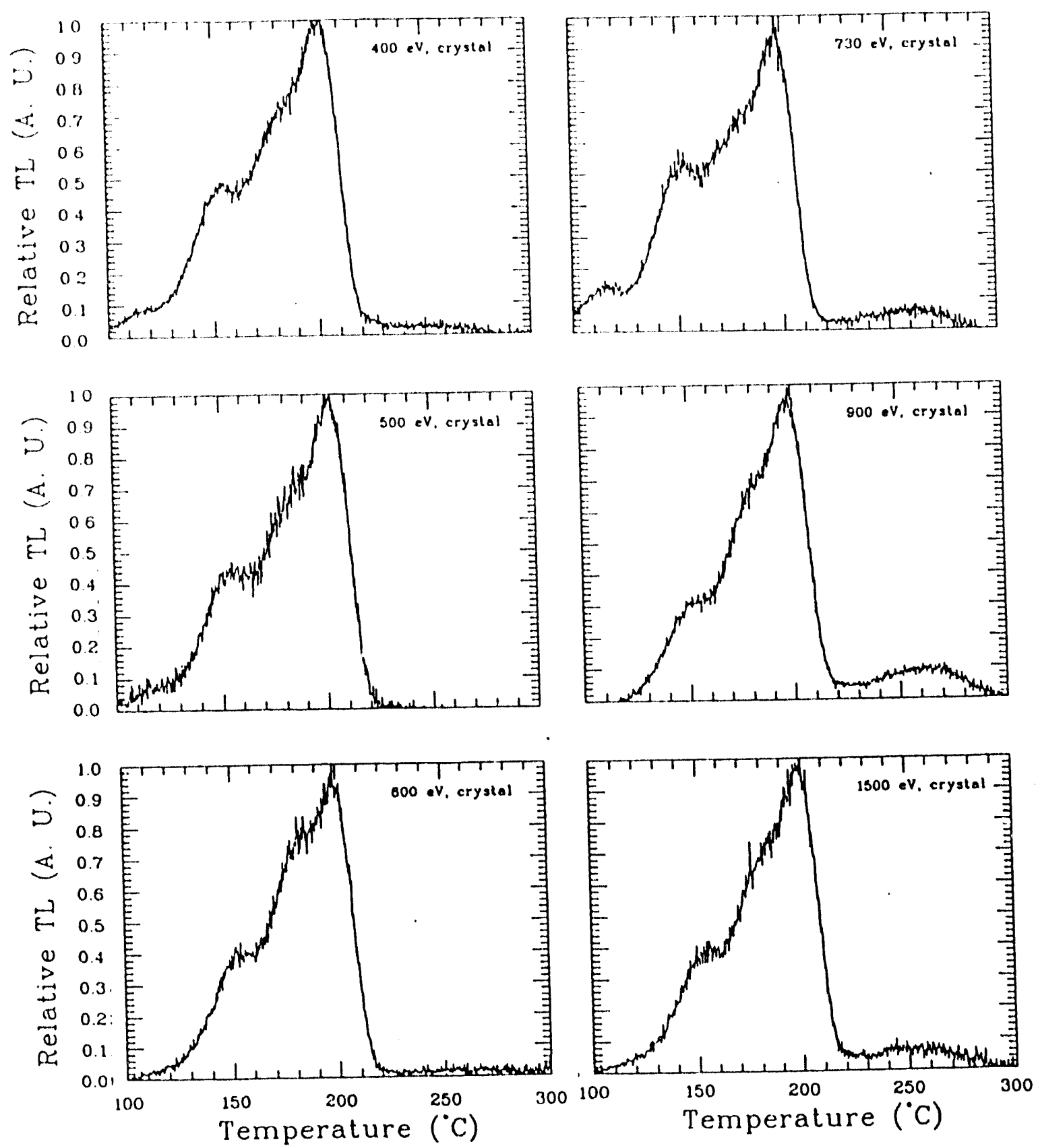

Figure 14: (ilow curves of lithium fluoride crystals exposed to 1500, 900, 730, 600, 500 , and $400 \mathrm{eV}$ photons. Curves have been normalized to have the same height a.t. the dosimetric peak at $200{ }^{\circ} \mathrm{C}$. 

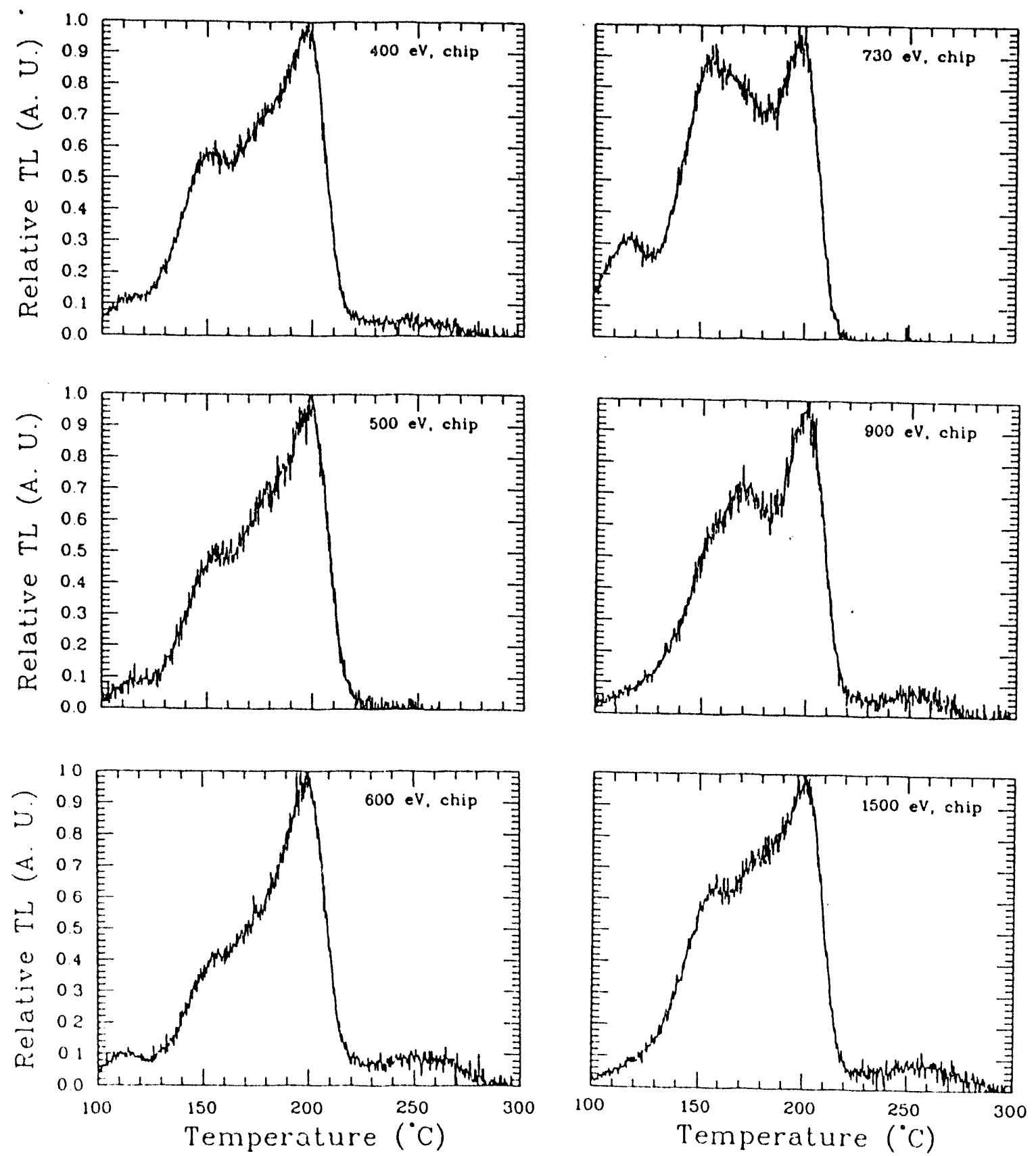

Figure 15: Glow curves of lithium fluoride chips exposed to $1500,900,730,600$, 500 , and $400 \mathrm{eV}$ photons. Curves have been normalized to have the same height of the dosimetric peak at $200^{\circ} \mathrm{C}$. 


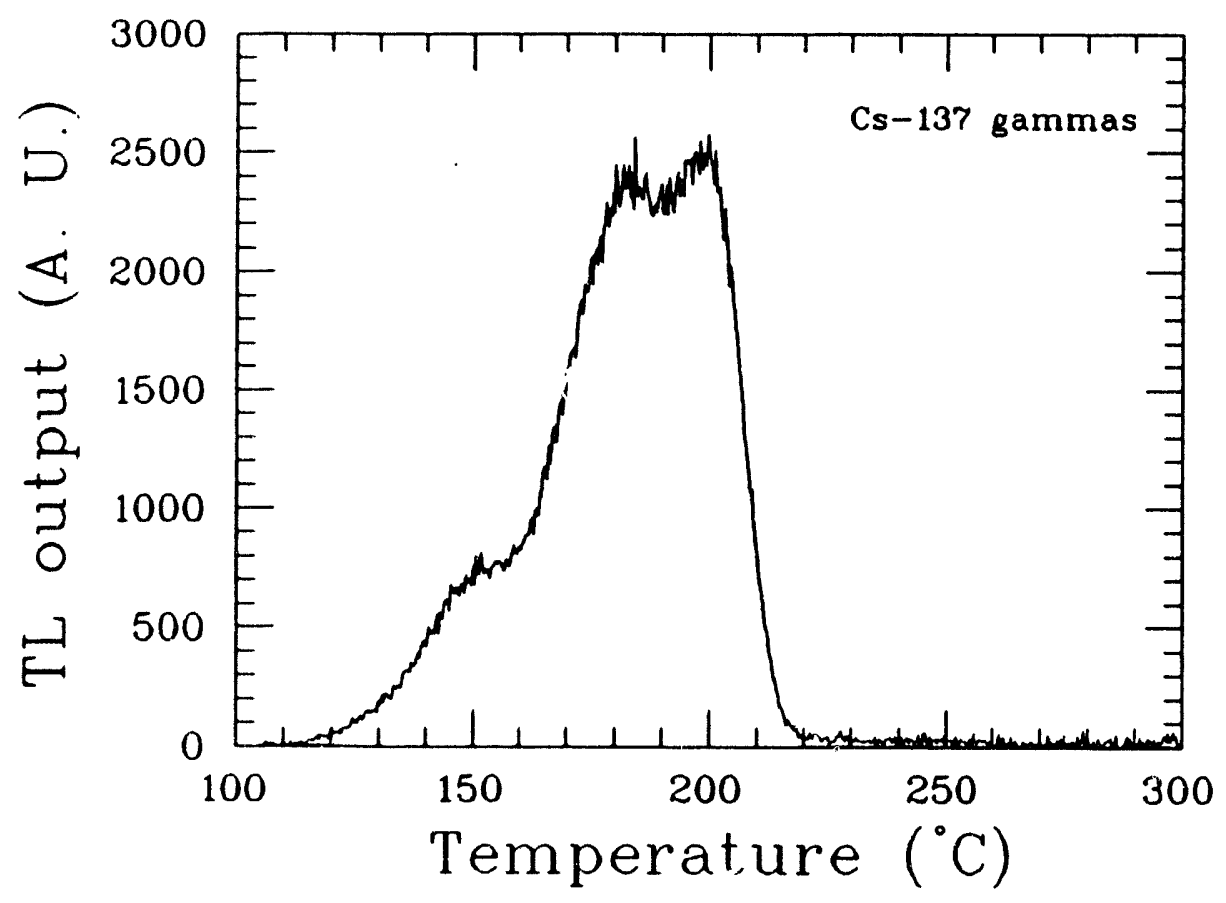

1

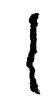

l

Y

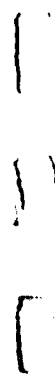

1

Figure 16: Glow curve of lithium fluoride crystals exposed to ${ }^{137} \mathrm{C}$ 's gamma rays. 


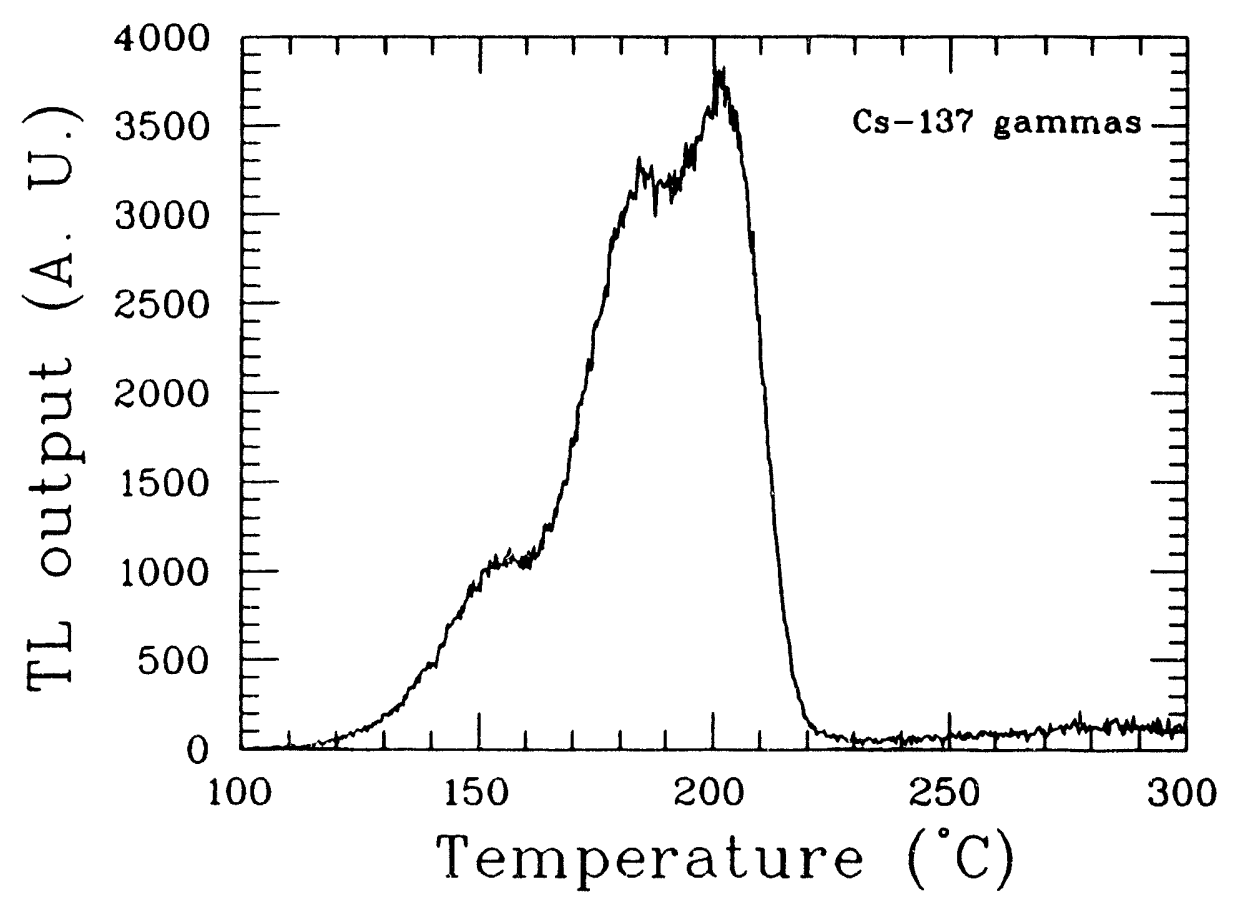

Figure 17: Glow curve of lithium fuoride chips exposed to ${ }^{137} \mathrm{C}$ s gamma rays. 


\subsubsection{Glow curve comparison of TLDs annealed in air and in He}

The effect of the annealing atmosphere in both types of TLD-100 dosimeters was studied also because previous results for gammas [18] and low-energy betas $[6,7,35,8,9]$ proved that the annealing atmosphere is crucial to get reproducible TL output and glow curves with TLD-100. To confirm that this was also the case for low-energy photons, three annealing treatments were used. For one of them a helium atmosphere was employed, while air was the atmosphere present during the other two annealings done for 1 and $23 \mathrm{hr}$. Results obtained so far are presented in the following figures.

Figure 18 shows the glow curves of crystals annealed in helium, and air (for 1 and $23 \mathrm{hr}$ ) when exposed to $1,500 \mathrm{eV}$ photons. The adverse effect of air anneal is clearly seen as an overall reduction on the height of the peaks, mainly the dosimetric peak. For the crystals annealed in air for $23 \mathrm{hr}$ the reduction is even more pronounced. Figures 19 and 20 present similar comparisons among the glow curves obtained with air- and He-annealed crystals following irradiations with 900 and $730 \mathrm{eV}$ photons, respectively.

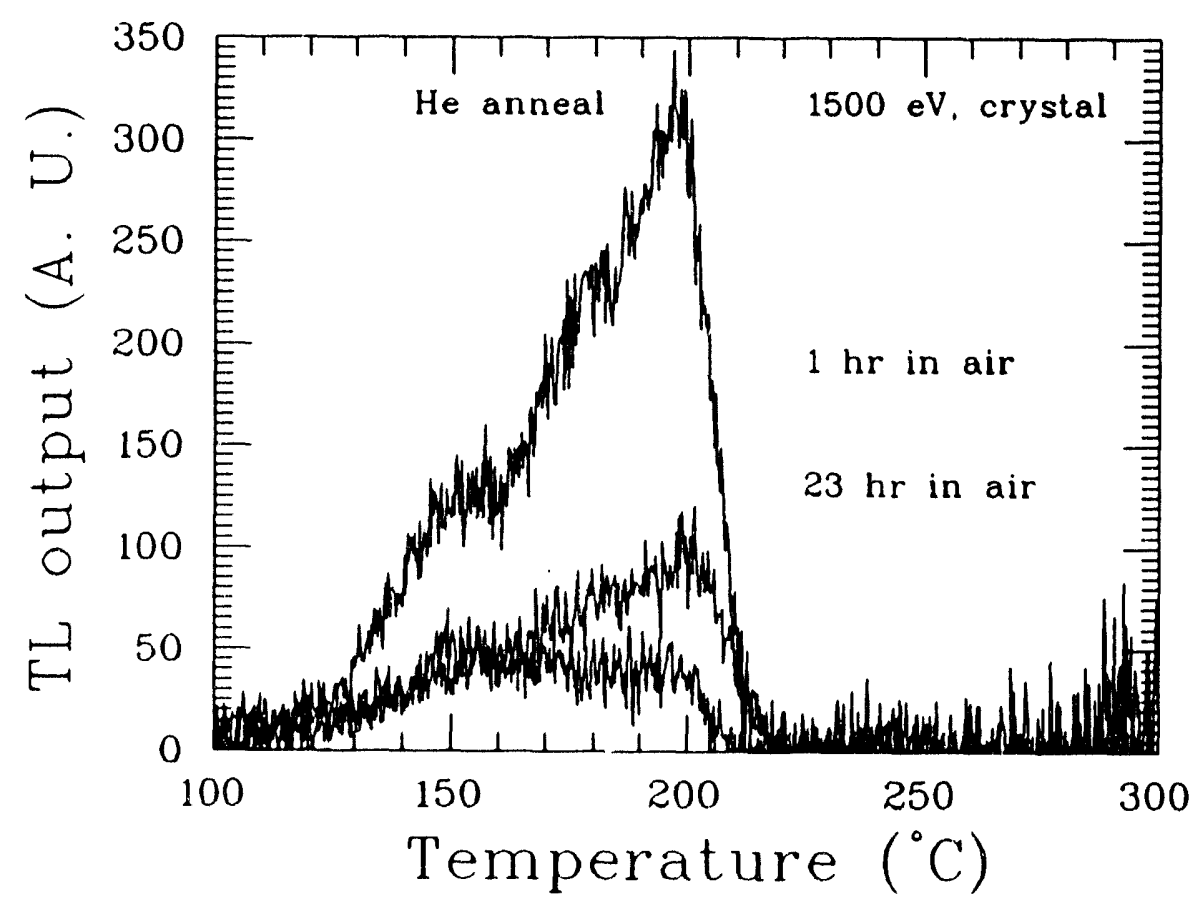

Figure 18: (Hlow curves of He- and air-annealed lithium fluoride crystals exposed to $1,500 \mathrm{eV}$ photons.

Figure 21 presents the glow curves of chips annealed in helium and air (for 1 


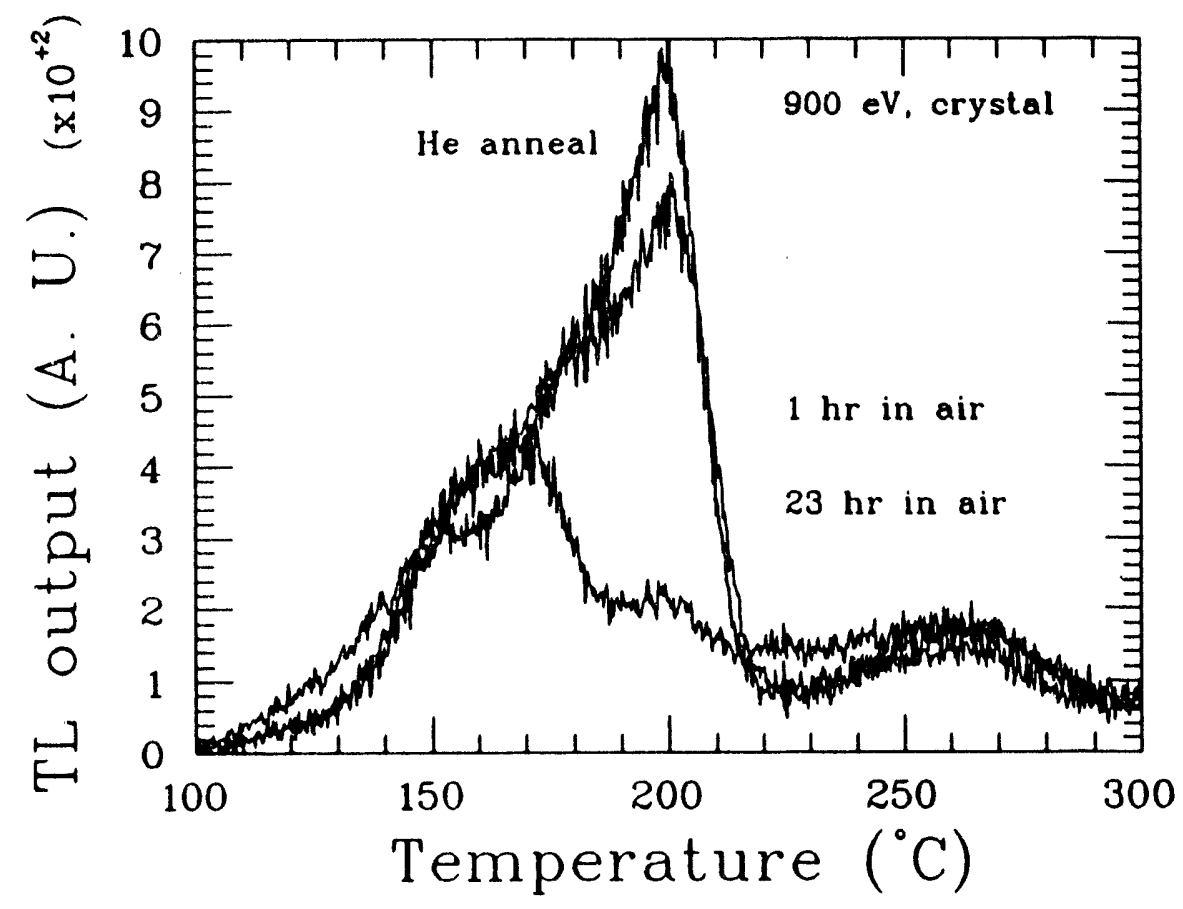

Figure 19: Glow curves of He- and air-annealed lithium fluoride crystals exposed to $900 \mathrm{eV}$ photons.

and $23 \mathrm{hr}$ ) when exposed to $1500 \mathrm{eV}$ photons. The adverse effect of air anneal is also seen as an overall reduction on the height of the dosimetric peaks. For the chips annealed in air for $23 \mathrm{hr}$ the reduction is more pronounced. Figures 22 and 23 present similar comparisons among the glow curves obtained with chips annealed in air and He, and then irradiated with 730 and $600 \mathrm{eV}$ photons, respectively.

\subsubsection{Surface dose calculations.}

As briefly discussed in section 4.5.1, the shallow penetration of the photons used in this study means that large surface doses are easily achieved. The incident photon beam energy is almost entirely deposited at superficial layers of the phosphor. This effect is clearly seen in figure 24 , where the curves shown describe how the TLD-100 dose, normalized to unity at the surface (zero depth) of the phosphor, decreases rapidly as a function of depth inside the dosimeters after only a few microns of depth. That figure presents calculated doses, based on the exponential attenuation of photons in matter and on the cross section for $\mathrm{T} L \mathrm{I}$ - 100 at the photon energies employed in this study [16]. The less penetrating a photon beam, the higher the superficial dose is, and the faster the dose will decrease as a function of depth. 

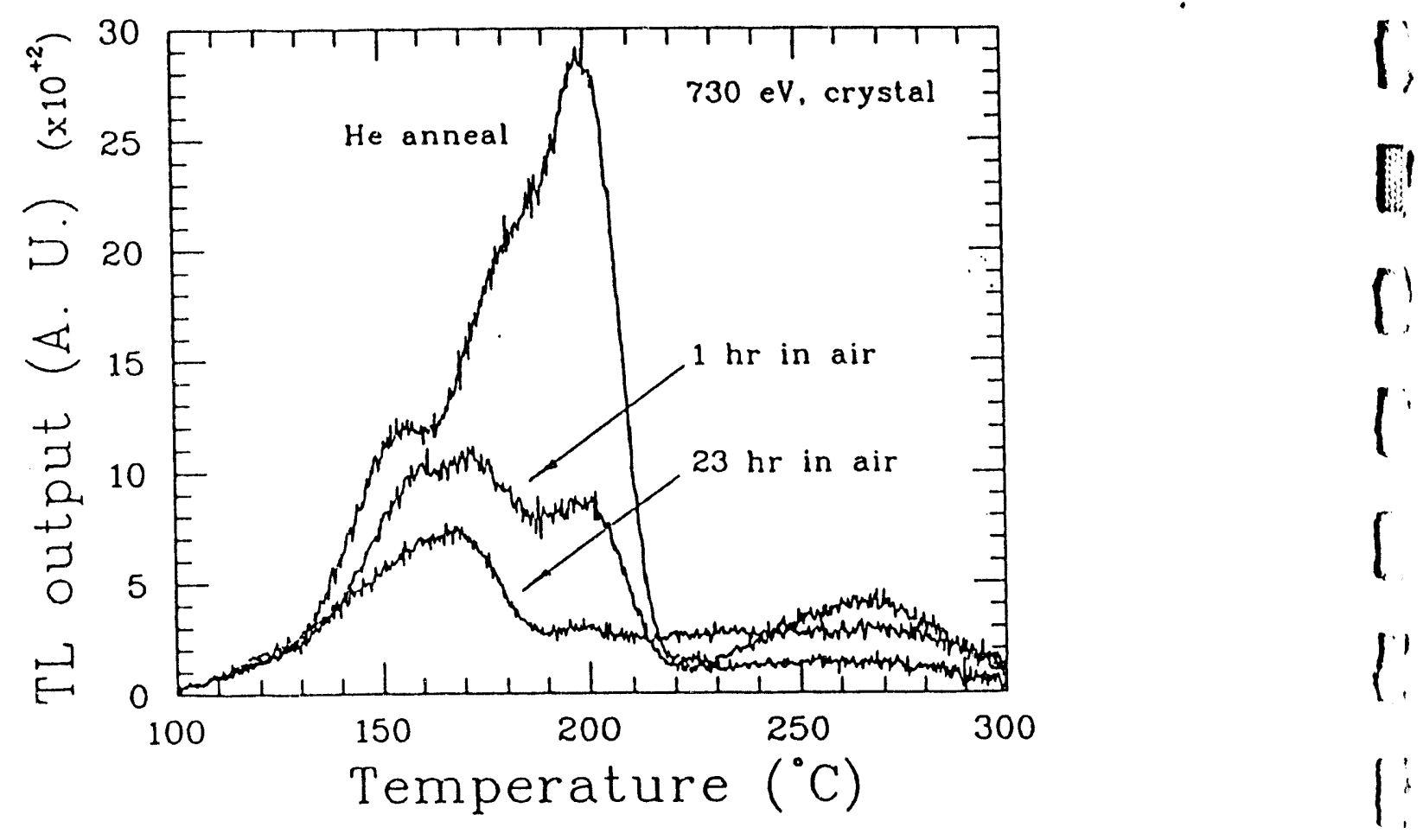

Figure 20: Glow curves of He- and air-annealed lithium fluoride crystals exposed to $730 \mathrm{eV}$ photons.

Similar dose behaviour as a function of penetration depth and photon energy is seen in other materials, including cells currently employed in radiobiology experiments. For TLD-100 the penetration, i.e., mean free path, of these photons is given by figure 9. From that figure we can see that 730 and $900 \mathrm{eV}$ photons are the least penetrating ones, while 500,1500 , and $600 \mathrm{eV}$ are the most penetrating photons in TLD-100 with about equal mean free path. Photons with an energy of $600 \mathrm{eV}$ are the ones with the maximum penetration among the energies studied. This fact is precisely the one that causes that in figure 24 the dose curves with the fastest decrease for increasing dosimeter thickness are those corresponding to 730,900 , and $400 \mathrm{eV}$, followed by the curves for $500,1500 \mathrm{eV}$, and finally for $600 \mathrm{eV}$ photons.

The phenomenon just described has a great impact on the TLD luminesrent response because TLDs have been known to present a linear TL, response as a function of dose, exposure or energy fluence, up to limits set by the type of phosphor and radiation employed, among others. Beyond that limit a supralinear TL, response is commonly found, especially for TLD-100 phosphors $[19,20,21,22,23,24]$. At even higher exposures saturation of the TL response of the phosphor is eventually reached, region where TL output is no longer proportional to exposure or energy fluence, and where irreversible damage to the phosphor is likely done 


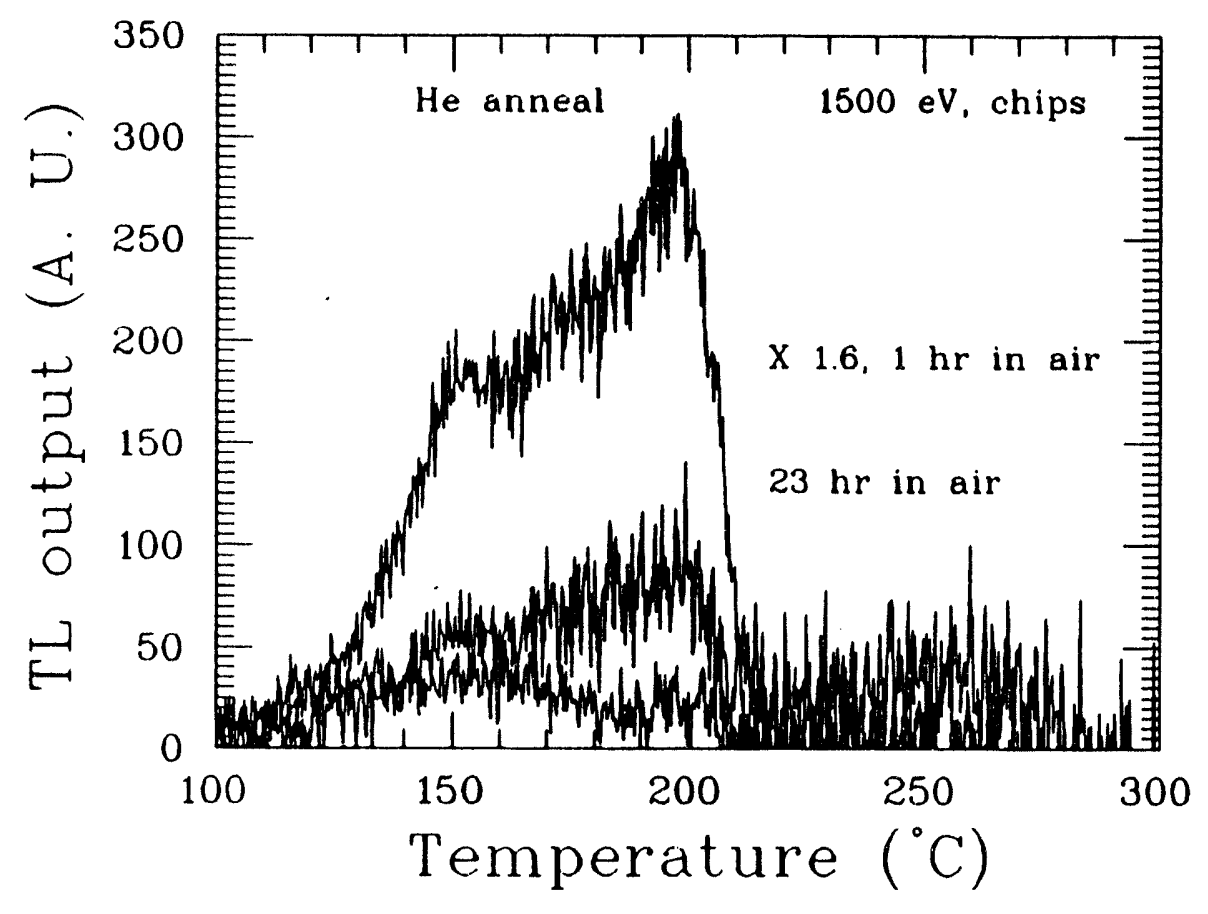

Figure 21: Glow curves of He- and air-annealed lithium fluoride chips exposed to $1,500 \mathrm{eV}$ photons.

$[10,17,18,25,26,27,28,29,30,31,32,33,34]$. To study this effect more closely the TI, response as a function of energy fluence, reported in section 4.5.1 before, provides some information. The slope of the curves presented in that section (TL response "s energy deposited) decreases as the saturation region is approached at large values of energy deposited. To gather even more information, the superficial dose clelivered by the irradiations to each type of dosimeters was also calculated. Figures 25 and 26 show the integrated TL response of crystals and chips, respectively, as a function of surface dose for all the energies used. On the other hand, figures 27 and 28 present the dosimetric peak height TL response of crystals and chips, respectively, as a function of surface dose. For all these figures the data seem to concentrate in two groups following different but parallel lines. Surface dose data for 900 and $7.30 \mathrm{rV}$ seem to follow one line, while the data for the other energies seem to follow another line. This behaviour is a direct result of their different penetration in the dosimeter, as shown in figure 9. Photon beams having similar penetration in TLI)-100 follow similar line responses. Photons of 730 and $900 \mathrm{eV}$ have similar mean free path in TLD-100, about 0.6 microns, and follow the same surface dose $"$ s. TI, line. () In the other hand, photons of 500,600 , and $1500 \mathrm{eV}$ have roughly the same mean free path of 3 microns in TLD-100, and follow about the same line response for them, 


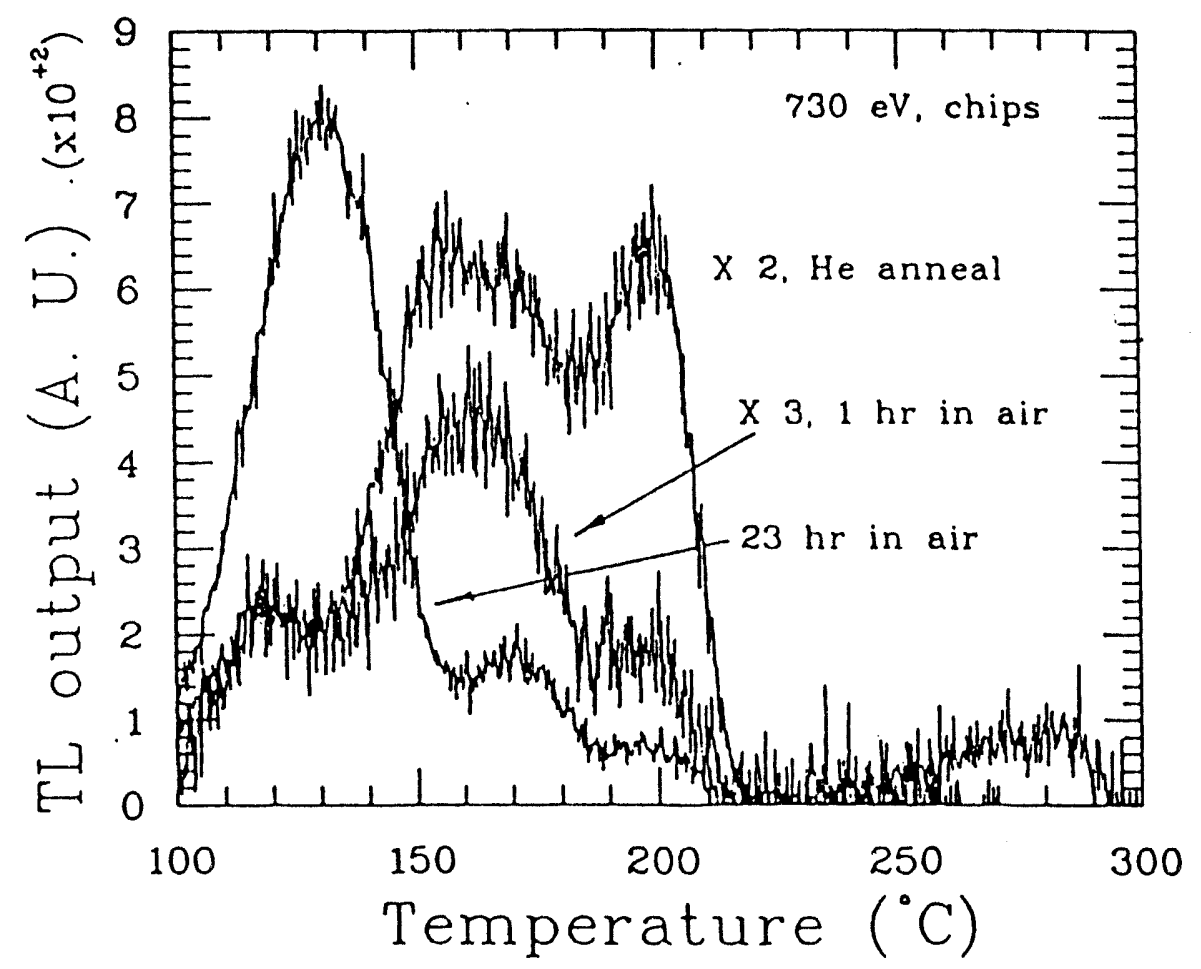

Figure 22: Glow curves of He- and air-annealed lithium fluoride chips exposed to $730 \mathrm{eV}$ photons.

different from the one for 730 , and $900 \mathrm{eV}$ photons.

\subsubsection{TL response per unit mean dose and mass; calculation of supra- linearity factors}

Supralinearity is a property commonly seen in TL phosphors, including TLI)-100, following irradiations of about 3-8 Gy or more in the case of gamma rays. In the dose region where a phosphor is supralinear the TL response increases with drose by a factor larger than unity. To calculate this factor the TL response per unit dose and mass of the dosimeter is usually plotted. The maximum of that calculaterl parameter, obtained before saturation, divided by the TL response per mint dose and mass at low doses (where the TLD is responding linearly as a function of dose) is the supralinearity factor of the phosphor. Figures 29 and 30 present such weighted ( $R O I$ ) responses as a function of mean dose delivered to TI,D-100 crystals and rlips, respectively. Similarly, figures 31 and 32 present the calculated results based on the dosinetric peak height response as a function of mean dose for the crystals and the chips, respectively. For all these figures the mean dose and mass were raleulater taking a photon penetration of two mean free paths, as discussed next. 


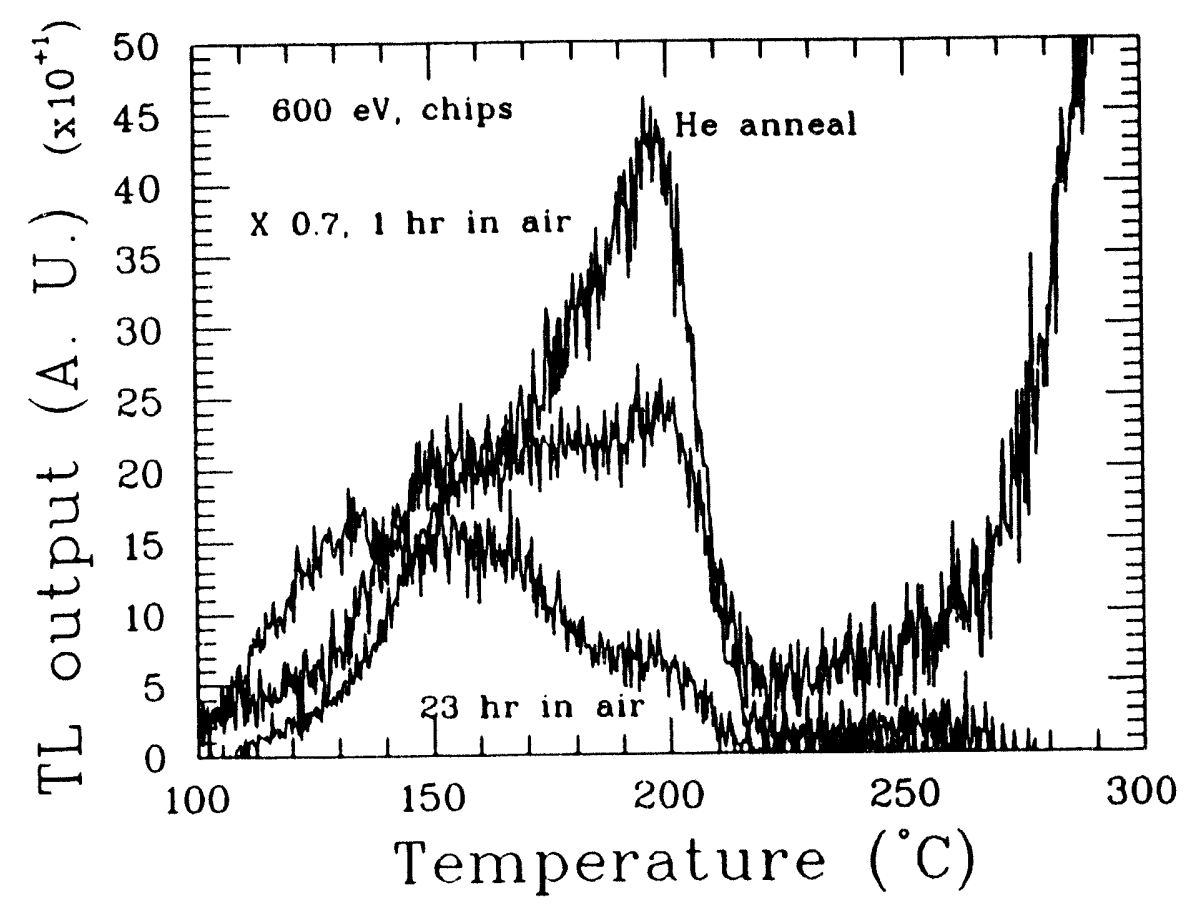

Figure 23: Glow curves of He- and air-annealed lithium fluoride chips exposed to $600 \mathrm{eV}$ photons.

After a depth of two mean free paths $86 \%$ of all incident photons have interacted with the dosimeter to deposit energy. Due to the very short range of photoelectrons produced by these low-energy photons (between 30 and $40 \mathrm{~mm}$ in LiF according to Lasky et al. $[7,35])$ and due to the fact that at these photon energies photoelectrons are mostly ejected at $90^{\circ}$ angles from the original photon trajectory [15], the energy deposited by these photons is dissipated within the depth they travel. 'This means that the TL is mostly produced in that region as well. Taking a larger dosimeter thickness for the calculations would only reduce the calculated mean dose, making it. and the surface dose rather different. This difference could lead to a miscalculation of the supralinearity factor, which for gamma rays extends within a dose range of about two orders of magnitude (from about 8 to 800 (iy for TLD-100 powder). Dose differences of more than three orders of magnitude are easily achieved after very modest penetrations in the dosimeters, as shown in figure 24 . Hence, to avoid complications caused by this, both the surface dose and the mean dose are taken here to be as similar as possible. This is achieved by taking a thickness of two mean free paths for our calculations. This allows the mean dose to be in the supralinear region almost at the same time the surface dose is. Supporting the above considerations it is worth mentioning that for gamma dosimetry the complete dosimeter thickness is 


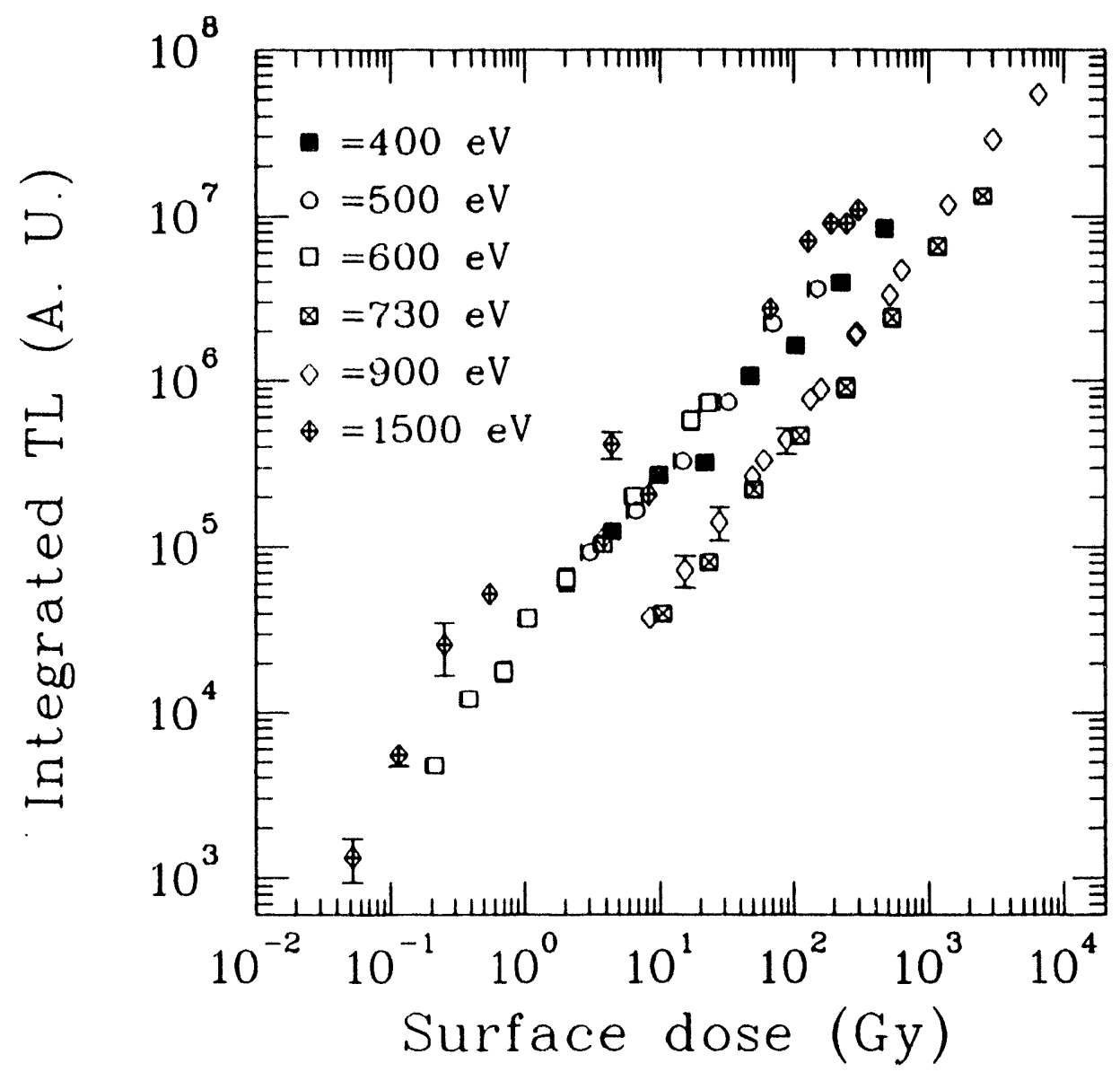

Figure 26: Integrated TL vs surface dose for chips at several energies

As pointed out in section 4.5.1, results with crystals and chips for the $1,500 \mathrm{eV}$ irradiations are being collected again to confirm those reported here. At that energy the last four figures show responses somewhat different from the other energies. Since beamline experimental problems are believed to be playing a role at this energy, the supralinearity factor for this energy will be deferred until more data are collected. On the other hand, $\mathrm{ROI}$ and peak height data for $600 \mathrm{eV}$ photons covers the low level dose region but not enough of the high level region where supralinearity seems to be present for other energies used in this study. The calculation of the supralinearity factor at this energy will be deferred also until more data become available. 


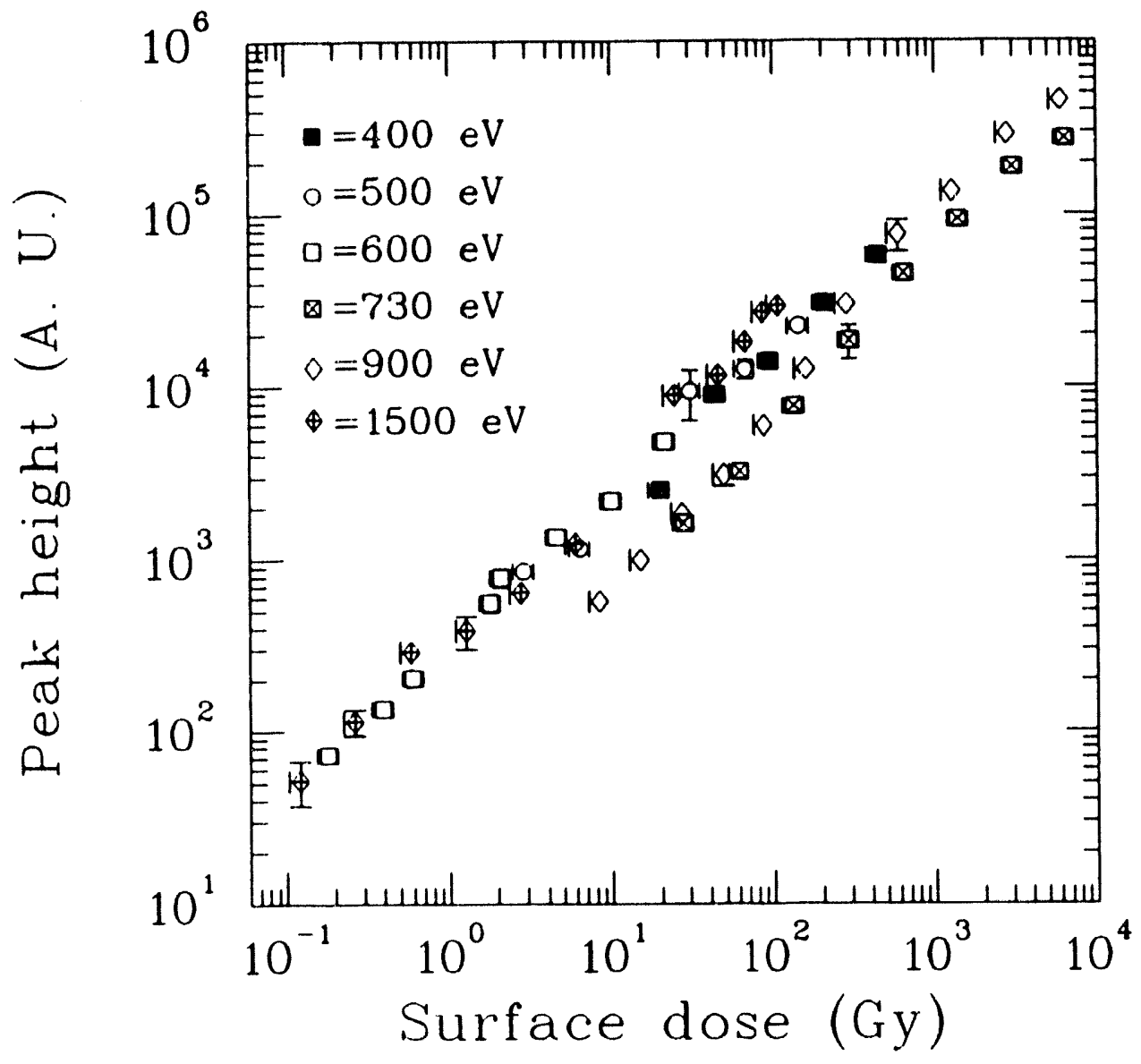

Figure 27: Peak height TL response of the main peak at $200{ }^{\circ}(\mathrm{in}$ TLD-100 crystals us surface dose. 


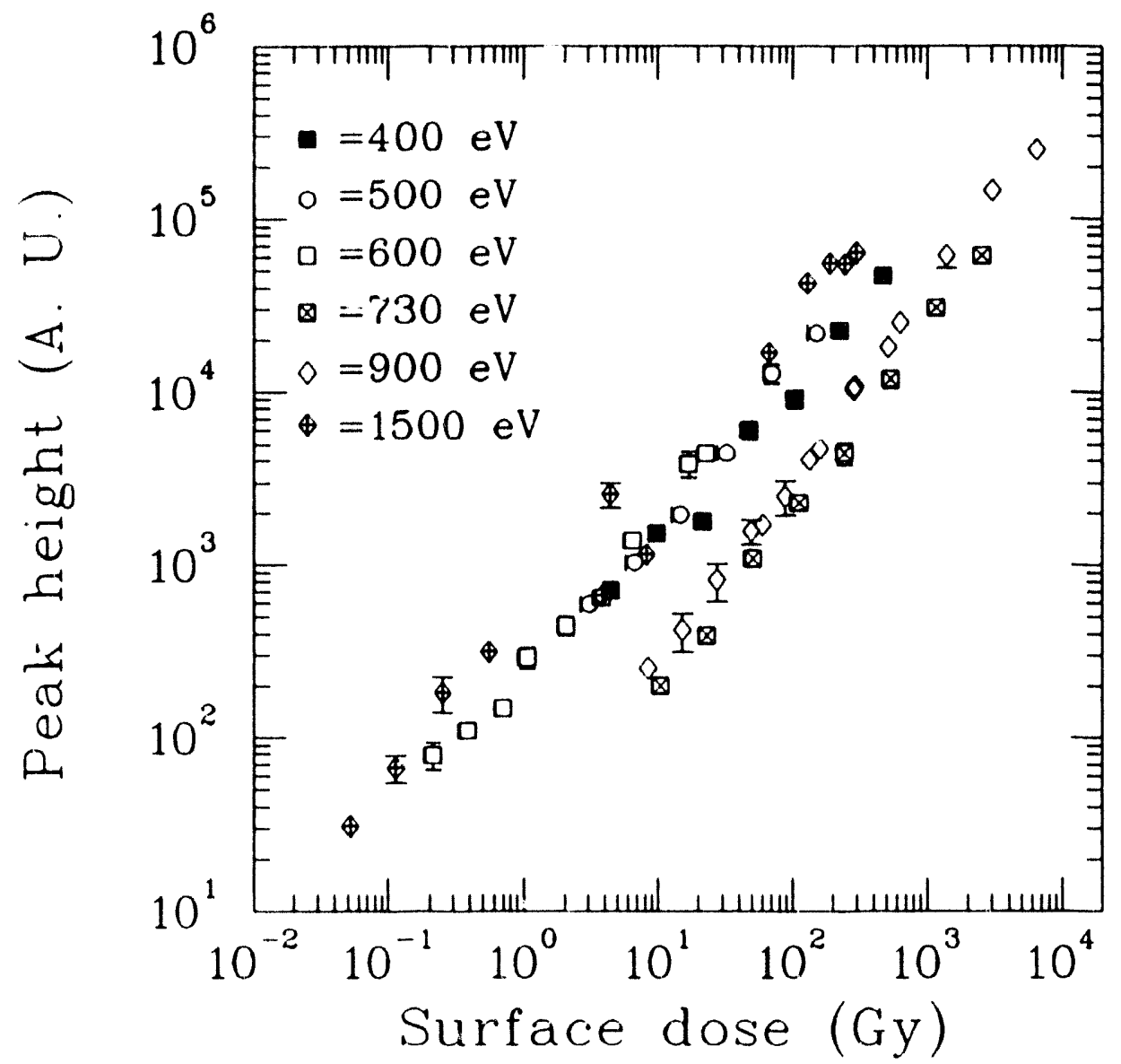

Figure 28: Peak height TL response of the main peak at $200{ }^{\circ}($ ' in 'TLD-100 chips us surface dose. 


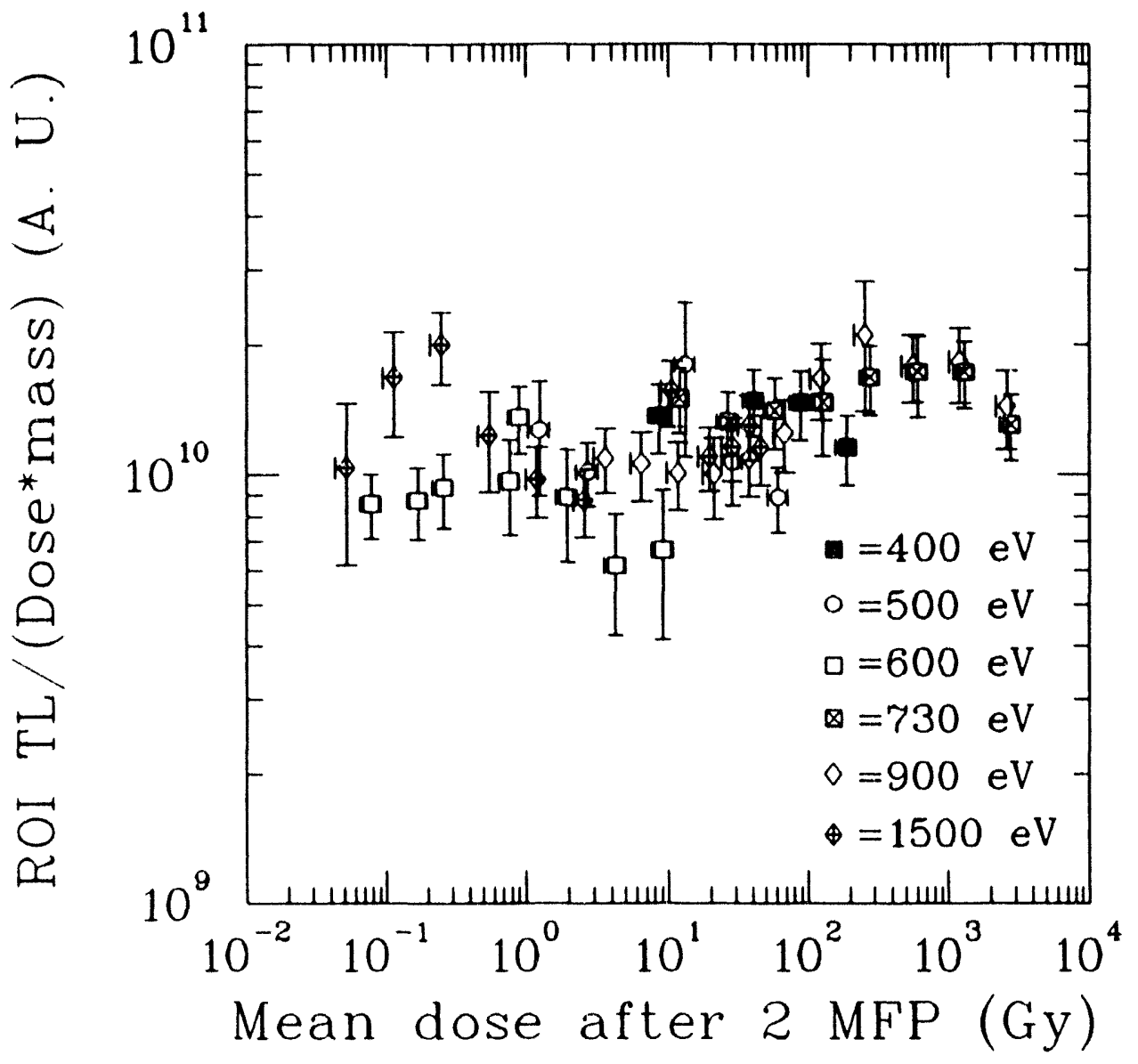

Figure 29: Integrated TL response per unit mean dose and mass vs mean dose for TLD-100 crystals at several energies 


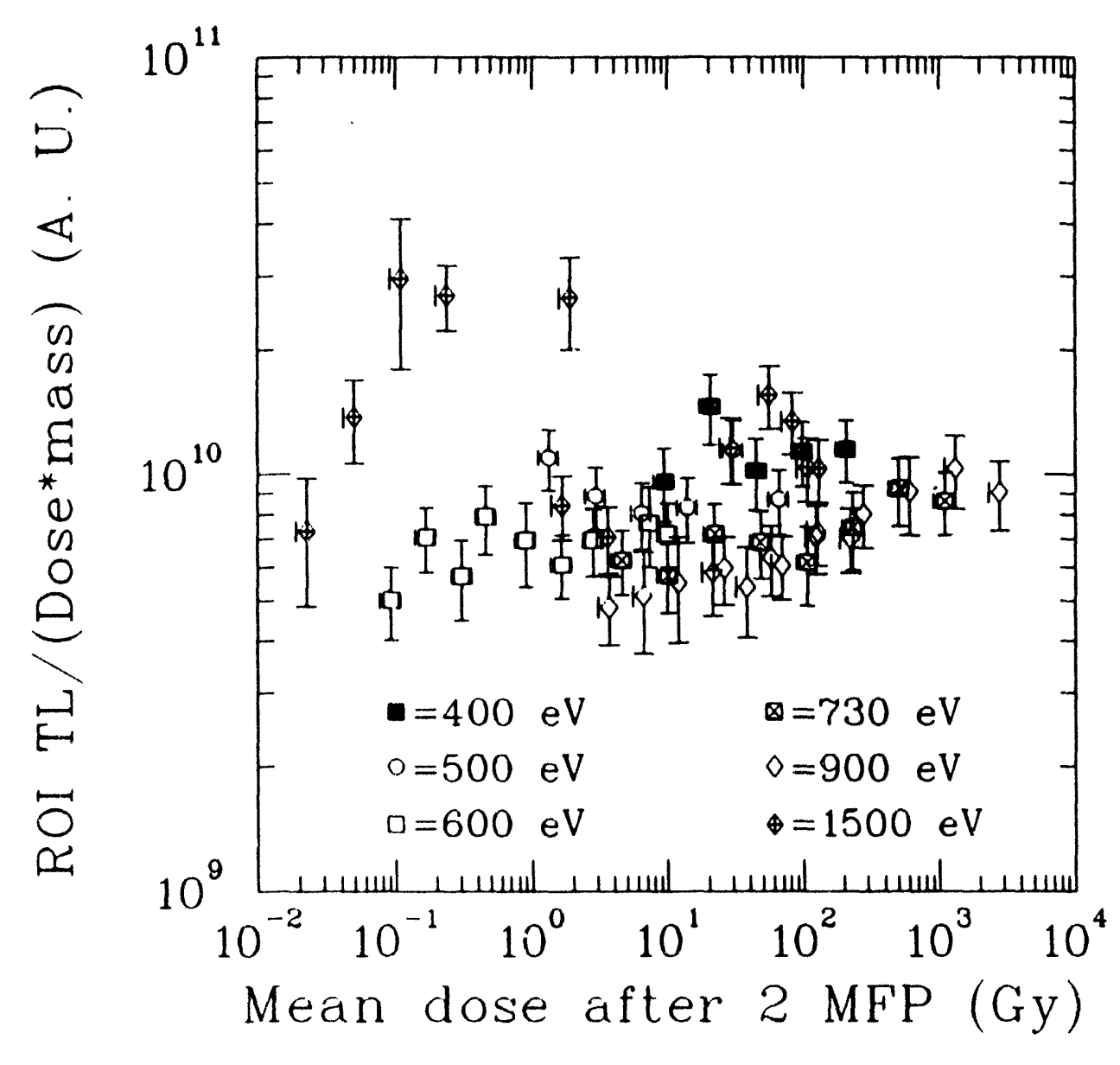

Figure 30: Integrated TL per unit of mean dose and mass vs mean dose for chips at several energies 


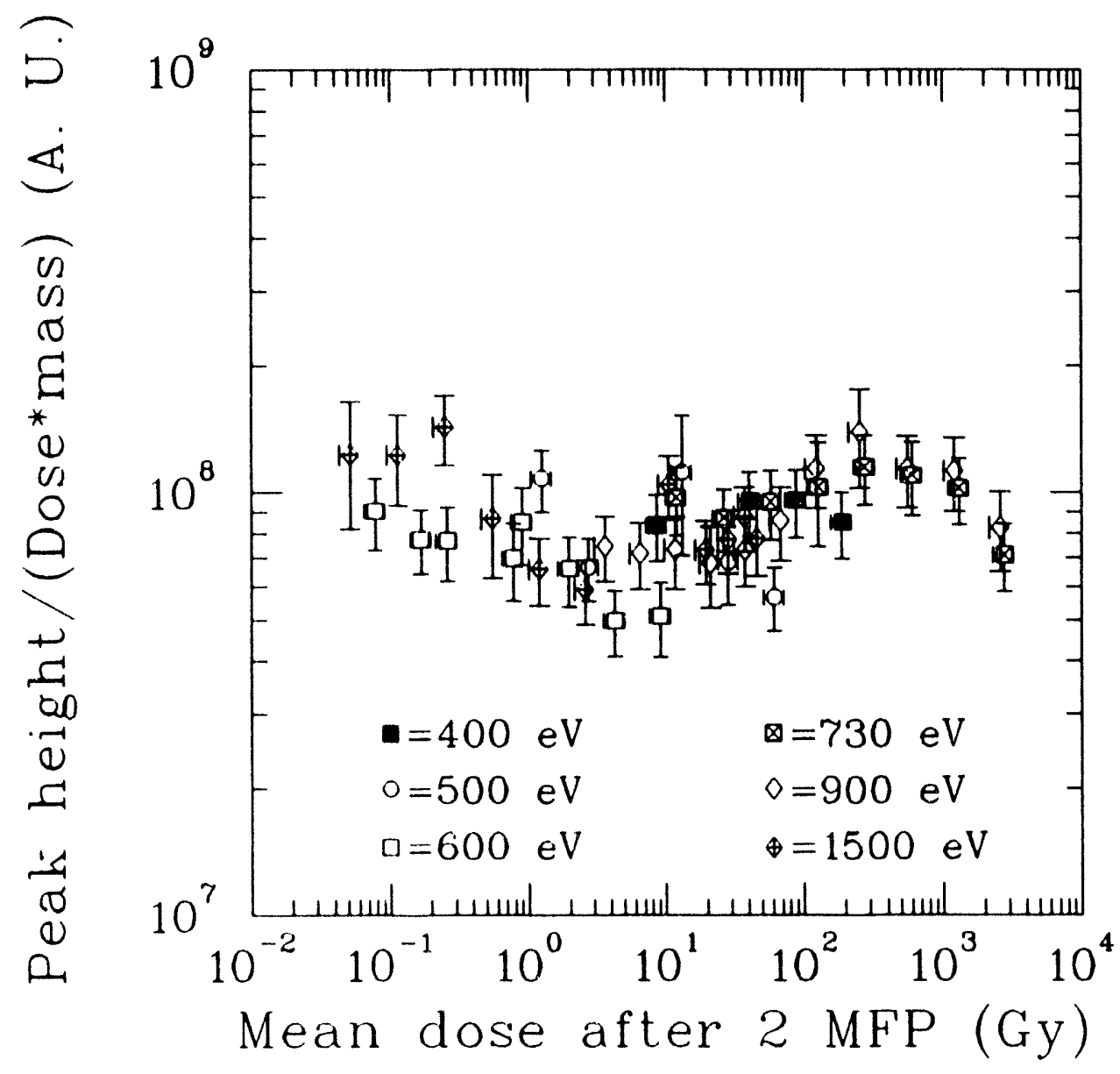

Figure 31: Peak height TL response per unit of mean dose and mass us mean dose of the main peak at $200^{\circ} \mathrm{C}$ : in TLD -100 crystals. 


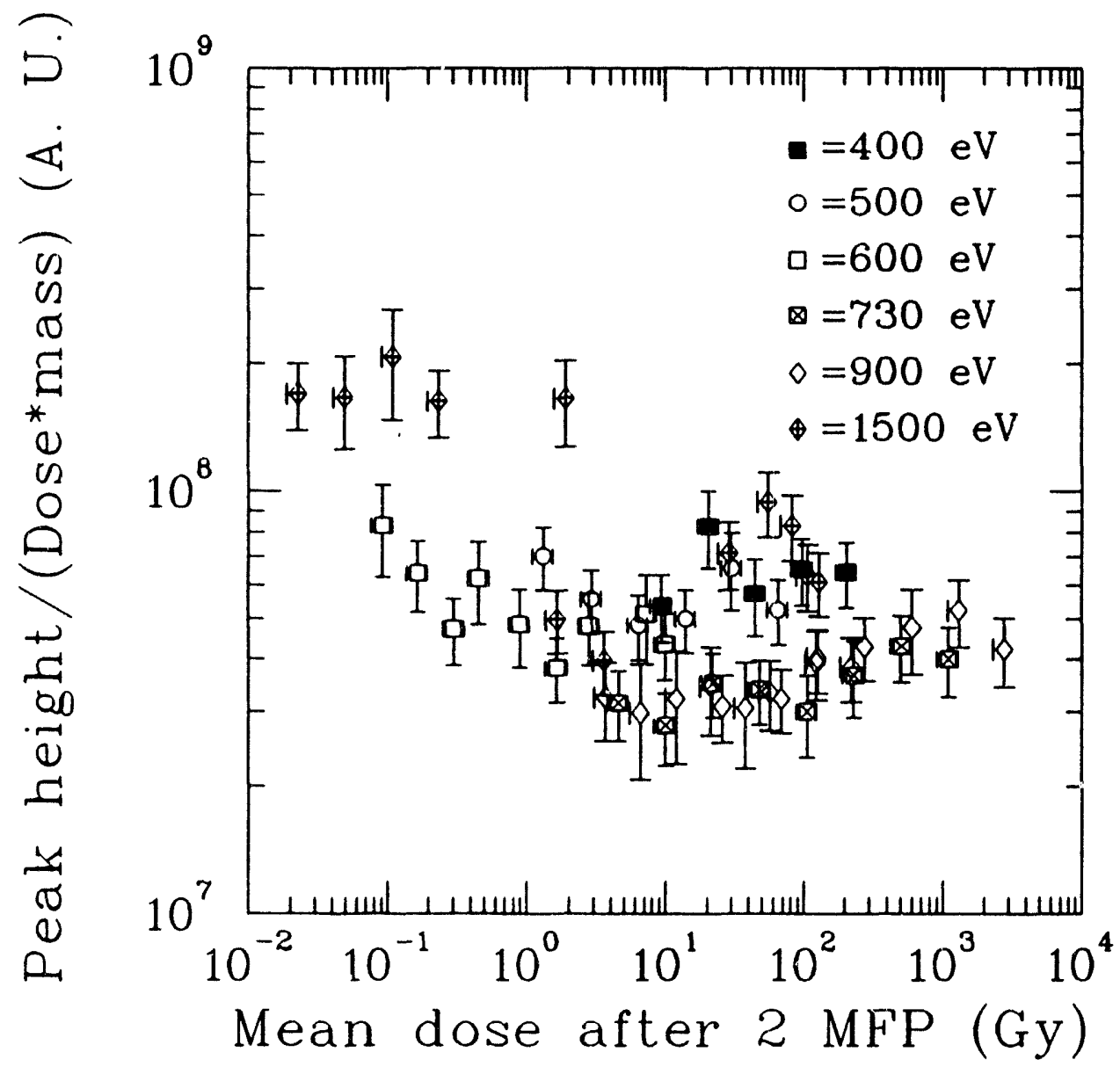

Figure 32: Peak height TL response per unit of mean dose and mass ".s mean close of the main peak at $200{ }^{\circ} \mathrm{C}$ in TLD- 100 chips. 


\subsection{Results for $\mathrm{CaF}_{2}: \mathrm{Dy}(\mathrm{TLD}-200)$}

\subsubsection{TL response as a function of dose}

Figure 33 shows the mean free path of photons in $\mathrm{CaF}_{2}: \mathrm{Dy}$ based upon available cross section data for the main constituents of TLD-200 [16]. The dots in the figure indicate the energies of the monoenergetic photon beams used during the TLD irradiations. The discontinuities seen in that figure are the result of the $K$ absorption edge of fluorine at $685 \mathrm{eV}$ and the L- absorption edge of calcium at 347 $\mathrm{eV}$, the main constituents of TLD-200. That figure also illustrates the fact that, as in the case of TLD-100 phosphors presented before, the mean free path of photons in the energy region of interest of this study is indeed very small, causing the shallow penetration that these low-energy photons have in materials.

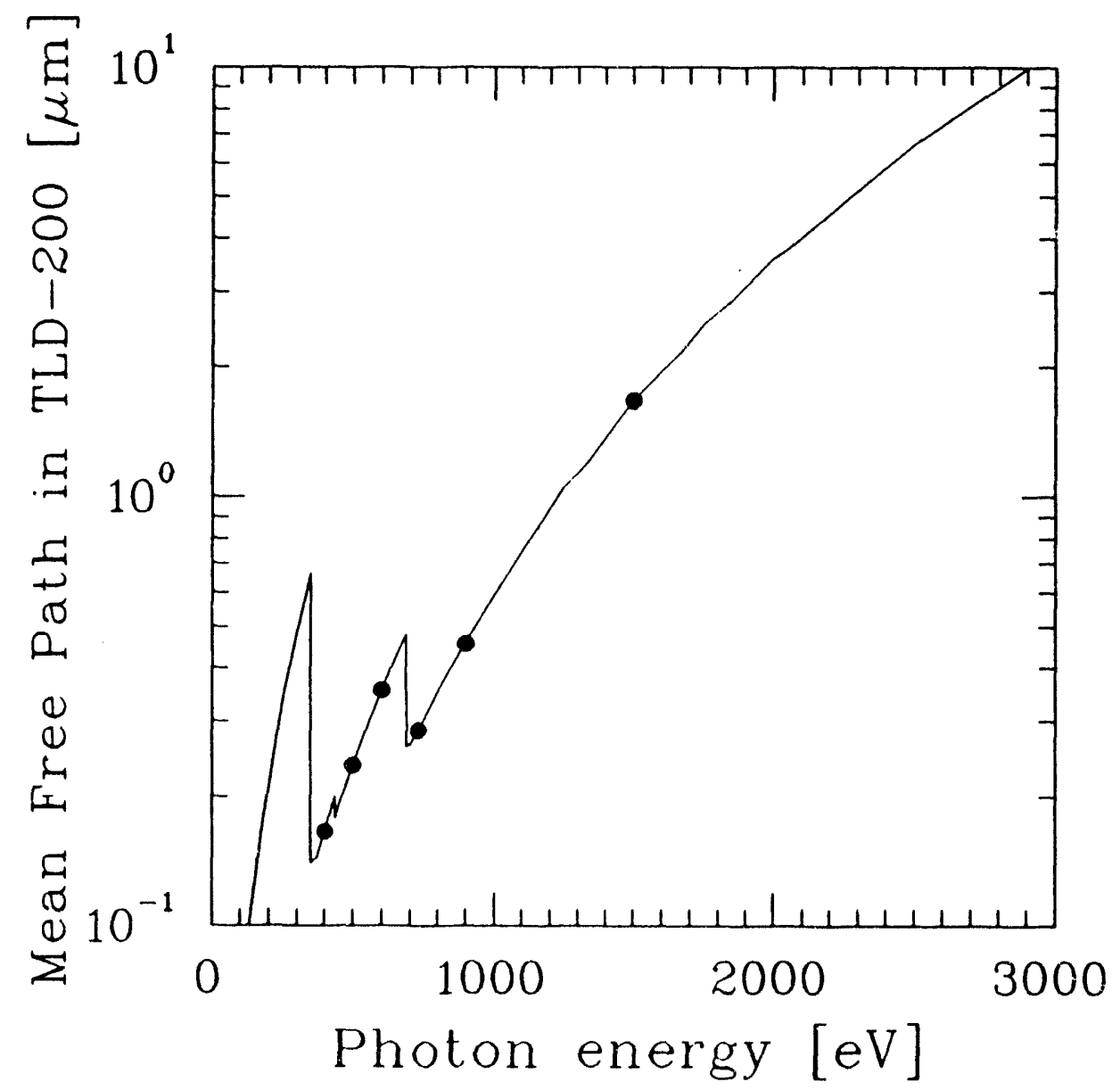

Figure 33: Mean free path in $\mathrm{CaF}_{2}: \mathrm{Dy}$ (TLD-200) as a function of photon energy. The $\mathrm{K}$ - and $\mathrm{L}$ - absorption edges of fluorine and calcium at 685 and $34 \mathrm{t} \mathrm{eV}$, respectively, are responsible for the discontinuities seen in the figure. Dots illustrate the energies used in this study. 
Figure 34 shows the TL response obtained as a function of energy deposited in the He-annealed chips for the photon energies used. The TL response is measured by the integrated area of the glow curve between $170^{\circ} \mathrm{C}$ and $250^{\circ} \mathrm{C}$. This temperature interval covers most of the stable TL output of this phosphor. The peak at around $145^{\circ} \mathrm{C}$, despite being the most prominent one for this TLD, presents relatively high fading that renders it not as useful as the peak at $200^{\circ} \mathrm{C}$. The latter peak is entirely included in the integration interval used here. Two techniques are commonly used with this phosphor to reduce errors due to fading of the $145{ }^{\circ} \mathrm{C}$ peak: a postirradiation anneal done at low temperature or integration of a high temperature TL interval of the glow curve. The latter method is the one followed in this study to avoid changes in glow curve and TL response commonly associated with annealings and high-temperature read outs in air.

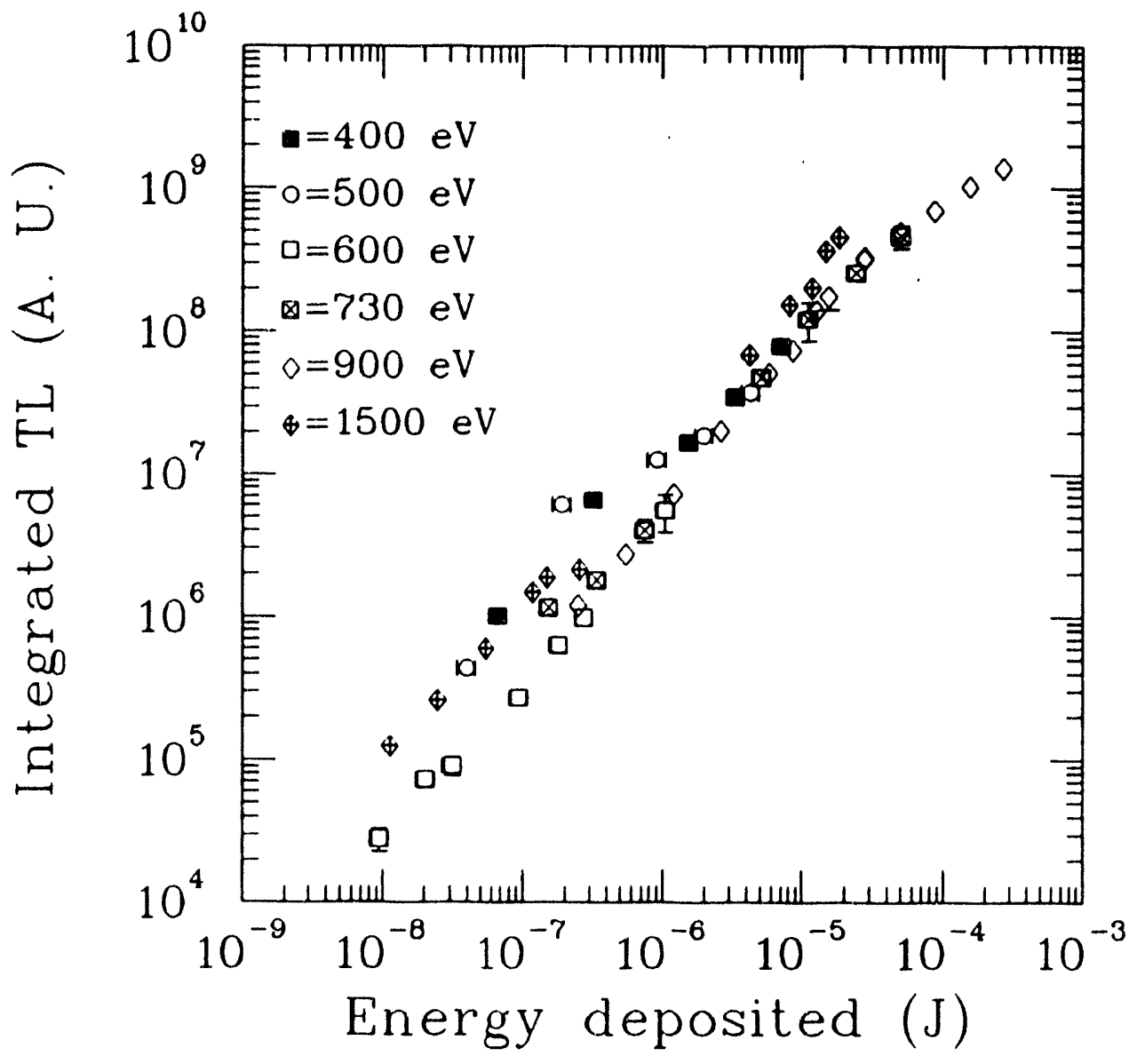

Figure 34: ROI TL of TLD-200 chips us energy deposited.

As seen in figure 34, the integrated TL response as a function of energy deposited in this TL phosphor seems to follow a linear behaviour for all photon energies used during the study. TL responses at the highest exposures seem to 
approach the beginning of the saturation region; more information about this will be presented in the following sections. Most of the TI responses of the chips at all energies seem to follow a single line indicating that the dosimeters employed in this study are responding similarly to each other. When the batch of chips was purchased, it was requested to have a sensitivity volume response with a deviation of $\pm 15 \%$ from the mean response to ${ }^{137} \mathrm{Cs}$ gamma rays. The fact that they were sorted according to their volume TL response is helpfuull at low-energy photons as well, although the TL response in the latter case is caused mainly by superficial layers of the chips and not by the complete volume as in the case of gammas. The batch of TLD-200 chips was brand new before this study, so their surfaces have had little opportunity for exposure to uncontrolled etching agents that could adversely effect their TL response to shallow penetrating radiation.

As for TLD-100 dosimeters, the TLD-200 data points for 1,500 eV exposures shown in figure 34 seem to follow a slightly different response pattern. This is believed to be caused by experimental problems present at the beamline when irradiations at this energy were performed. Exposures at $1,500 \mathrm{eV}$ photons are currently being repeated to confirm our results at that energy.

Several peaks are seen in the glow curves obtained for TLD-200 chips following the low-energy photon irradiations. The most prominent peak is still the one at about $145^{\circ} \mathrm{C}$, as is the case of gamma irradiations $[36,37,38]$. This peak is the one with the highest TL output. However, it presents fading at room temperature, which does not allow its common use for routine dosimetry. More frequently, the more stable peak at $200{ }^{\circ} \mathrm{C}$ is the one used for long term applications. Figure 35) shows the TL response of the height of this peak at $200^{\circ} \mathrm{C}$ as a function of energy deposited for the crystals.

\subsubsection{Glow curves in $\mathrm{He}$}

Figure 36 presents glow curves for TLD-200 chips. These curves have been normalized to the $200{ }^{\circ} \mathrm{C}$ peak, the more stable peak of this phosphor. The energy deposited at each energy was in the vicinity of $260 \mathrm{~nJ}$. Two other peaks are seen in the glow curves at $145{ }^{\circ} \mathrm{C}$, the most prominent one, and at $245{ }^{\circ} \mathrm{C}$. The lowtemperature peak presents fading at room temperature as discussed before, reason why is not as useful as the other two peaks at 200 and $245{ }^{\circ} \mathrm{C}$. Among the photon beams used, the one penetrating the least in calcium fluoride is that with an energy of $400 \mathrm{eV}$, as indicated in figure 33. From that figure we can also see that photons at $500,730,600,900$, and $1500 \mathrm{eV}$ have increasing penetration in this phosphor. However, from the curves presented in figure 36 we can see that the energy, i.e., penetration, of the irradiating photons does not seem to have any effect on the shape of the glow curves at this exposure level.

$\Lambda$ s a matter of comparison, gamma induced glow curves were collected as well. 


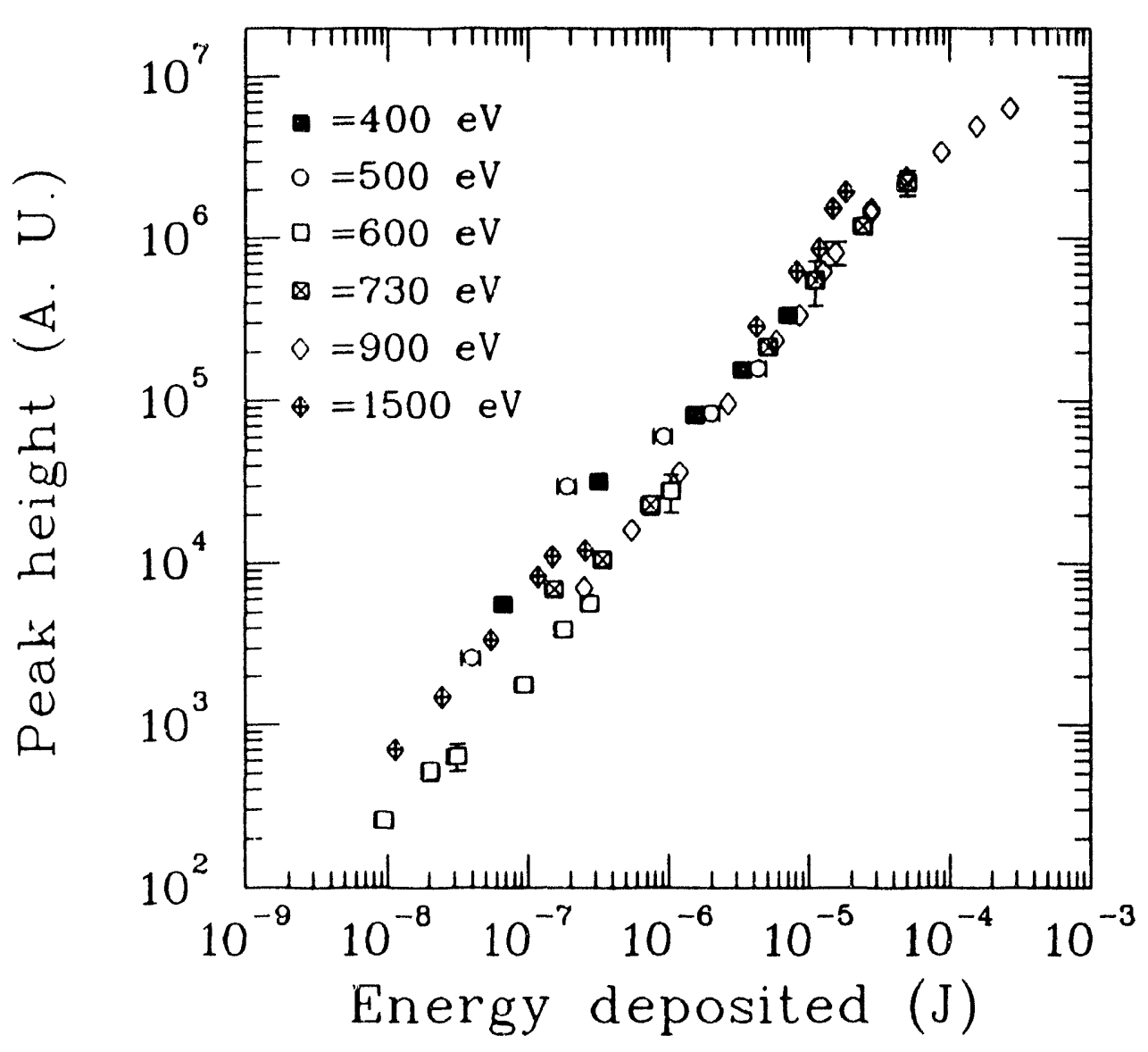

Figure 35: Peak height TL response of the peak at $200^{\circ} \mathrm{C}$ of TLD-200 chips as a function of energy deposited.

Figure 37 shows the glow curve obtained for chips following a ${ }^{137}$ ('s gamma-ray exposure of $258 \mu \mathrm{C} / \mathrm{kg}(1 \mathrm{R})$. In general, glow curves for 'TLD-200 chips exposed to low-energy photons during this study closely resemble the glow curve obtained following gamma irradiations. 

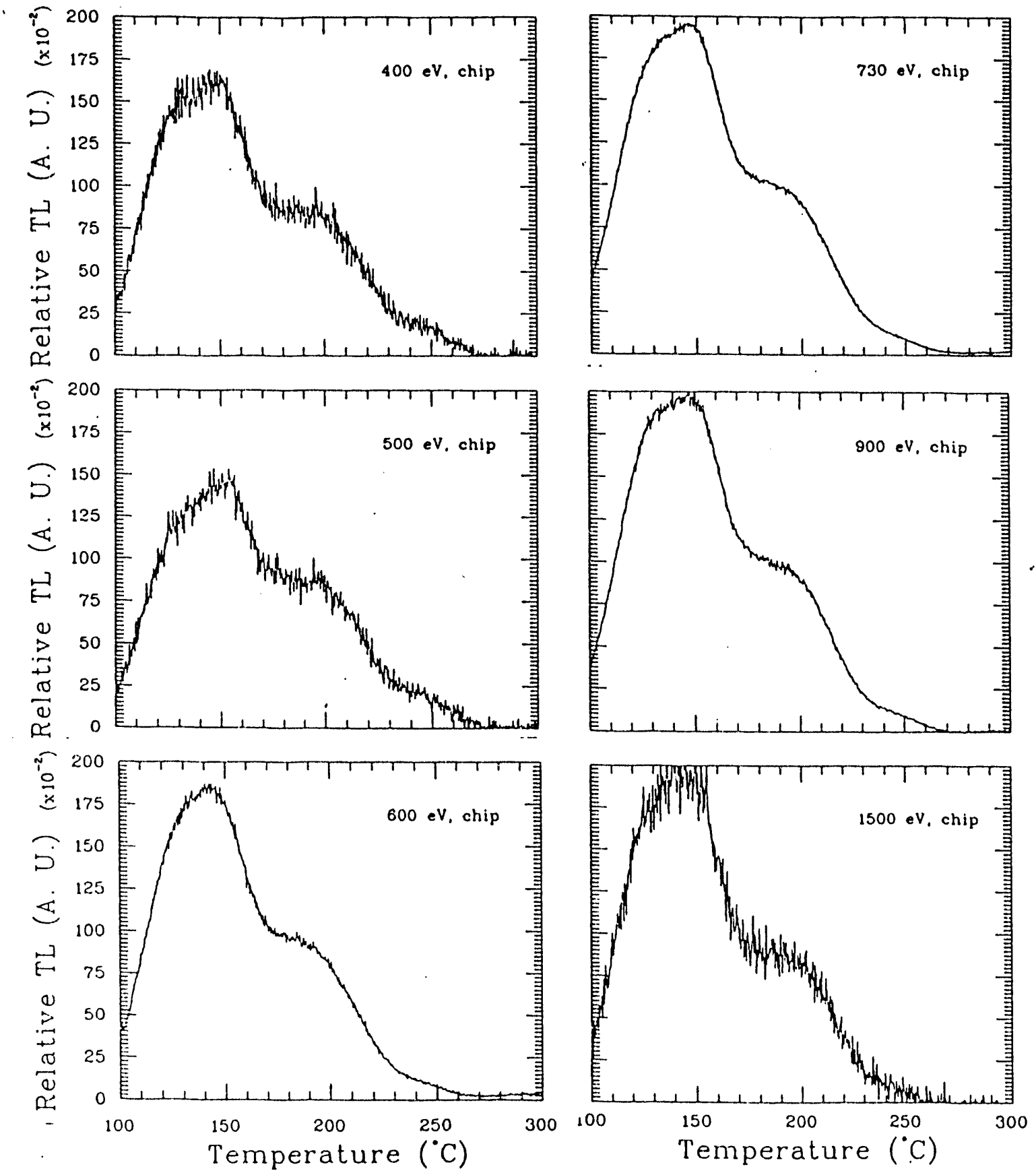

Figure 36: Glow curves of calcium fluoride chips exposed to 1500, 900, 730,600 , 500 , and $400 \mathrm{eV}$ photons. Curves have been normalized to have the same hright of the peak at $200{ }^{\circ} \mathrm{C}$. 


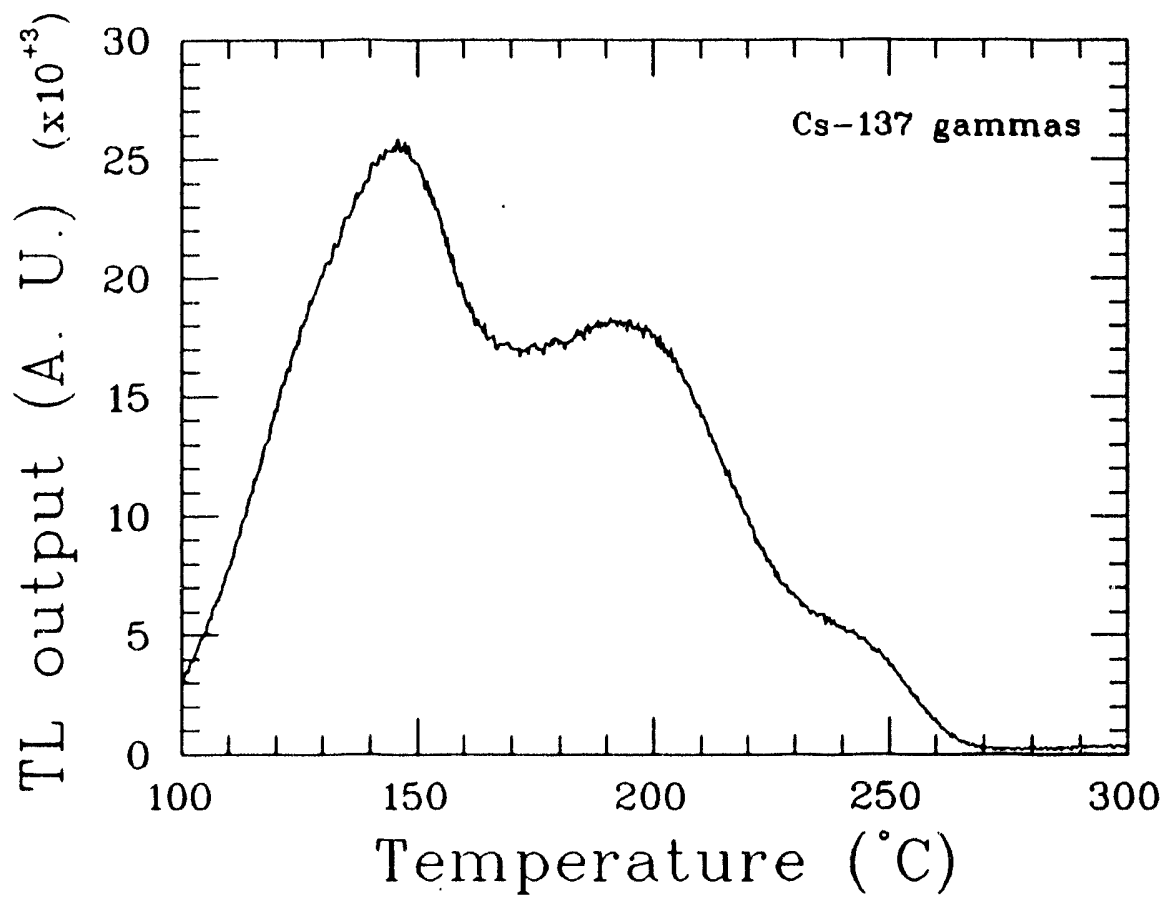

Figure 37: Glow curve of calcium fluoride chips exposed to ${ }^{137} \mathrm{C}$ 's gamma rays. 


\subsubsection{Glow curve comparison of chips annealed in air and in He}

The effect of the annealing atmosphere in TLD-200 chips was also studied because previous studies for another phosphor (TLD-100) exposed to gammas [18] and lowenergy betas [6] proved that the annealing atmosphere is crucial to obtain reproducible TL output and glow curves. No study was found reporting similar results for TLD-200, although the same damaging mechanism could be present. To confirm that this was the case with low-energy photons and TLD-200, three annealing treatments were used with this phosphor. Helium was the atmosphere employed in one case, while air was the atmosphere present during the other two annealings done for 1 and for $23 \mathrm{hr}$. As in the case of TLD-100 phosphors, glow curves for air-annealed chips at some energies are not available yet. Figures below presents the data available to date.

Figure 38 shows the glow curves for chips annealed in helium and air (for 1 and $23 \mathrm{hr}$ ), and then exposed to $1,500 \mathrm{eV}$. The adverse effect of air anneal is clearly seen as an overall reduction on the height of the peaks. For the chips annealed in air for $23 \mathrm{hr}$ the reduction is more pronounced. Figures 39 and 40 present similar comparisons between the glow curves obtained with chips annealed in air and in He following irradiations with 730 and $600 \mathrm{eV}$ photons, respectively.

\subsubsection{Surface dose calculations}

As briefly discussed in section 4.6.1, the shallow penetration of low-energy photons in chips means that large doses are easily achieved at the surface of a chip. As in the case of TLD-100, the energy of the incident photon beam is almost entirely deposited at superficial layers of phosphor. This effect is clearly seen in figure 41 , where the curves show how the chip dose, normalized to unity at the surface (zero depth) of the phosphor, decreases rapidly after only a few microns inside the TLD-200 chips. That figure presents calculated dose curves for the photon energies employed in this study. The less penetrating a photon beam, the higher the dose at superficial layers will be compared to the dose inside the chip, and the faster the dose will clecrease as a function of depth. Similar dose behaviour as a function of penetration depth and photon energy is seen in other materials, including silicon wafers currently employed to manufacture microscopic integrated circuits with synchrotron radiation. For TLD-200 the penetration of the photons is given by figure 33 presented before. From that figure we can see that 400 and $500 \mathrm{eV}$ photons are the least penetrating, while 730,600 , and $900 \mathrm{eV}$ are more penetrating photons in TILD-200 with alont equal mean free paths. Photons with an energy of $1500 \mathrm{eV}$ are the ones with the maximum penetration in TLD-200 among the energies studied. As a consequence, the dose curves presented in figure 41 and showing the fastest decrease for increasing chip thickness are those corresponding to 400 , and $500 \mathrm{eV}$, followed by the curves for $730,600,900$, and finally $1500 \mathrm{eV}$. 


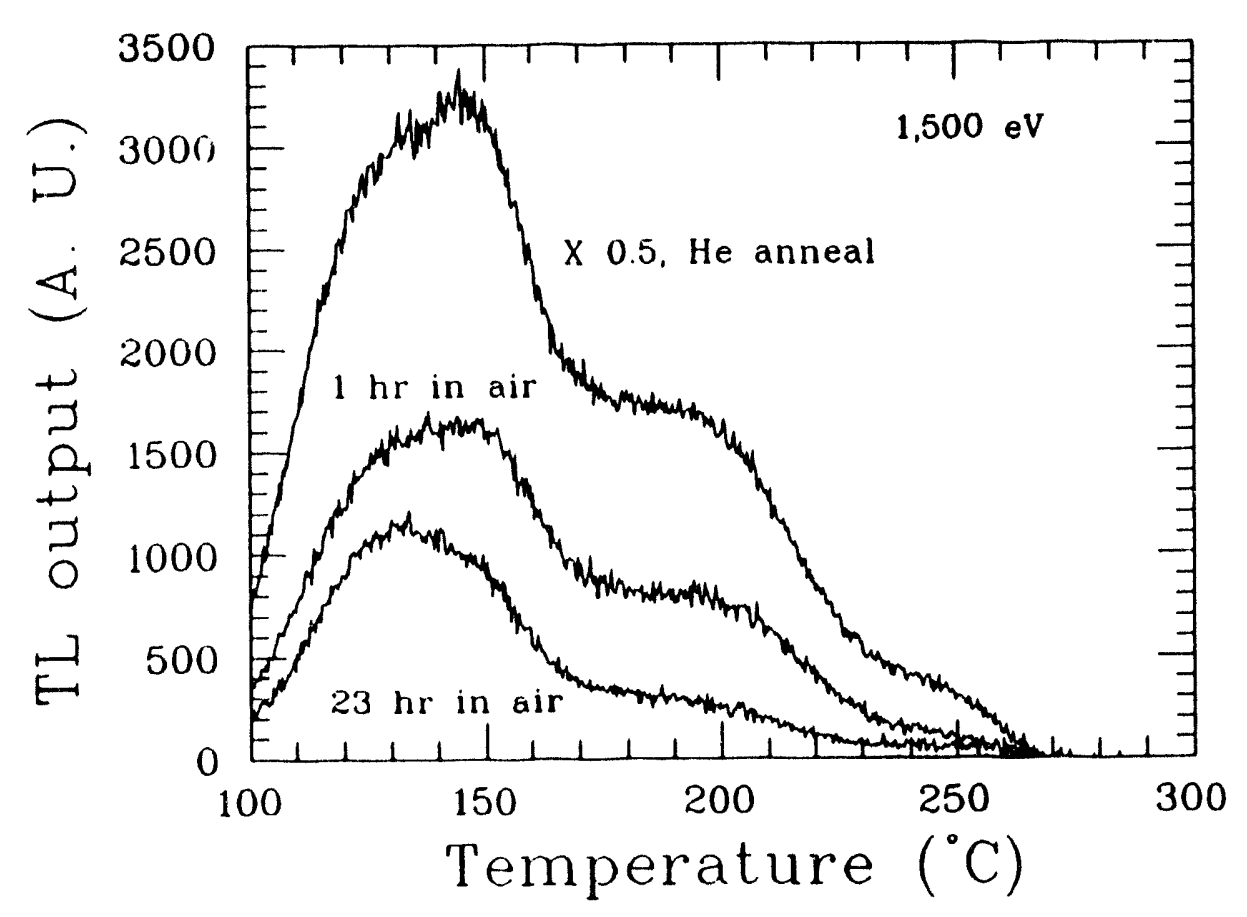

Figure 38: Glow curves of He- and air-annealed calcium fluoride chips exposer to $1,500 \mathrm{eV}$ photons.

As in the case of TLD-100 phosphors, the phenomenon just described has a great impact on the TLD-200 luminescent response because many types of TLDs have been known to present a linear TL response as a function of dose up to limits set by the type of phosphor and radiation employed. Beyond that limit a supralinear TL response is commonly found, and at even higher exposures saturation of the $T L$ response of the phosphor is eventually reached. $[10,36,3 \tau, 39,40]$. To study this effect, the TL response as a function of energy fluence, reported in section 4.6.1 before, provided some information. The slope of the curves presented in that section (TL response $v s$ energy deposited) was seen to decrease as the saturation region is approached at large values of energy deposited. To gather more information, the superficial dose to the chips was calculated also. Figure 42 shows the integraterl TI response of chips as a function of surface dose for all the energies used. On the other hand, figure 43 presents the TL response of the chips as given by the peak at $200^{\circ}($ : as a function of surface dose. For both figures the data seem to concentrate in two groups following different but parallel lines. Surface rose data for 1,500 eV photons follow one line, while the data for the other energies follow the other. This is a direct result of their different penetration in the dosimeter, as shown in figure 33. Photon beams having similar penetration in the TILI)-20() chip follow similar line 


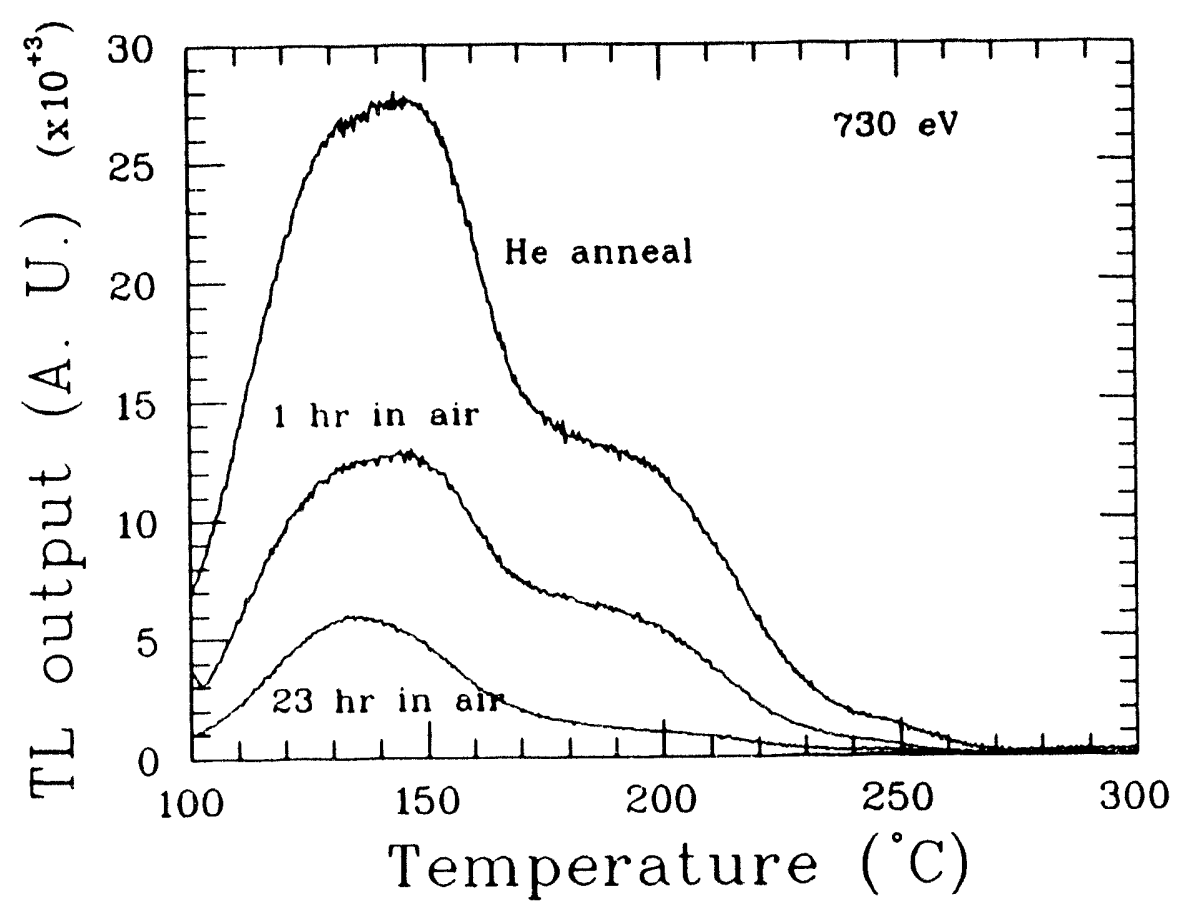

Figure 39: Glow curves of He- and air-annealed calcium fluoride chips exposed to $730 \mathrm{eV}$ photons.

responses. Photons of $400,500,600,730$ and $900 \mathrm{eV}$ have similar mean free path of about 0.3 microns in TLD-200, and follow the same TL "s surface dose line. On the other hand, $1,500 \mathrm{eV}$ photons have a mean free path of about 1.7 microns in TLD-200, and follow a line response different from the one for all the other energies.

\subsubsection{TL response per unit mean dose and mass; calculation of supra- linearity factors}

Supralinearity is a property commonly seen in TL phosphors. The exact value at which supralinearity starts is a function of the phosphor type, annealing treatment, specific peak under study, and radiation type, among others. Since hightemperature anneals in air are known to change the 'TL response for other phosphors to shallow penetrating radiation, TLD 200 chips used during this study did not receive the high-temperature annealing treatment in air reported to make the TL response linear up to saturation $[36,37]$. This means that our chips should present supralinearity at high exposures, which they do as reported below.

To calculate the supralinearity factor, the T'L response per unit dose and mass of the dosimeter is usually plotted. Figure 44 presents such weighted (ROI) response 


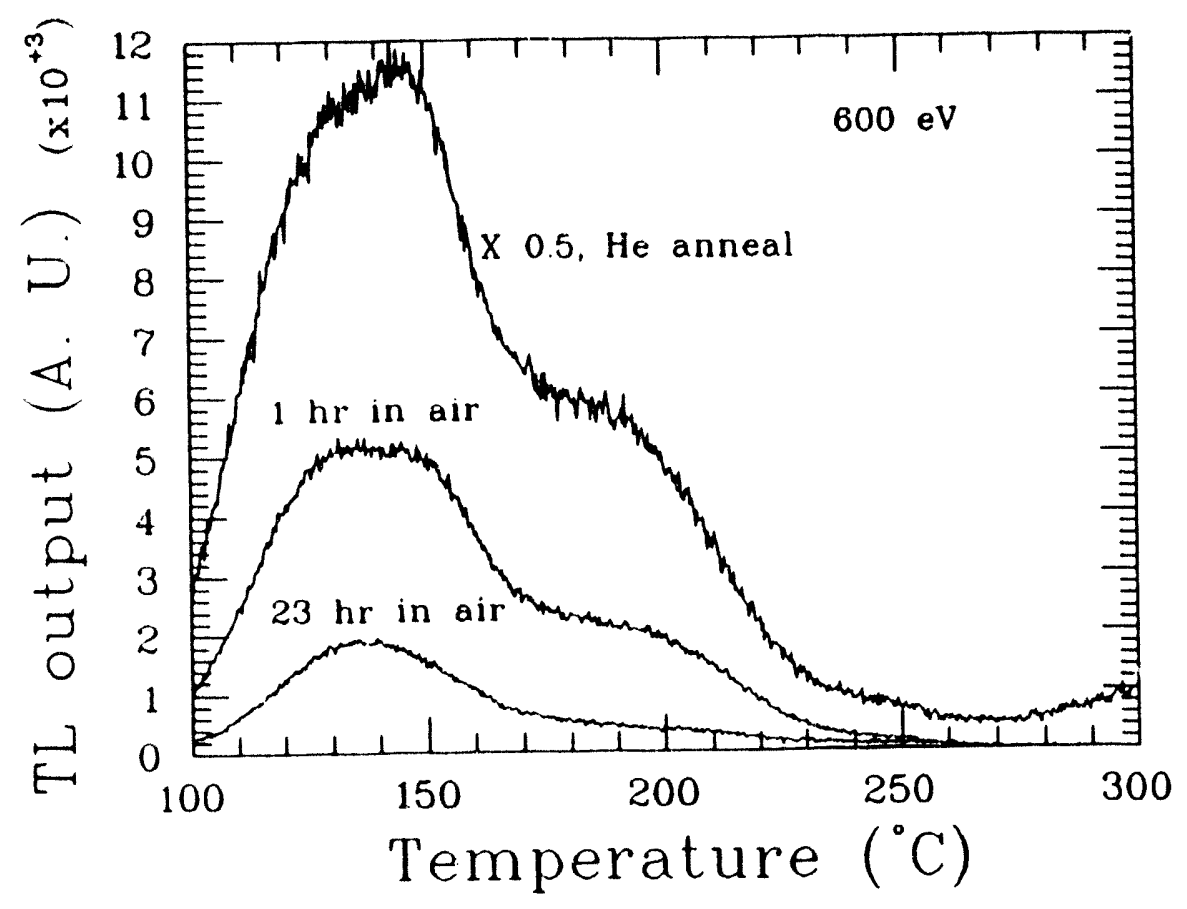

Figure 40: Glow curves of He- and air-annealed calcium fluoride chips exposed to $600 \mathrm{eV}$ photons.

as a function of mean dose delivered to TLD-200 chips. Figure 45 presents the calculated results based on the dosimetric peak height response as a function of mean dose for the chips. For both figures the mean dose and mass were calculated taking a photon penetration of two mean free paths, following the same consiclerations given in section 4.5.5 for the case of TLD-100 dosimeters.

As in the case of TLD-100 results, there are still limitations regarding the amount of data collected at several energies and dose levels to calculate the supralinearity factor for TLD-200 chips. We will proceed with the data we have for 900 and $730 \mathrm{eV}$ photons. Data for the ROI response of the TLD-200 chips to $900 \mathrm{eV}$ photons yield a supralinearity factor of $2.6 \pm 0.7$. A similar result of $1.9 \pm 0.5$ is again provided by the peak height response of the TLD-200 chips at $900 \mathrm{eV}$. For $730 \mathrm{eV}$ photons the ROI data yield a supralinearity factor of $2.3+0.9 \mathrm{in} \mathrm{TLI)}$. 200 chips, while peak height calculations yield a supralinearity factor of 1.6 t 0.6 . There are no similar results to compare with for this phosphor at these energies, although our results are within the range of values reported by other anthors for this phosphor for low-energy $x$ - rays and gammas $[36,37]$.

As pointed out in section 4.6.1, results for the TLD-200 chips irradiations at 1,500 -V are being collected again to comfin those obtained and reported lere. At 


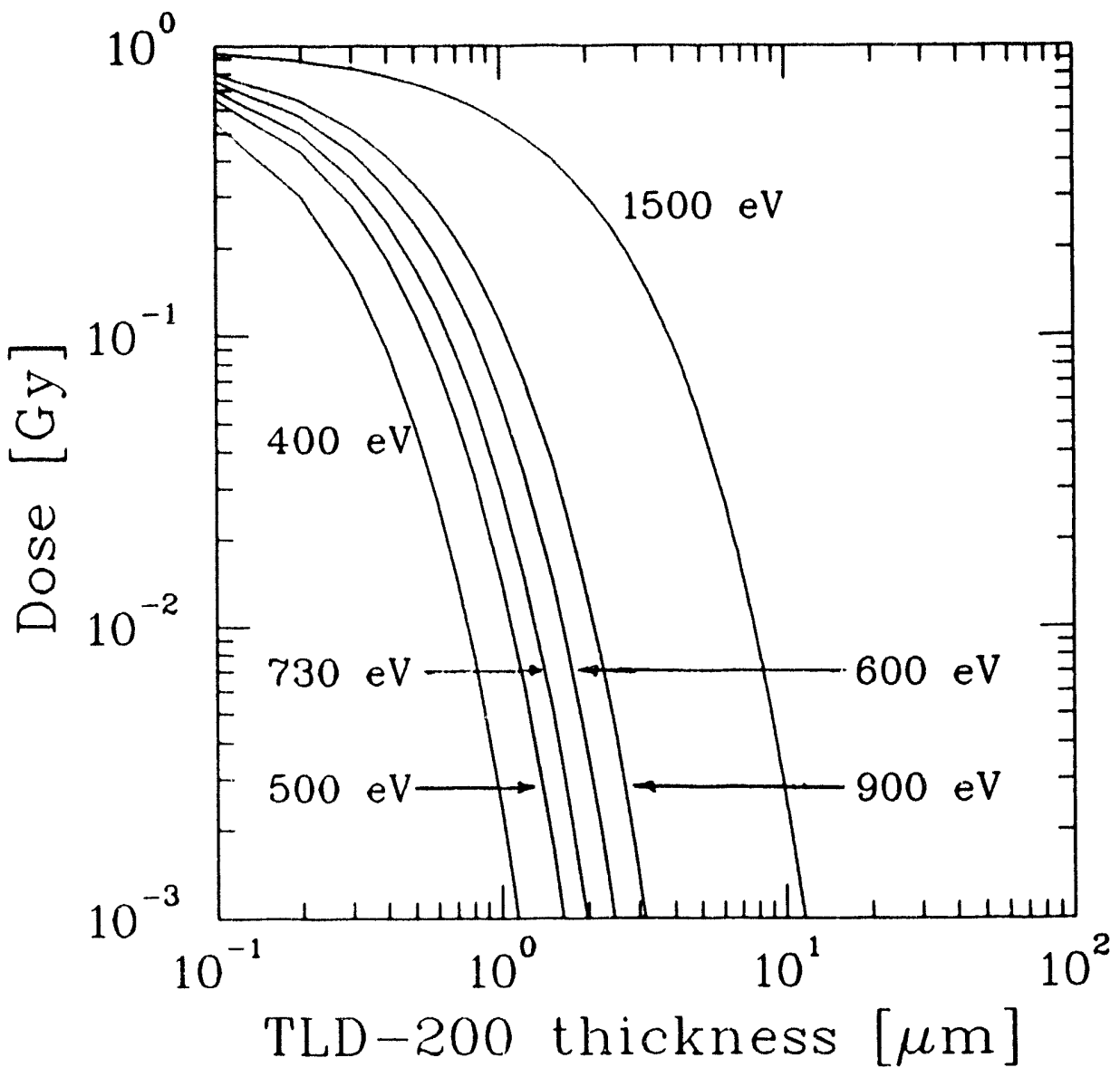

Figure 41: Dose "s depth in TLD-200.

that energy the last two figures show responses somewhat different from the other energies, although the behaviour displayed by the $1,500 \mathrm{eV}$ results still resemble the one found for the other energies. Since beamline experimental problems are believed to be playing a role at this energy, the supralinearity factor calculation will be deferred until more data are collected. Data for $600 \mathrm{eV}$ photons covers the low level dose region but not enough of the high level region, where supralinearity seems to be present for other energies used in this study. The calculation of the supralinearity actor will be deferred also until more data become available. 


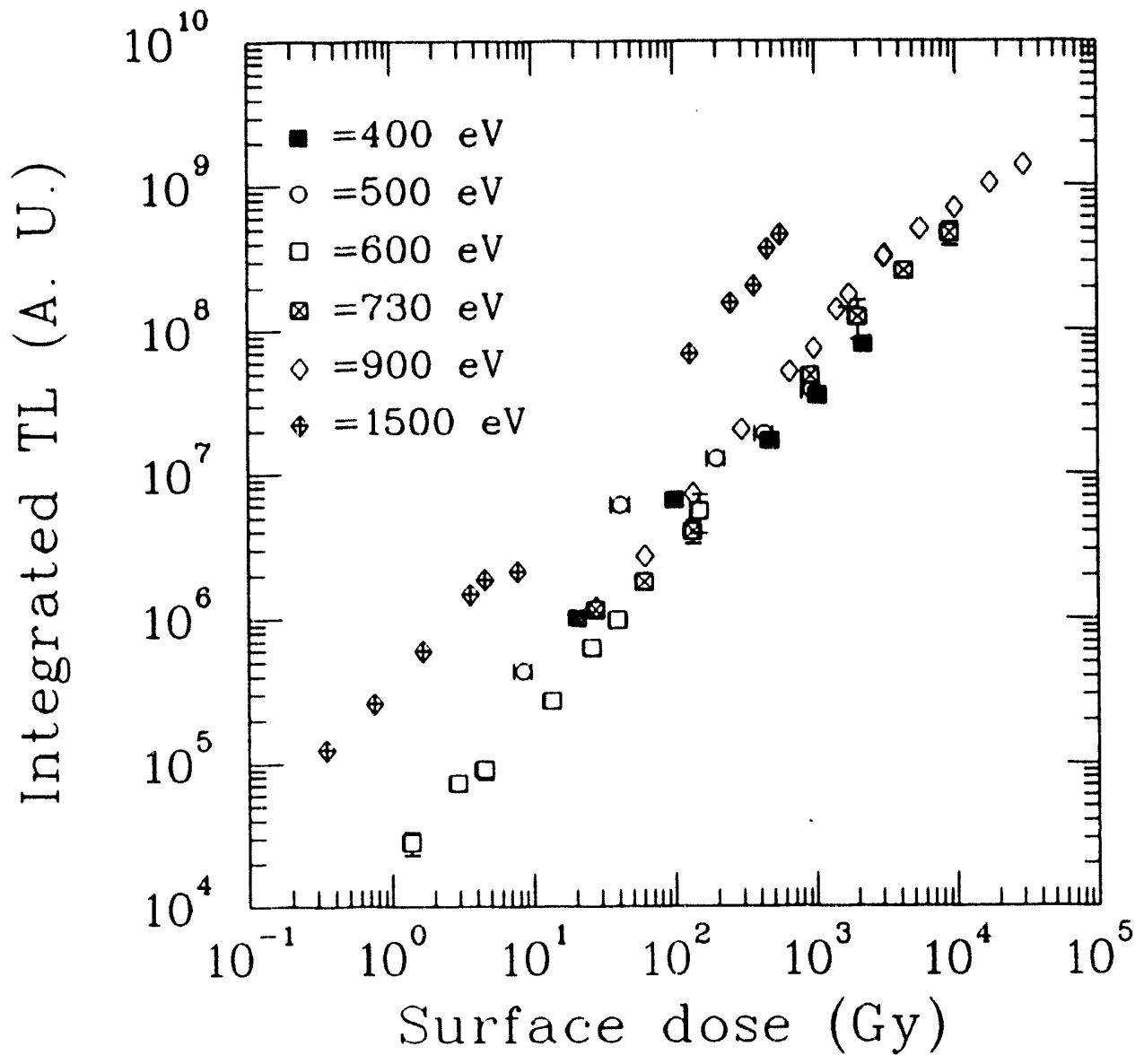

Figure 42: Integrated TL response of TLD-200 chips us surface dose. 


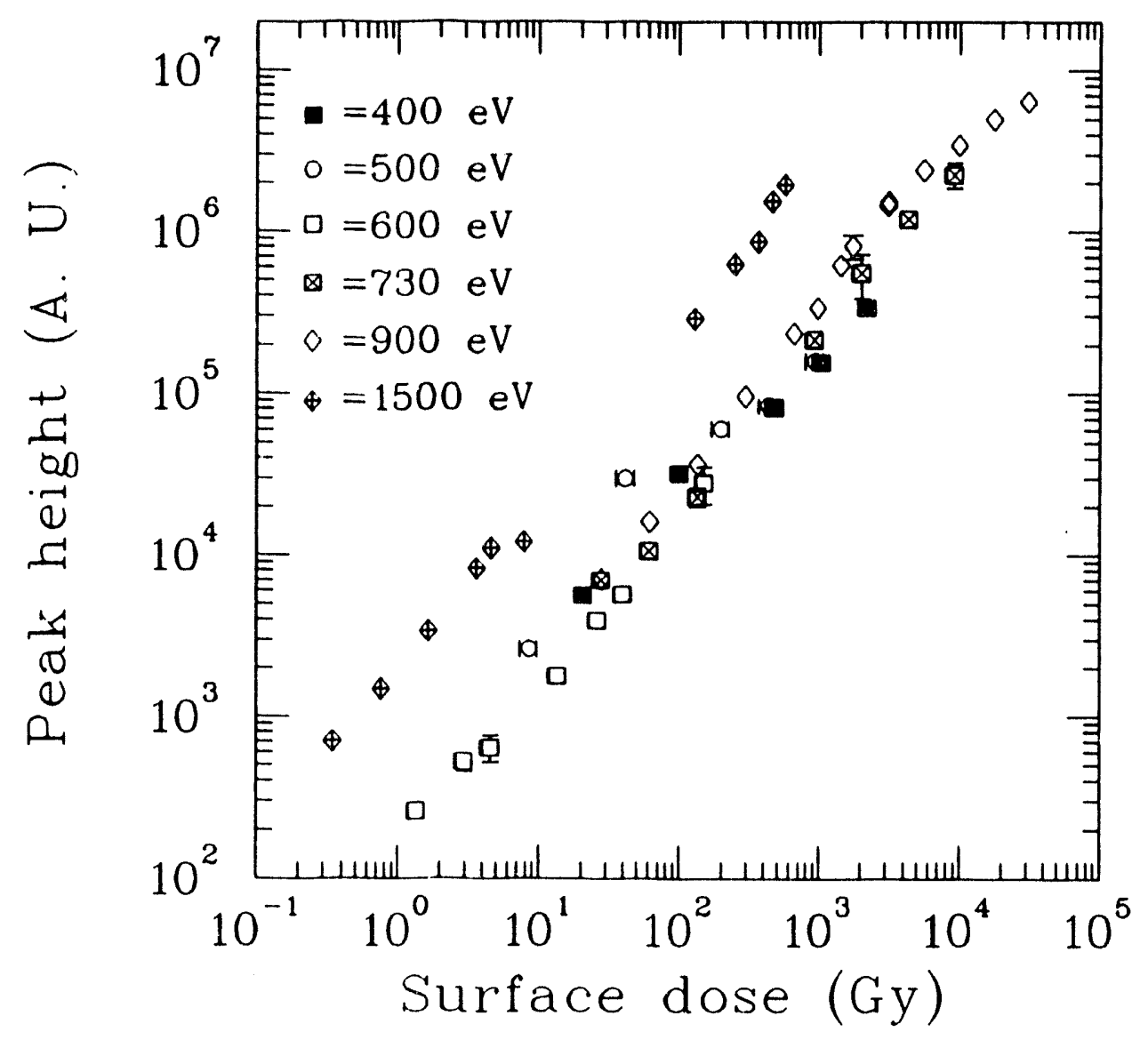

Figure 43: Peak height TL response of the peak at $200{ }^{\circ} \mathrm{C}$ in TLD-200 chips us surface dose. 


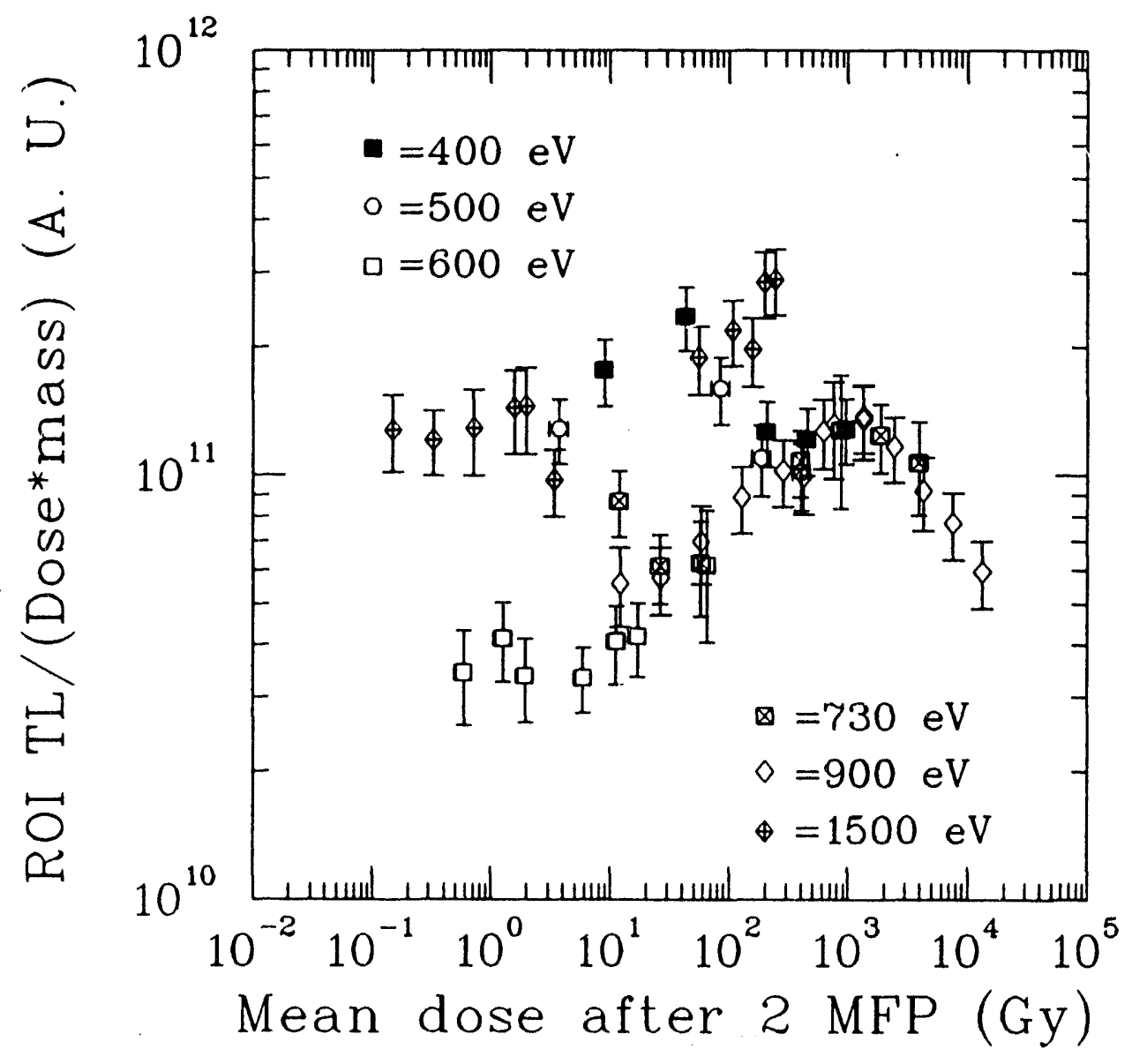

I

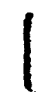

Figure 44: Integrated TL per unit mean dose and mass of TLD-200 chips vs mean dose. 


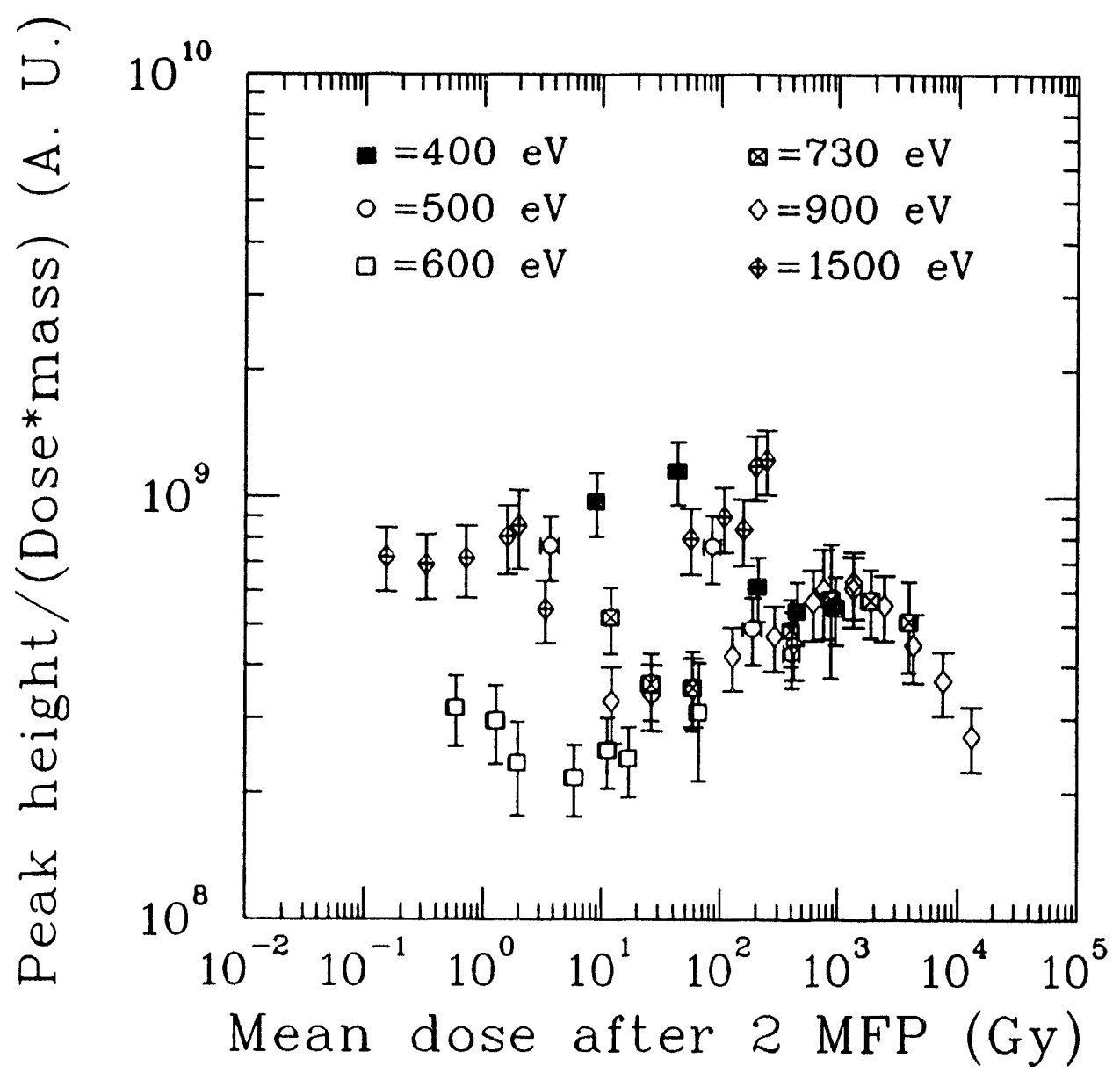

Figure 45: Peak height TL response per unit of mean dose and mass vs mean dose for the peak at $200{ }^{\circ} \mathrm{C}$ in TLD-200 chips. 


\section{References}

(1) Meger, C. M., Pearson, D. W., DeLuca, P. M., Jr., Wells, G. M., Redaelli, R. and Cerrina, F. A comparison of three detectors for soft $X$-ray dosimetry. Nucl. Inst. Meth. A266 608-611 (1988).

[2] Meger, C. M. Dosimetry and Radiobiology of synchrotron-produced ultrasoft $X$-rays. Ph. D. Thesis. UW-Madison (1989).

(3) Meger, C. M., Pearson, D. W., DeLuca, P. M., Jr., Wells, G. M., Redaelli, R. and Cerrina, F. A simple total absorption calorimetry technique to incasurc soft X.ray energy fluence. Radiat. Prot. Dos. 21(4) 219-222 (1987).

[4] Meger, C. M., Pearson, D. W., DeLuca, P. M., Jr., Wells, G. M., Cerrina, F. and Gould, M. A beamline and irradiation chamber for dosimetry and Biology studies using synchrotron radiation. Rev. Sci. Inst. 60(7) 2235-2238 (1989).

[5] Meger, C. M., Pearson, D. W., DeLuca, P. M., Jr., Kennan, W. S. and Gould, M. Synchrotron produced ultrasoft $X$-rays: a tool to study the biophysical model of radiation damage. Int. J. of Radiat. Biology 59(4) 985-996 (1991).

[6] Lasky, J. and Moran, P. Thermoluminescent response of LiF (TLD-100) to 5-30 ke $V$ electrons and the effect of annealing in various atmospheres. Phys. Med. Biol. 22(5) 852-862 (1977).

17] Lasky, J. and Moran, P. Thermoluminescent response of LiF (TLD)-100) to 0.1-5 ke $V$ electrons: An energy-range relationship and comparison of the $T L$ glow with TSEE glow curves. J. Appl. Phys. 50(7) 4951-4957 (1979).

[8] Carrillo, R. E. and DeLuca, P. M., Jr. Low energy beta ray thermoluminescent dosimetry. Available as University of Wisconsin WMP Report \# 189 from the Department of Medical Physics, University of Wisconsin, Madison, WI (1990).

[9] Carrillo, R. E. and DeLuca, P. M., Jr. Thermolumincscent dosimctry of 0.130 le $V$ electrons with lithium fluoride. Proc. of the IV Congreso Nacional sobre Dosimetria Termoluminiscente, Mexico DF, 12-13 Sep 1991.

[10] Carrillo, R. E., and DeLuca, P. M., Jr. High lcvel gamma ray themoluminescent dosimetry. Proc. of the III Seminario Nacional sobre Dosimetria 'Termolumincscente, Mexico DF, 1718 Sep 1990. This is also available as University of Wisconsin WMP Report \#1 190 from the Department of Medical Pliysics, University of Wisconsin, Madison, WI (1990). 
[11] Carrillo, R. E. and DeLuca, P. M., Jr. U.V. dosimetry with thermoluminescent. materials. Proc. of the III Seminario Nacional sobre Dosimetria Termoluminescente, Mexico DF, 17-18 Sep 1990. This is also available as University of Wisconsin WMP Report \# 191 from the Department of Medical Physics, University of Wisconsin, Madison, WI (1990).

[12] Folkard, M., Roper, M. J., and Michael, B. D. Measurement and analysis of supralinearity in LiF TLD-100 irradiated by 1.5 keV $x$-rays. Phys. Med. Biol. 34(6) 707-715 (1989).

[13] Carrillo, R. E., Characterization of the thermoluminescent response of several phosphors to monoenergetic photon beams with energics from 100 to 3,000 $\epsilon V$. Ph.D. Thesis Prospectus, Department of Medical Physics, University of Wisconsin, Madison, WI (1990).

[14] Becker, K., Solid State Dosimetry. CRC Press, Ohio (1973).

[15] Attix, F. H., Introduction to Radiological Physics and Radiation Dosimetry. John Wiley \& Sons, Inc., New York, NY (1986).

[16] Plechaty, E. F., Cullen, D. E., and Howerton, R. J. Tables and Graphs of Photon-interaction cross sections from 0.1 ke $\mathrm{V}$ to $100 \mathrm{MeV}$ derived from the LLL Evaluated-Nuclear-Data Library. UCRL-50400(6), Rev. 3, Nat. Tech. Inf. Serv., US Dept. of Commerce (1981).

[17] Cameron, J. R., Suntharalingam, N. and Kenney, C. N., Thermoluminescent. dosimetry. University of Wisconsin Press, Madison, WI (1968).

[18] DeWerd, L. A., and Stoebe, T. G. The influcnce of hydroxide impuritics on. TL in LiF. Proc. Third Int. Symp. Lum. Dosimetry, Riso Rep. 249, Part I $78-89$ (1971).

[19] Vana, N., Aiginger, H., and Hager, A. Supralinearity in LiF. Proc. Fourth Int. Conf. Lum. Dosimetry, Institute of Nuclear Physics, Krakow, 123 (1974).

[20] Piesch, E., Burgkhardt, B., and Kabadjova, S. Supralincarity and r. evaluation of different LiF dosimeter types. Nucl. Inst. Meth. 126563 (1975).

[21] Naylor, G. P. Thermoluminescent phosphors: variation of quality response with dose. Phys. Med. Biol. 10564 (1965).

[22] Horowitz, Y. S. TL Dose Response in Thermoluminescence and thermoluminescent dosimetry. Ed: Horowitz, Y. S., Vol II. CRC: Press, Boca Raton, Florida (1984). 
[23] Stoebe, T. G., and Watanabe, S. Thermoluminescence and lattice defects in LiF. Phys. Stat. Sol. (a) 20 11-29 (1975).

[24] Jain, V. K. Thermoluminescence of lithium fluoride. Radiat. Prot. Dosim. 2 141-167 (1982).

[25] Gorbics, S. G., and Attix, F. H. Thermoluminescent dosimeters for high-dose applications. Health Phys. 25 499-506 (1973).

[26] Oberhofer, M. High-level photon dosimetry with thermoluminescent materials. Atomkernenergie 31 209-216 (1978).

[27] Charalambous, S., and Petridou, C. The thermoluminescence behaviour of LiF (TLD.100) for doses up to 10 MRad. Nucl. Inst. and Meth. 137 441-444 (1976).

[28] LaRiviere, P. D. A unique throwaway LiF dosemeter. Proc. Second Int. Symp. Lum. Dosimetry. 78-81 (1968).

[29] Jain, V. K., Kathuria, S. P., and Ganguly, A. K. Supralinearity and sensitization in LiF TLD phosphor. J. Phys. C: Solid State Phys. 7 3810-3816 (1974).

[30] Jones, J. L., and Martin, J. A. Use of LiF (TLD.700) for doses greater than 0.1 Mrad. Health Phys. 14 521-522 (1968).

[31] Chandra, B., Lakshmanan, A. R., and Bhatt, R. C. High level gammadosimetry using high temperature TL peaks in LiF (TLD-100). Int. J. Appl. Radiat. Isot. 33 679-680 (1982).

[32] Burgkhardt, B., Piesch, E., and Singh, D. High-dose characteristic of LiF and. $\mathrm{Li}_{2} \mathrm{~B}_{4} \mathrm{O}_{7}$ thermoluminescent dosemeters. Nucl. Inst. and Meth. 148 613-61T (1978).

[33] Goldstein, N., Tochilin, E., and Miller, W. (1. Millirad and megarad dosimetry with LiF. Health Phys. 14 159-162 (1968).

[34] Horowitz, Y. S. General characteristics of T'L materials in Thermoluminescence and Thermoluminescent dosimetry. Fd: Horowitz, Y. S., Vol I. CIRC: Press, Boca Raton, Florida (1984).

[35] Lasky, J. B. Thermoluminescent response of LiF (TLID. 10(0) to $70 \mathrm{el}$.30 keV clectrons. Ph. D. Thesis. UW-Madison (1976). 
[36] Binder, W., Disterhoft, S., and Cameron, J. R. Dosimetric properties of $\mathrm{CaF}_{2}: D y$. Proc. Second Int. Conf. Lum. Dosimetry. USAEC Div. Tech. Inf. Rep. CONF-680920 43-53 (1968).

[37] Binder, W., Cameron, J. R. Dosimetric properties of $C a F_{2}: D y$. USAEC Rep. C00-1105-146 Department of Medical Physics, University of Wisconsin, Madison, WI (1969).

[38] Sunta, C. M. A review of thermoluminescence of calcium fluoride, calcium sulphate and calcium carbonate in Thermoluminescent materials. Ed: McKeever, S. W. S., Rad. Prot. Dos. 8 25-44 (1984).

[39] Burgkhardt, B., Singh, D., and Piesch, E. High-dose characteristics of $\mathrm{CaF}_{2}$ and $\mathrm{CaSO}_{4}$ thermoluminescent dosemeters. Nucl. Inst. and Meth. 141 363368 (1977).

[40] Hasan, F., and Charalambous, S. The thermoluminescence behaviour of $\mathrm{CaF}_{2}$ Dy (TLD-200) for low up to high doses. J. Phys. C: Solid State Phys. 16 5921-5928 (1983). 


\section{Ultra-thin TLD Response to Ultra-Soft X-rays}

\subsection{Participants}

Zhixin Zhou, Phoebe Shulman, Ricardo E. Carrillo, Juan Miranda, Paul M. DeLuca, Jr., David W. Pearson, and Janes F. Mackay.

\subsection{Introduction}

The Medical Physics beamline at the Wisconsin Synchrot ron Radiation Cienter provides a tuneable source of soft $\mathrm{x}$-ray photons for research in dosimetry and radiation effects. One project currently on the Medical Physics beamline that is supported by this grant is a study of some common thermoluminescent phosphors to photon energies between 100 and $3000 \mathrm{eV}[1,2]$. We are testing small TLDs for use as convenient, non-intrusive fluence meters for the synchrotron's ultra-soft $x$-rays that can be placed next to a specimen to monitor the photon beam during irradiation.

During the past grant period, Dr. Zhixin Zhou of the Shanghai Institute of Radiation Medicine in the People's Republic of C'hina collaborated with this research group and introduced two types of ultra-thin thermoluminescent materials: $\mathrm{LiF}: \mathrm{Mg}, \mathrm{Cu}, \mathrm{P}, 5 \mathrm{mgcm}^{-2}, 18.9$ microns thick and $\mathrm{CaSO}_{4}: \mathrm{Tm}^{\mathrm{m}} 2 \mathrm{mgcm}^{-2}, 7.7 \mathrm{mi}-$ crons thick. These materials are manufactured in the PRC and consist of a layer of powdered crystal on top of a thin film of aluminum (about 10 microns). They are not available in the USA.

The thickness of these materials is of similar order to the depth that ultra.soft. $\mathrm{x}$-rays penetrate. Figure 46 shows the attenuation per micron of 100 to $3000 \mathrm{eV}$ photons in $\mathrm{LiF}$ and $\mathrm{CaSO}_{4}$ calculated from a computer model developed at the Synchrotron Radiation Center.

Ultra-soft $x$-rays deposit their energy within microns of the TLI) surface. Given the attenuations shown in Figure 46, it is impractical to make TLDs thin enough to be a Bragg-Gray cavity for ultra-soft x-rays. However, a somewhat thicker TLD is quite useful as a fluence meter where the TLD absorbs all the inciclent radiation. In this case, surface effects are the primary problem of TL materials for use with ultra-soft $x$-rays. Some crystals have an insensitive layer at their surface which does not contribute to the TL light output. Because ultra-soft x-rays penetrate so shallowly, a significant fraction of the dose may be lost in this layer. Other materials have surface specific trapping states which then exhibit a different $T I$, glow curve $[3,4]$. Dr. Zhou's materials presented us with phosphors made from a manufacturing process that is not currently used in this country. It was of interest to examine their response.

While Dr. Zhou was here, we made some preliminary measurements of the response of his two ultra-thin materials to ultra-soft $x$-rays. TLIDs marle from these 


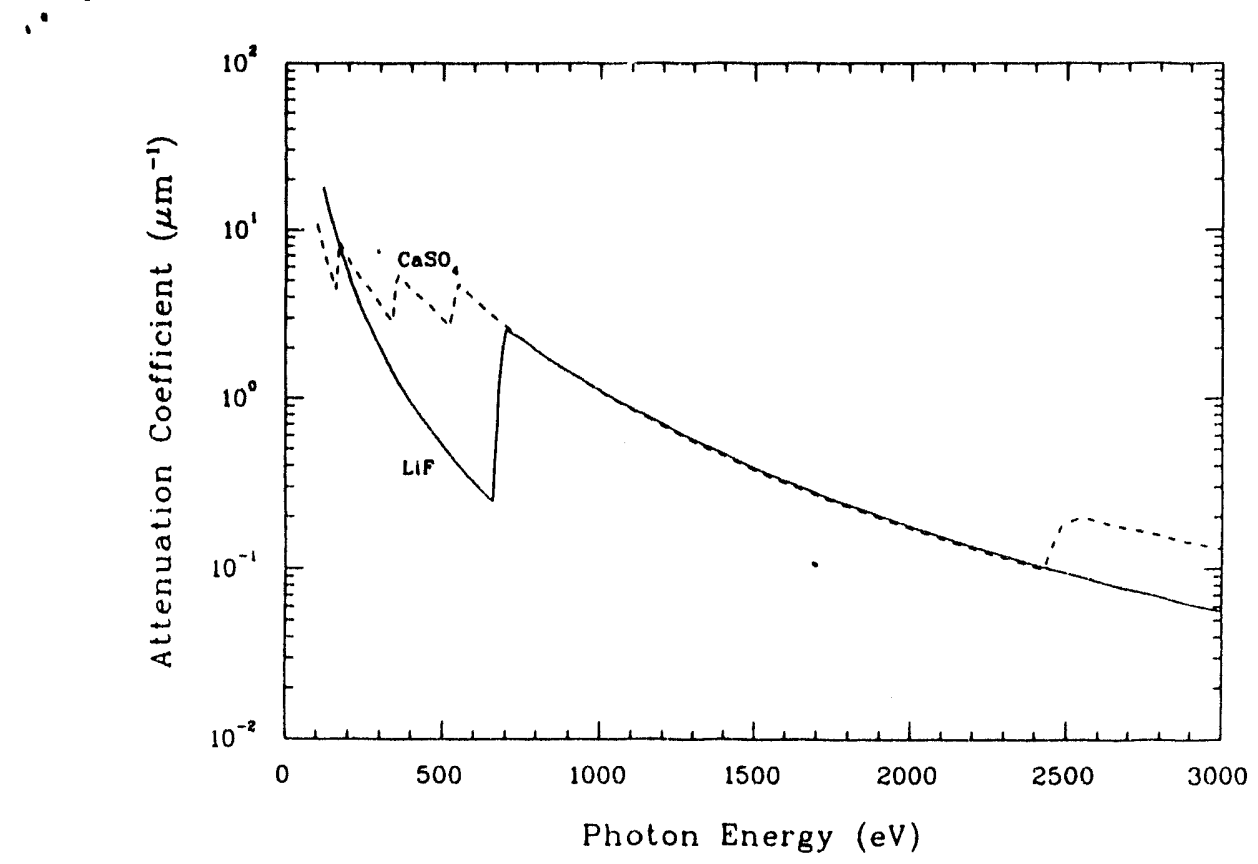

Figure 46: The calculated attenuation per micron of ultra-soft X-rays in LiF and $\mathrm{CaSO}_{4}$.

materials were included in some of the runs of the other phosphors under study, and were irradiated with $600,731,900$ and $1500 \mathrm{eV}$ x-rays.

\subsection{Methods and Materials}

All irradiations took place on the Medical Physics beamline at the Wisconsin Synchrotron Radiation Center. An experimental vacuum chamber is connected to the beamline and the samples are placed in a holder within the chamber. A computerized scanning system moves the holder vertically through the photon beam at a speed corresponding to the desired exposure. A monitor near the beamline displays the electron current in the storage ring at all times.

The TL material was annealed before irradiation. For these preliminary measurements, the ultra-thin $\mathrm{CaSO}_{4}$ and $\mathrm{LiF}$ were heated in air for 4 hours at $400^{\circ}$ and $240^{\circ} \mathrm{C}$, respectively. The materials were then cut into $3 \mathrm{~mm}$ diameter circles. Details on the handling of the TLD-100 extruded chips are described elsewhere in this document. All the TLDs were placed in individual slots in the holder which held them perpendicular to the photon beam.

$\mathrm{X}$-ray Si photodiodes ${ }^{9}$ were used to measure the intensity of the photon beam at the TLD surface just prior to irradiation. The electron current in the storage ring was also recorded at that time. During the irradiation, the electron current. was recorded as the photon beam scanned over each sample. At the end of the

\footnotetext{
${ }^{9} \mathrm{AX} U \mathrm{~V}-100$ International Radiation Detectors, XUV-005 UI) T' Sensors Inc.
} 
irradiation both the electron current and photon beam were again recorded. The energy fluence on the TLDs during irradiation was taken to be the pre-irradiation energy fluence from the photodiode corrected with a decay factor estimated from the decay of the ring electron current.

The TLDs were read out in a modified TL reader/footnoteHarshaw with single photon counting. The integrated light output between $130^{\circ}$ and $230^{\circ} \mathrm{C}$ was used, although the planchette was heated to $400^{\circ} \mathrm{C}$. Because they are so thin, this heating was sufficient to anneal out any residual dose in the ultra-thin TLDs and they were not annealed any further.

After readout, the individual TLDs were given a calibration exposure with betas from $a^{90} \mathrm{Sr}$ source. The source was an eye applicator with a flat active surface of about $1 \mathrm{~cm}$ in diameter. Its dose rate was calibrated for various heights above a plastic phantom against a calibrated ${ }^{137} \mathrm{C}$ s source. A TLD was calibrated by placing it on the phantom and placing the source at a specific height above it for a given period of time. Readout parameters were the same as mentioned above. The TL light output/energy deposited was calculated for each TLD, and this figure was then used to calculate the energy deposited and energy fluence from the ultra-soft $\mathrm{x}$-ray irradiations.

After irradiation and calibration, new ultra-thin TLDs were cut and the old ones thrown away, although it is possible to reuse them. For TLDs that we have used 10 times with all heating done in air, we see a $25 \%$ decrease in sensitivity. We have not yet tested the effect of heating the materials in helium.

\subsection{Results and Conclusion}

Prelininary results from the irradiations, summarized in Table 3, suggest that the ultra-thin materials, in particular the ultra-thin $\mathrm{C}_{\mathrm{aSO}} \mathrm{S}_{4}$, may be more accurate than the TLD-100. For energies where $\mathrm{CaSO}_{4}$ and LiF have comparable transmissions, the ultra-thin $\mathrm{CaSO}_{4}$ yielded the highest energy fluence of the three TIDs. This suggests that less dose was lost to surface effects in this material. In the $600 \mathrm{eV}$ run where the transmission through $\mathrm{CaSO}_{4}$ is significantly lower than through lif (see Table 4), the $\mathrm{C}^{\mathrm{aSO}}{ }_{4}$ energy fluence was not the highest. 'This is probably because the dose was deposited more shallowly in the $\mathrm{CaSO}_{4}$, increasing the loss to surface effects. The data also suggest that the ultra-thin materials might be more consistent with dose than the TLD-100. In the 1500 and $600 \mathrm{eV}$ runs especially, the TLD-100 relative response varied more than either of the ultra-thin materials. However, it should be stressed that at this point the results are preliminary and further measurements are needed to make any definitive conclusions abont these materials. 


\begin{tabular}{|c|c|c|c|}
\hline Photodiode $\left[J \mathrm{~cm}^{-2}\right]$ & $\overline{\mathrm{LiF}}$ & $\bar{C}_{\mathrm{a}} \overline{\mathrm{S}} \overline{\mathrm{O}}_{4}$ & $\bar{T} \bar{L} \overline{\mathrm{D}}-10 \overline{0}$ \\
\hline \multicolumn{4}{|c|}{$-1500 \mathrm{eV}-$} \\
\hline $4.3 \cdot 10^{-5}$ & 0.11 & \multirow[t]{2}{*}{ not irradiated } & 0.30 \\
\hline $8.3 \cdot 10^{-5}$ & 0.12 & & 0.41 \\
\hline $1.2 \cdot 10^{-4}$ & \multicolumn{2}{|l|}{0.13} & 0.37 \\
\hline $1.6 \cdot 10^{-4}$ & \multicolumn{2}{|l|}{0.11} & 0.27 \\
\hline \multicolumn{3}{|l|}{$2.0 \cdot 10^{-4}$} & 0.27 \\
\hline \multicolumn{4}{|c|}{$-900 \mathrm{eV}-$} \\
\hline $1.2 \cdot 10^{-4}$ & 0.06 & 0.29 & 0.004 \\
\hline \multicolumn{4}{|c|}{$-731 \mathrm{eV}-$} \\
\hline $2.6 \cdot 10^{-6}$ & 0.25 & 1.00 & 0.15 \\
\hline $5.8 \cdot 10^{-6}$ & 0.22 & 0.85 & 0.19 \\
\hline \multicolumn{4}{|c|}{$-600 \mathrm{eV}-$} \\
\hline $2.9 \cdot 10^{-8}$ & 1.00 & 1.5 & 5.9 \\
\hline $9.7 \cdot 10^{-8}$ & 0.90 & 1.4 & 2.7 \\
\hline $2.9 \cdot 10^{-7}$ & 0.79 & 1.4 & 1.6 \\
\hline $9.7 \cdot 10^{-\tau}$ & 0.71 & 1.2 & 1.1 \\
\hline
\end{tabular}

Table 3: The fraction of energy fluence measured from the three TLD types. Values are normalized to the photodiode energy fluence.

\begin{tabular}{|c|l|l|}
\hline Photon Energy & \multicolumn{3}{|c|}{ Transmission per $\mu \mathrm{m}$} \\
\hline$[\mathrm{eV}]$ & $\mathrm{Li} \overline{\mathrm{F}}$ & $\overline{\mathrm{CaSO}}_{4}$ \\
\hline 1500 & 0.687 & 0.679 \\
900 & 0.237 & 0.239 \\
731 & 0.093 & 0.089 \\
600 & 0.726 & 0.020 \\
\hline
\end{tabular}

Table 4: The calculated transmission through LiF and $\mathrm{CaSO}_{4}$ for the ultra-soft. $\mathrm{x}$-ray irradiations.

The ultra-thin material does have the advantage that it is very easily cut to a desired size and shape. It is also very quickly and easily annealler compared to TLD-100, and currently we include TLDs made from the ult ra-thin (aSO $)_{4}$ m all radiobiological irradiations at the synchrotron to verify the uniformity of the photon beam scan wer the area of the biological sample. 


\section{References}

[1] Carrillo, R.E., Pearson, D.W., Deluca, Jr. P.M., and MacKay, J.F. Thermoluminescent response of lithium fluride (TLD-100) to monoenergetic photon bcams of 600, 730, 900, and 1,500 eV. (submitted to Rad. Prot. Dos.)

[2] Carrillo, R.E., Pearson, D.W., DeLuca, Jr. P.M., and MacKay, J.F. The thermoluminescent response of calcium fluoride (TLD-200) to monoenergetic photon beams of 600, 730, 900, and 1,500 eV. Proc. of the V Congreso Nacional sobre Dosimetria Termoluminiscent Mexico DF, 3-5 Sept 1992.

[3] Lasky, J. and Moran, P. Thermolulminescent response of LiF (TLD-100) to 5-30 keV electrons and the effect of annealing in various atmospheres. Phys. Med. Biol. 22(5) (1977) 852-862.

[4] Lasky, J. and Moran, P. Thermoluminescent response of LiF (TLD-100) to 0.1.5 keV electrons: An energy-range relationship and comparison of the $T L$ glow with TSEE glow curves. J. Appl. Phys. 50(7) (1979) 4951-4957. 


\section{$\therefore$ \\ 6 Dosimetry of ${ }^{90} \mathrm{Sr}$ Ophthalmic Applicators}

\subsection{Summary}

Average surface dose rate of a ${ }^{90} \mathrm{Sr}$ ophthalmic applicator was mensured using a CaSO4:Tm/Al ultra-thin thermoluminescent dosimeter of $2 \mathrm{mg} / \mathrm{cm}^{2}$ thickness. The thickness of the dosimeter and the simple annealing process at $400{ }^{\circ} \mathrm{C}$ make this thermoluminescent dosimeter attractive for beta dosimetry. An easy and quick technique for obtaining an average dose rate measurement is described. TLDs were calibrated against ${ }^{60} \mathrm{Co}$. The extrapolation ion chamber technique was also used for the same ${ }^{90} \mathrm{Sr}$ ophthalmic applicator. Results of both measurements are presented.

\subsection{Introduction}

Ophthalmic applicators are beta-ray sources that have been used in the postoperative treatment of certain superficial nommalignant eye disorders such as Ptrygium. The treatment usually consists of delivering a certain dose by holding the applicator in contact with the area to be treated. The applicator most often used consists of a disk shaped ${ }^{90} \mathrm{Sr}$ beta source in secular equilibrium with its daughter product. ${ }^{90} \mathrm{Y}$ covered with stainless steel of around $0.1 \mathrm{~mm}$ thickness. The maximum beta energies are $0.546 \mathrm{MeV}$ and $2.283 \mathrm{MeV}$ for ${ }^{90} \mathrm{Sr}$ and ${ }^{90} \mathrm{Y}$, respectively, while the mean energies are 0.2 and $0.8 \mathrm{MeV}$.

There are many dosimetric techniques used with applicators such as extrapolation ion chambers, thermoluminescent dosimeters, photographic films, scintillators, radiochromic foils etc. The extrapolation ion chamber provides an absolute measurement although it is probably the most difficult and most time consuming method. Amersham International (the only manufacturer currently) supplies applicators with the surface dose rate calibrated. The National Institute of Standards and Technology (NIST) has offered a service for the calibration of the applicators since 1978 . However, there is no international agreed upon calibration procedure. In 1988 a $36 \%$ discrepancy was observed in the calibration of the same source by Amersham International and NIST [1]. In 1991, NIST revised its technique and the discrepancy reduced to $21 \%[2]$.

Although the use of ${ }^{90} \mathrm{Sr}$ beta applicators is widespread, there is no generally agree upon protocol which makes it very difficult to asses clinical efficacy whrn comparing results from various treatment centers. Having accurate dose response data and having an easier method than the extrapolation ion chamber would allow optimization of the therapeutic effect. This makes it important to know accurately the output of ${ }^{90} \mathrm{Sr}$ ophthalmic applicators.

In the present investigation we describe a method for measuring the average sur-

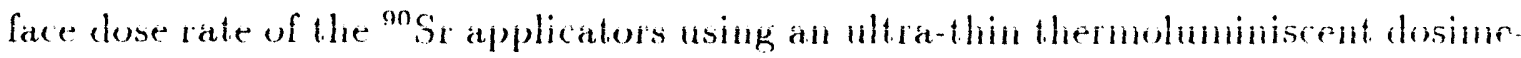


ter (UT-TLD). Average surface dose rate using the extrapolation ion chamber technique was also measured. Results of both measurements are compared.

\subsection{Materials and Methods}

CaSO4:Tm/Al UT-TLDs with a thickness of $2 \mathrm{mg} / \mathrm{cm}^{2}(7.7 \mathrm{~lm})$ having a.n aluminum layer base of 10 microns were used. These UT-TLDs present two important features (a) they are suitable for skin-dose assessment, and (b) their Al base allows annealing at $400{ }^{\circ} \mathrm{C}$ without changing their physical properties. The $\mathrm{C}$ aSO4: $\mathrm{Tm} / \mathrm{Al}$ was cut in thin disks of $1 \mathrm{~cm}$ diameter.

The ${ }^{90} \mathrm{Sr}$ applicator used in this study was manufactured by Isotope Products Laboratory (model $67-850, \mathrm{~s} / \mathrm{n}$ E-887). The active surface is flat and has a diameter of $0.88 \mathrm{~cm}$. Sr-90 decays by beta emission to the radioactive daughter Y-90 with a half life of 28.5 years. The maximum energy of the enitted electrons is $0.546 \mathrm{MeV}$. Y-90 also decays by beta emission with a half-life of 64 hours. $2.283 \mathrm{MeV}$ is the maximum energy of its emitted electrons.

The extrapolation ion chamber utilized was manufacutred by Far West Technology, Inc. (Model EIC-1, s/n 187-TG). It is a tissue equivalent parallel plate ionization ion chamber. The detecting volume is a right circular cylinder whose height is adjusted by turning an aluminum ring on which the entrance window is mounted. The outer plate is connected to the high voltage. It has a diameter of $3.5 \mathrm{~cm}$ and is made of conductive polyethylene $\left(7 \mathrm{mg} / \mathrm{cm}^{2}\right)$. The inner plate, which is the collecting electrode, is made of A-150 tissue equivalent plastic and has a diameter of $2 \mathrm{~cm}$. The plate spacing can be changed from 0.02 to $0.45 \mathrm{~cm}$.

Measuring the surface dose rate with the UT-TLD involves the use of one single UT-TLD disk besides the background disk. First the UT-TLD is annealed at 400 ${ }^{\circ} \mathrm{C}$ for $4 \mathrm{hr}$, then is irradiated to a certain dose with a calibrated ${ }^{60} \mathrm{Co}$ unit. Next it is read in a single photon counting TLD reader. To measure the surface dose rate of the applicator, a lucite plate $1.3 \mathrm{~cm}$ thick with a cylindrical hole in it matching the diameter of the UT-TLD disk as well as the diameter of the source is used. The UT-TLD disk, without being annealed, is put in the cylindrical hole of 1.02 ! $\mathrm{cm}$ diameter and $0.5 \mathrm{~cm}$ height. These dimensions were chosen to simulate the condition under which the extrapolation chamber measurements were performerl. The applicator is placed in the lucite plate hole that contains the UT-TLD disk for a measured time. The UT-TLD disk is then read and the surface dose rate determined. Placing the beta source in contact with the UT-TLD chip as describer implies giving the disk a high dose rate. Moreover, since it is desirable to hold the beta source for a 'reasonable' period of time such that the error introduced due to motor visual coordination of the experimenter is minimized, the given dose to the thin disk is high. The time used in our experiment was $60 \mathrm{sec}$ which gave a dose of approximately 50 ciy. The initial calibration with the ${ }^{60}$ (:o unit can be done 


\begin{tabular}{||l|l||}
\hline Technique & $\overline{\mathrm{D}}(\mathrm{cGy} / \mathrm{s}) \pm$ overall uncertainty \\
\hline CaSO4:Tm UT-TLD & $78.57 \pm 10 \%$ \\
Extrapolation Chamber & $70.78 \pm 15 \%$
\end{tabular}

Table 5: Average surface dose rate (D) for the IPL Model 67-850 S/N E-88T ophthalmic applicator using extrapolation ion chamber and UT-TLD.

with a few $\mathrm{mGly}$ and the result of the measurement can be considered preliminary. However, once the order of magnitude of the dose being measured is known, a new calibration against the ${ }^{60} \mathrm{Co}$ unit is carried out giving this time a dose similar to that from the beta source. In this way potential problems of supralinearity and changes of the glow curve with dose can be avoided. Since the UT-TLD disks are reused without being annealed, residual dose readings are present indicating that the 400 ${ }^{\circ} \mathrm{C}$ reached for a few seconds on the planchette during the readout cycle is not enough to avoide the annealing process. Characteristics of the residual dose were studied at different doses. For doses between 20 and $50 \mathrm{~Gy}$ a $2.5 \%$ to $3 \%$ residual dosimeter reading was found. Annealing at $400^{\circ} \mathrm{C}$ for $4 \mathrm{hr}$ is required to completely remove the residual dose. The measurements with the extrapolation ion chamber were performed in the traditional fashion that is described in the literature $[1,2,3,4]$. Results are presented below.

\subsection{Results and Conclusions}

Table 5 summarizes the results obtained with the two differents techniques used for measuring the average surface dose rate of the IPL model 67-850 s/n E-88T ophthalmic applicator. The extrapolation ion chamber measurement have been normalized to a $1 \mathrm{~cm}$ diameter for comparison to the method of Goetsch et al. [1]

The results of this investigation show that GaSO4:Tn UT'-TLD can be used to measure the average surface dose rate of ophthalmic ${ }^{90} \mathrm{Sr}$ applicators. This measurement can be obtained easily and quickly by the method described above and with an eventually improved precision with respect to the extrapolation ion chamber technique. The combined uncertainty was obtained adding in quadrature the percent of statistical errors and the percent of systematic errors. The overall uncertainty is the combined uncertainty times two.

\section{References}

11) Steven J. Goetsch and Kari S. Sunderland. Surface dose rate calibration of ${ }^{90}$ Sr plane ophthalmic applicators. Med. Phys. $18(2)$ (1991) 161-16if. 
[2] C.G. Soares. Calibration of ophthalmic applicators at NIST: A revised approach, Med. Phys. 18(4) (1991) 787-793.

[3] J.S. Pruit. Calibration of beta-particle ophthalmic applicators, NBS Speciai Publication 250-9 (1986).

[4] Y. Herbaut, A. Heeren de Oliveira, R. Vivia, J.B. Leroux and M. Delahaie. Characteristcs of an extrapolation ion chamber FWT type EIC.1 in beta radiation fields. Radiat. Protect. Dosim. 14(2) (1986) 187-191. 

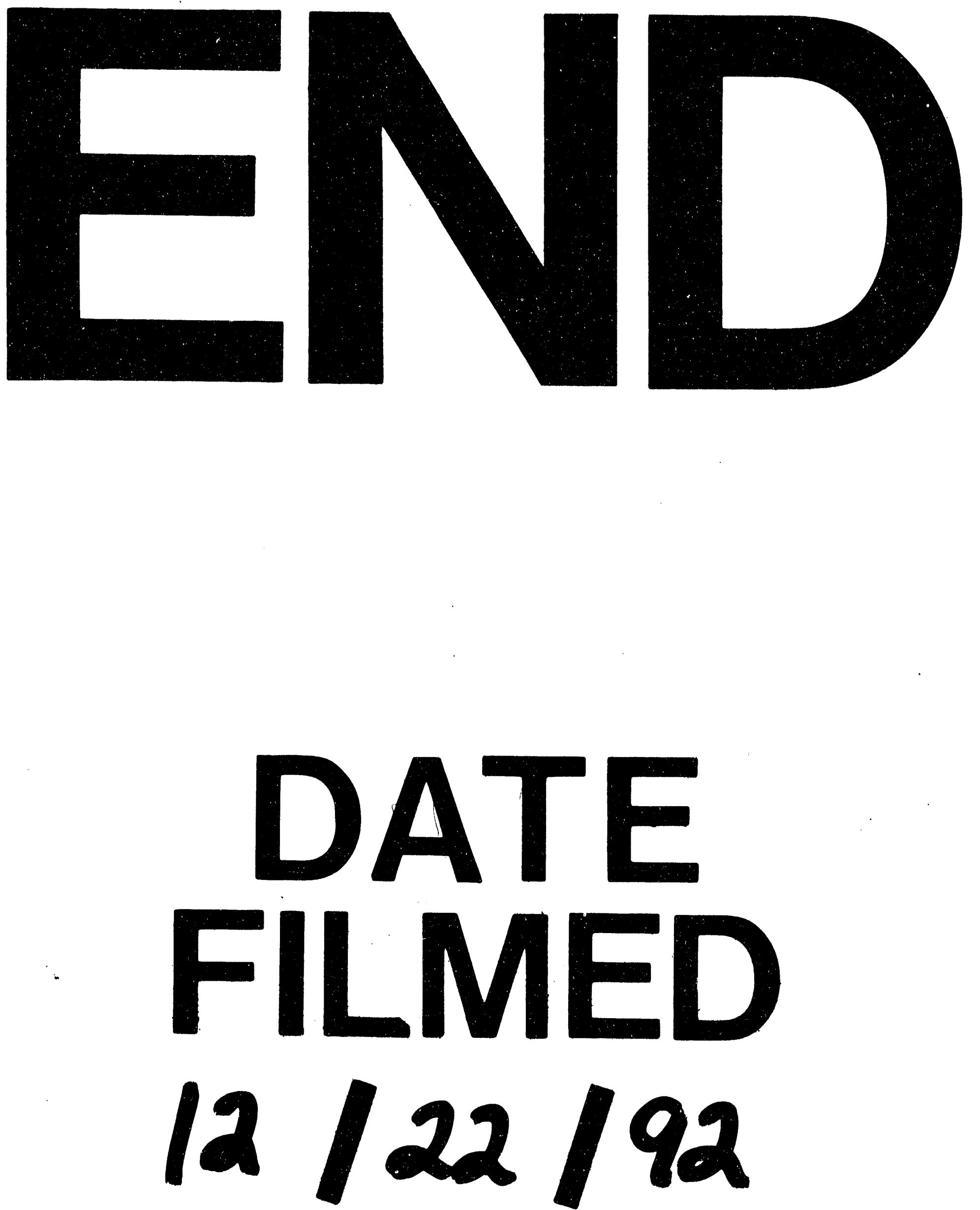
